\title{
WestVirginiaUniversity
}

THE RESEARCH REPOSITORY @ WVU

Graduate Theses, Dissertations, and Problem Reports

2011

\section{Dispositions in Teacher Education}

Lisa Simpson

West Virginia University

Follow this and additional works at: https://researchrepository.wvu.edu/etd

\section{Recommended Citation}

Simpson, Lisa, "Dispositions in Teacher Education" (2011). Graduate Theses, Dissertations, and Problem Reports. 3106.

https://researchrepository.wvu.edu/etd/3106

This Dissertation is protected by copyright and/or related rights. It has been brought to you by the The Research Repository @ WVU with permission from the rights-holder(s). You are free to use this Dissertation in any way that is permitted by the copyright and related rights legislation that applies to your use. For other uses you must obtain permission from the rights-holder(s) directly, unless additional rights are indicated by a Creative Commons license in the record and/ or on the work itself. This Dissertation has been accepted for inclusion in WVU Graduate Theses, Dissertations, and Problem Reports collection by an authorized administrator of The Research Repository @ WVU.

For more information, please contact researchrepository@mail.wvu.edu. 


\title{
Dispositions in Teacher Education
}

\author{
Lisa Simpson
}

\author{
Dissertation submitted to the \\ College of Human Resources and Education \\ at West Virginia University \\ in partial fulfillment of the requirements \\ for the degree of
}

\author{
Doctor of Education \\ in \\ Curriculum and Instruction
}
David Callejo-Pérez, Ed.D., Co-Chair
Sebastián R. Díaz, Ph.D., J.D., Co-Chair
Patricia Obenauf, Ed.D.
David Campbell, Ph.D.
Perry Phillips, Ed.D.
Joy Saab, Ed.D.

Morgantown, West Virginia, USA

2011

Keywords: Dispositions, Accreditation, NCATE, Health Education, Physical Education, Certification

Lisa Simpson (C) 2011 All Rights Reserved 


\section{ABSTRACT \\ Dispositions in Teacher Education}

\section{Lisa Simpson}

The assessment of educator dispositions has created numerous challenges for teacher education institutions. Many of the issues surrounding dispositions assessment relates to the uncertainty in determining the dispositions that are most important to address in all teacher education programs. Additionally little consideration has been given to the possibility that some dispositions may be more important to some fields of education than to others. This research is an investigation into the importance and efficacy of identified clusters of dispositions, as well as the identification of dispositions important to Health and Physical Education in comparison with those important to all areas of education. The research questions include the following:

1. Building upon prior work of Simpson and Diaz, what are overall general perceptions of the importance and efficacy related to each category of identified dispositions?

2. Are there differences in teacher education students' (both undergraduate and graduate), local school professionals' (including teachers, administrators, and counselors), and teacher education faculty's perception of how well the institution develops the identified dispositions categories in its candidates?

3. What dispositions are perceived to be important specifically to the fields of Health and Physical Education?

A survey was sent to teacher educators, mentor teachers, and teacher education students. Participants rated the importance and efficacy of ten conceptual clusters of 
dispositions. Additionally, participants listed specific dispositions perceived to be important to teaching Health and Physical Education and those perceived to be important to all fields of education. Results were analyzed using descriptive statistics, analysis of variance, and frequency distribution.

Results of this study indicate that all ten conceptual clusters are considered very important to education. The perception of efficacy of each of the ten clusters is good. There was significant variability in the perception of importance among teacher education faculty, teacher education students, and mentor teachers for five of the ten clusters. There was significant variability in the perception of efficacy for one of the ten clusters. There appears to be differences in the dispositions important for teaching Health and Physical Education in comparison with all fields of education. The results of this study have implications for the preparation of teacher education students, the accreditation guidelines for teacher education institutions, and state certification practices. 


\section{Acknowledgements}

“Dear Lord, help Mom with her 'crappertation'....I don't even know what a 'crappertation' is, but help her get it over with!” The Hurricane

The journey of completing my doctorate has been filled with both personal and professional challenges. At times it seemed impossible to balance the demands of family, work, and school. At times I lost my motivation to finish. The people in my life kept me going, and I am forever grateful for the role each has played.

To my boys, Brice (age 11) and Hayden (the "Hurricane", age 8): I did it! I'm finally finished! I'm really not sure I would have been able to do this if I didn't have the two of you. Thank you for making me laugh, for the crazy nicknames you had for my dissertation, for gladly eating pizza or chicken nuggets when I was working, for keeping me going when I wanted to quit, for your understanding, for your prayers, for the random hugs and kisses you gave me as I was sitting as my computer, and for all the sacrifices you made while "Mom" was becoming "Dr. Mom"! I have many people who have helped me along the way, but you two are my true source of strength. I finished this for you. The serious side of me hopes this accomplishment makes you proud, and I hope I have set a good example of strength and perseverance. The silly side of me, however, looks forward to the endless jokes you'll make when I inevitably do or say something that is "a little less than intelligent". My favorite from Hayden so far is, "Geesh, Mom.... and they call you a 'doctor'!!" I also look forward to hearing the ways my new title improves your creative vocabularies. My favorite from Brice is, "She's not just 'Mom'...she's 'Dr. Mommatastical'!!” You guys make me giggle more than anybody I've ever known! I can't wait to get back to the nonsense and utter hilarity of spending time with my two favorite boys!!! I love you both more than anything in this world!! Thanks for being such great kids!!!

To my Miltenberger family: Thank you for standing by me, for supporting me through the multitude of challenges I faced on this journey, for listening to me vent my frustrations, and for understanding the millions of times I bailed out of family dinners to work. Hayley and Zach, thanks for providing hours of entertainment as I worked on Sunday afternoons at MeeMaw's!! :) Mom, thanks for teaching me which homonyms to use, for editing my work in the early phases, for your many offers to help with anything I needed, and for being a role-model for overcoming the challenges of life. Thank you for the emphasis you placed on education and for helping me value hard work and achievement. Miltenbergers are strong women. We don't give up. We overcome adversity. I have encountered some pretty big bumps along this road, but I kept plowing through because I am one of the "Miltenberger girls", and that's just what we do!

To my Simpson Family: I am so grateful to you for pushing me through, for standing by me in the midst of the chaos, for loving me as your own, for praying for me, and for reminding me to finish this for my boys. Marlene (my favorite realist), thank you for the silly cards you sent, for your texts and e-mails, and for your simple and sensible words of wisdom.

To my work family: Sam and Lauren, you are the BEST!! You have been invaluable to me the last few months...covering my classes at the last minute, taking care of so many "little things" at work, and mentoring our BLOCK students like absolute pros. I never had to worry about work because I knew you you'd gladly step in when I needed 
you most. You are two of the most amazing, professional, and competent graduate assistance I've ever had, and I am so glad you have been with me these last few semesters. Thank you for the many, many things you did to keep my mood light as I was coping with the stress of finishing this dissertation. For example, breaking into my office to give "Edward" a new home, orchestrating my $40^{\text {th }}$ birthday party (with the help of Lindsay and Steve!!), telling me hilarious stories like "the spider on steroids", drinking way too much coffee and dancing through the halls, and attacking the special "research project" (shopping online for my dissertation defense outfit) with absolute enthusiasm and creativity!! Like good graduate students, you girls took your research VERY seriously!! :- To my HPE crew, and especially Nicole and Becky, I am so thankful we are a team. Thanks for listening and commiserating with me through this, and for covering meetings and advising appointments, and for taking care of issues when I was unavailable. I look forward to MANY more years with you, and I look forward to helping you through your own journeys to finish!

To my HPE students and graduates: I truly love what I do. I love working with you, helping you transform into teachers, watching you grow along the way, rejoicing with you when you succeed, helping you through your personal and professional challenges, LAUGHING about the silly stories we've shared or the crazy things that are said or done in class, applauding you as you walk across the stage at graduation, helping you find jobs, and hearing the excitement in your voice (or in your emails, texts, and Facebook chats) when you tell me about your first years of teaching. At times, completing this dissertation seemed like an insurmountable task, but I kept pushing through because I couldn't imagine not doing what I do! There were so many of you who came to mind as I was writing. So many of you are dispositionally gifted teachersand genuinely good, honest, caring, hard-working people. You make me so proud!

To my friends: Thank you for your words of encouragement, texts, cards, emails, prayers, celebrations, and Facebook posts, chats, and distractions! Ian, thank you for your continual reminders to barrel through the challenges, to fight like a bull, and to "ROCK ON!"!! To my "girls' night out" girls, you have been a source of escape, laughter, stress relief, and sanity for me during this process!! To my "favorite nerd", a blast from my $8^{\text {th }}$ grade past, thanks for being living proof that being a "doc" clearly doesn't mean we have to be serious all the time!! :-

To my committee members and my professors: I cannot thank you enough for your support and dedication, for reading and rereading, for guiding my research, and for broadening my perspectives. David, thank you for the many times you spent reading my developing prospectus, pointing me in new directions, and for helping me finally pull things together. Sebastian, thank you for mentoring me through the research process, for the role you played in designing the studies, for the mini-therapy sessions you gave me to get me through the challenges I faced, and for the jokes you made about my PE wardrobe. Thank you for the hours you spent with me completing IRB forms, crunching numbers, making charts, and enduring the incredibly tedious task of reformatting my final product. "I, Lisa Simpson, hereby promise to NEVER use the 'enter' key for spacing or to manually number a list again!" (;)

THANKS TO ALL!! $\sim$ Lisa $:$ 


\section{Table of Contents}

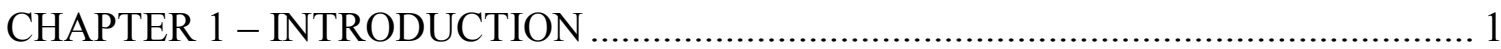

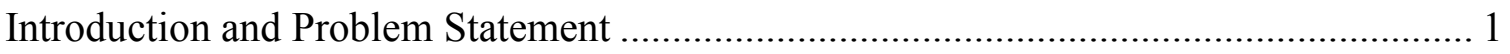

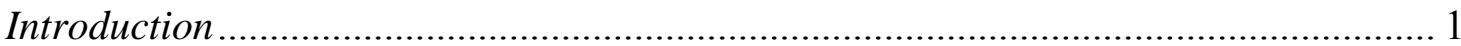

Problem Statement ............................................................................................ 4

The History of NCATE's Dispositions Requirements ............................................. 8

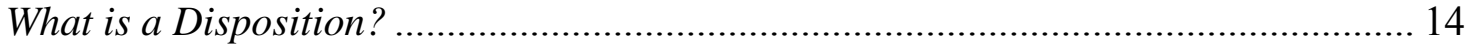

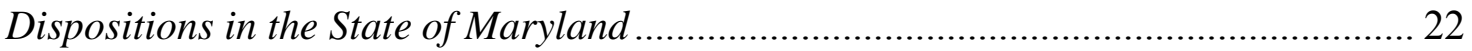

The Impact of Dispositions and Dispositions Requirements.................................... 30

Dispositions at Frostburg State University .......................................................... 43

Relationship of Dispositions to Health and Overall Academic Success ...................... 46

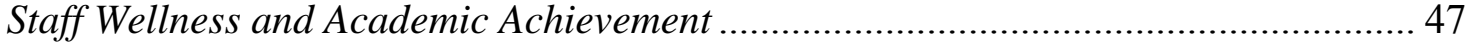

Dispositions, School Connectedness, Health and Academic Achievement ................... 48

Dispositions in Health and Physical Education.................................................... 49

Dispositions and Certification Practices in Maryland .......................................... 54

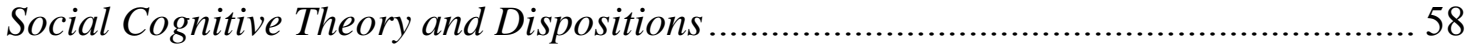

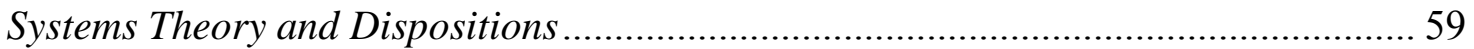

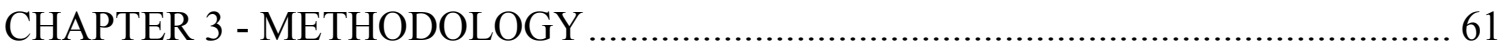

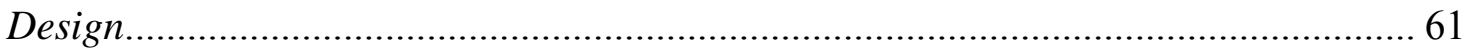




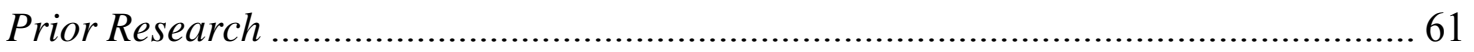

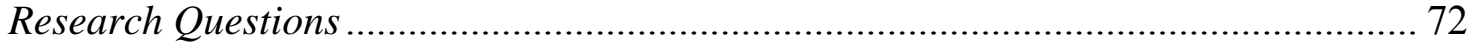

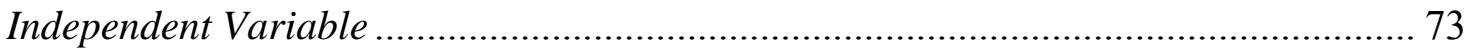

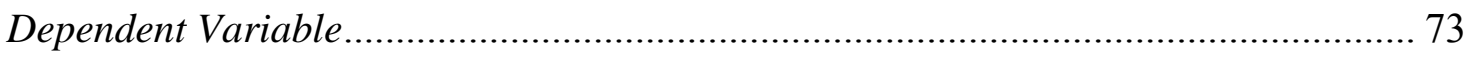

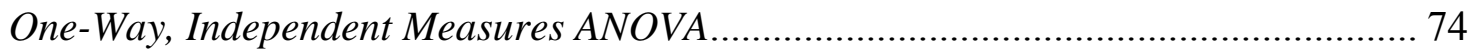

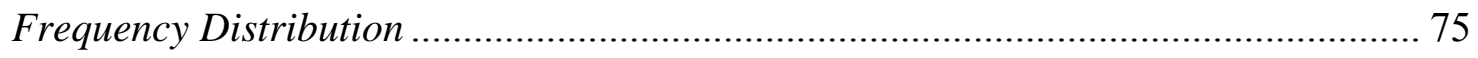

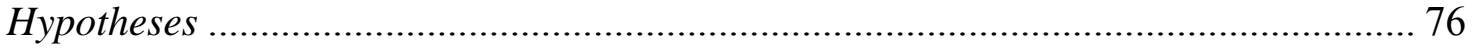

Null Hypotheses............................................................................................ 78

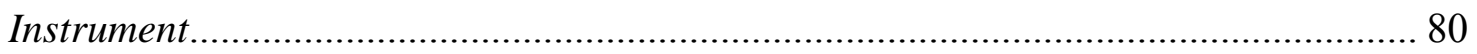

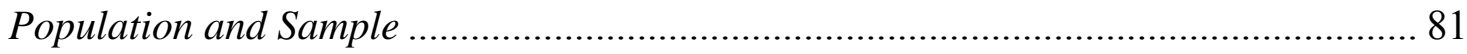

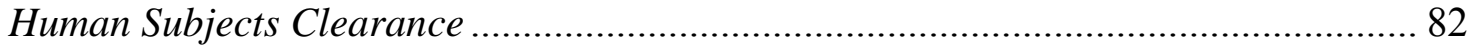

Procedure of Analysis for ANOVA....................................................................... 82

Procedure of Analysis for Frequency Distribution ............................................... 83

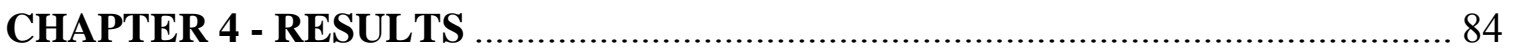

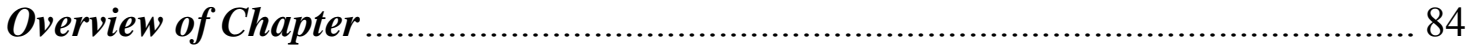

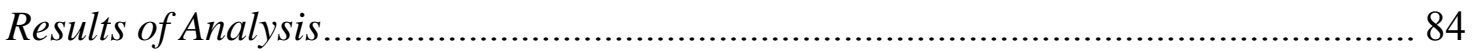

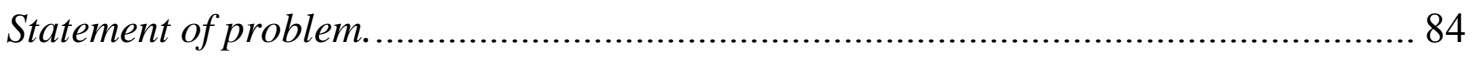

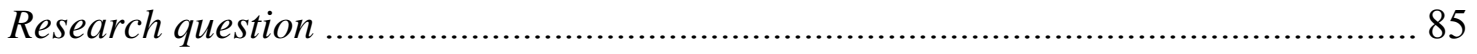

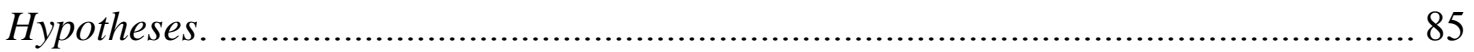

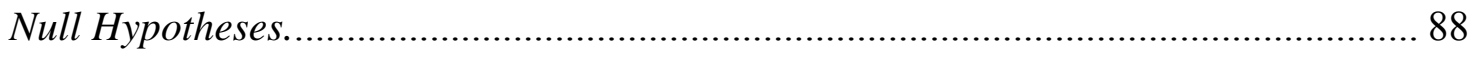




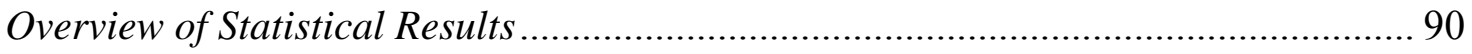

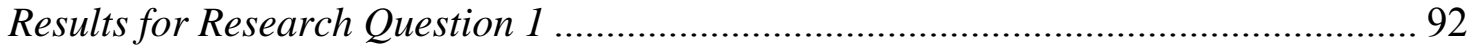

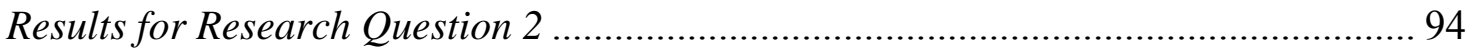

Omnibus test and post-hoc comparisons for relative importance .............................. 94

Omnibus test and post-hoc comparisons for efficacy........................................... 96

Results for Research Question 3 ................................................................... 100

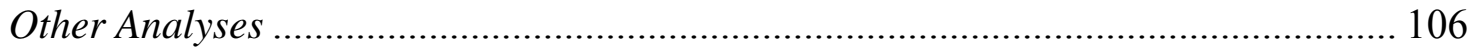

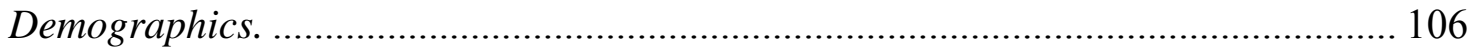

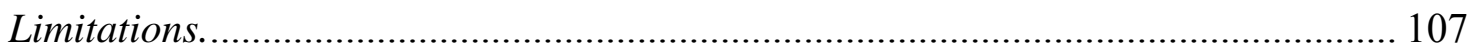

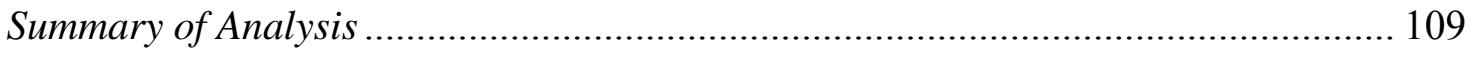

CHAPTER 5 - CONCLUSIONS, IMPLICATIONS AND RECOMMENDATIONS.. 111

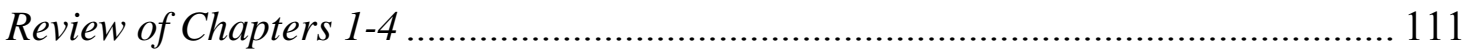

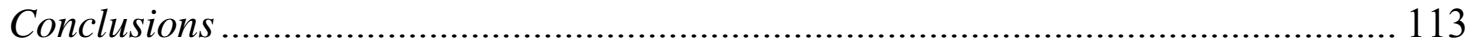

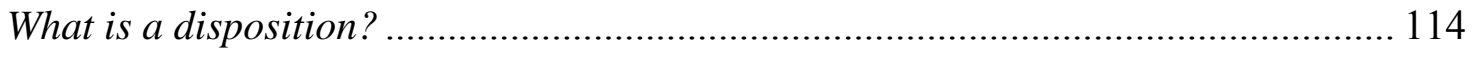

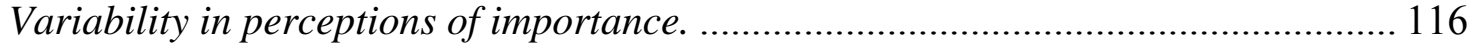

Accreditation standards. .............................................................................. 121

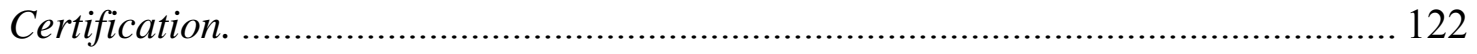

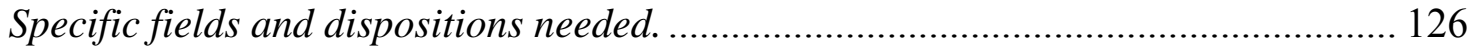

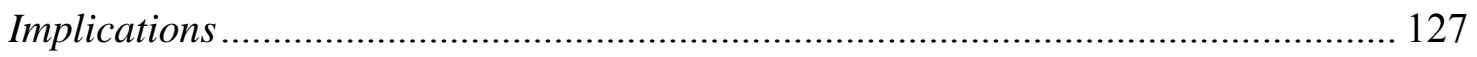

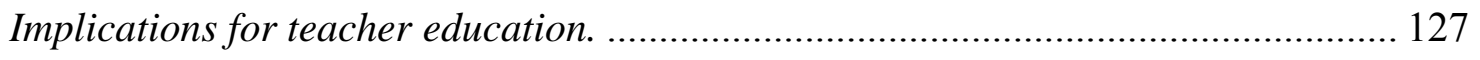


Implication for teacher education accreditation.

Implications for certification practices.

Efficacy and the possibility of advanced dispositions.

Recommendations for Future Research

References 136

Appendix A: Survey Instrument 144

Appendix B: SPSS Data Tables 157

\section{List of Tables}

Table 1. Descriptive Results for Importance and Efficacy..........................90

Table 2. Results of Importance Ratings........................................91

Table 3. Results of Efficacy Ratings........................................ 92

Table 4. Relative Importance Descriptive Statistics..............................93

Table 5. Relative Efficacy Descriptive Statistics............................. 94

Table 6. ANOVA Results for Relative Importance Ratings.........................99

Table 7. ANOVA Results for Relative Efficacy Ratings......................................100

\section{List of Figures}

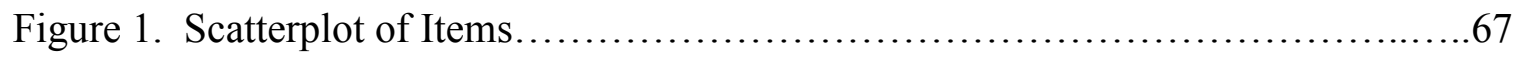

Figure 2. Importance Dispositions by Category................................ 102 


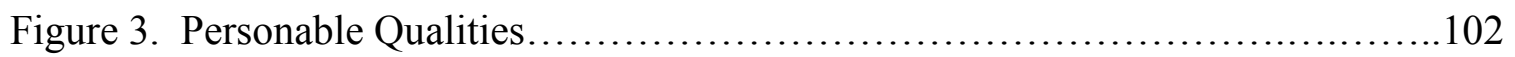

Figure 4. Professionalism.................................................. 103

Figure 5. Response to Social/Educational Needs.............................. 104

Figure 6. Response to Challenges............................................. 105

Figure 7. Psychosocial Maturity .......................................... 106

Figure 8. Respondent Certification Area, or Undergraduate/Graduate Major............107 


\section{CHAPTER 1 - INTRODUCTION Introduction and Problem Statement}

\section{Introduction}

The concern for improving public education for American youth has led to an emphasis on improving teacher quality. However, with high retirement and attrition rates, school districts have struggled to find credentialed teachers to fill positionsparticularly in the areas of special education, math, science, and in schools with more challenging populations of students (U. S. Department of Education, 2004; U. S. Department of Education, 2011). As a result, school districts have been forced to issue emergency teaching permits to applicants who have not met traditional teacher certification requirements, and have often placed them in the most challenging schools in the district, providing them with insufficient or nonexistent training or support (U. S. Department of Education, 2004). In 2001, the No Child Left Behind Act (NCLB) addressed teacher quality by requiring states to have a plan for ensuring teachers were "highly qualified." Under NCLB, "highly qualified teachers" are those who have earned a bachelor's degree, have been credentialed by the state, and have demonstrated knowledge (as determined by state requirements) of each subject they teach (No Child Left Behind Flexibility: Highly Qualified Teachers).

The NCLB Act brought into focus the importance of teacher knowledge. Around the same time NCLB was released, the National Council for Accreditation of Teacher Education (NCATE) issued their 2001 Standards, which included an additional area of emphasis for teacher preparation institutions: professional dispositions (NCATE, 2001). 
As part of new NCATE requirements, teacher education institutions were to include dispositions in their conceptual frameworks and to systematically assess the development of candidate dispositions (NCATE, 2001). NCATE defined the term dispositions in their 2000 standards as:

"The values, commitments, and professional ethics that influence behaviors toward students, families, colleagues, and communities and affect student learning, motivation, and development as well as the educator's own professional growth. Dispositions are guided by beliefs and attitudes related to values such as caring, fairness, honesty, responsibility, and social justice. For example, they might include a belief that all students can learn, a vision of high and challenging standards, or a commitment to a safe and supportive learning environment" (NCATE, 2001, p. 53).

The term social justice generated some controversy among teacher education institutions regarding what exactly students were required to show (Villegas, 2007). In 2007, NCATE revised their standards, using the term professional dispositions instead of dispositions, and eliminated the use of the term social justice. In the glossary of the 2007 NCATE standards, professional dispositions are defined as, "professional attitudes, values, and beliefs demonstrated through both verbal and non-verbal behaviors as educators interact with students, families, colleagues, and communities. These positive behaviors support student learning and development" (NCATE, 2008, p. 89-90). They attempt to provide further clarification for institutions by stating the assessment of professional dispositions should be "based on observable behaviors in educational settings" (NCATE, 2008, p. 90). NCATE expects institutions to assess fairness and the 
belief that all students can learn, but they may also identify, define, and operationalize additional professional dispositions based on the unit's mission and conceptual framework (NCATE, 2008).

With the required assessment of dispositions and very little guidance from NCATE, institutions have been left floundering to determine what and how to assess candidates' dispositions, as well as what to do with the assessment results (Shiveley \& Misco, 2010). The struggle with assessing dispositions comes from the lack of clarity among professionals regarding precisely what a disposition is; which dispositions impact teacher effectiveness; how dispositions can objectively be assessed; whether dispositions can be "taught" or not; how much a person's knowledge and/or skill impacts his/her disposition; and how dispositions assessment results should be used for admission to a teacher education program, retention and advancement in a program, and graduation from a program (Honawar, 2008; Shussler, Bercaw, \& Stooksberry 2008; Edwards \& Edick, 2006). Additionally, it is unclear whether certain dispositions are more important to some areas of education than others. For example, in the fields of Health and Physical Education, it may be extremely important for teachers to be perceived by others as models of health in all domains of health and wellness because of the content they teach. If Health and Physical Educators stress the importance of being physically active, eating a balanced diet, managing stress, or visiting the doctor regularly, then it stands to reason that they should practice the very principles of good health they teach. In contrast, in order to be an effective secondary math educator, the expectations for practicing principles of good health would likely not be as extensive. Additionally, if living a healthy lifestyle is considered extremely important for health and physical educators, is it 
equally important for elementary teachers who teach Health and Physical Education in addition to multiple other subjects? Health and Physical Education are rather unique areas of education because they are so closely related with allied health, a field not typically considered in public education. Allied health addresses personal behaviors, and therefore the dispositions required to effectively teach health-related curricula may more closely resemble those in health professions, rather than those in education.

Questions surrounding dispositions will be explored in more detail in Chapter 2 of this dissertation. A particular emphasis will be placed on defining dispositions, examining the history of dispositions, examining issues associated with assessing dispositions, and dispositions and teacher quality. Additionally, two theoretical models will be considered. The first is the social cognitive approach to dispositions. Secondly, the notion of addressing dispositions as a complex interactive system will be explored using systems theory.

\section{Problem Statement}

Teacher education institutions are required by accrediting agencies to systematically assess the dispositions of teacher education candidates. However, institutions have struggled for several years to determine what dispositions should be assessed and how to assess them systematically across all programs in the unit. The unit is defined by the National Council for the Accreditation of Teacher Education (NCATE) as, "the institution, college, school, department or other administrative body with the responsibility for managing or coordinating all programs for the initial and continuing preparation of teachers and other school personnel" (NCATE, Glossary). In other words, institutions must identify and assess dispositions common to all teacher education 
programs in the unit. While it is likely that there are some common dispositions important to all programs, it is equally likely that there are some dispositions that are important for some types of educators, but not others, or some which have greater importance in certain disciplines, grade levels, or positions (administration, counseling, etc.). Accreditation agencies provide little guidance regarding the identification and assessment of critical dispositions, and there is a need for research to provide guidance to institutions that are attempting to develop and implement a dispositions assessment system.

Numerous dispositions have been deemed important in the literature, but there appears to be no published studies in which specific dispositions are identified as important and systematically conceptualized into manageable groups. Efforts to address dispositions in education have been driven by accreditation policy, rather than by a body of scientific research. The first study for conceptualizing clusters of dispositions important for PK-12 education was an unpublished conducted in 2007 by Simpson and Diaz. A group of twelve participants, which included PK-12 educators, administrators, guidance counselors, teacher education faculty at a small rural university, teacher education graduate students, and a college of education dean, identified what they perceived to be dispositions important to educators. Over one hundred dispositions were identified and categorized by participants. While the sample size for the 2007 study was small and the participants lacked the diversity of larger study, the results have been used to structure the research plan described in this proposal. One of the issues with addressing dispositions in teacher education is considering the context in which studies on dispositions are conducted. The participants of this study, while varied in their role in 
education, all had a background in teaching, and were all affiliated with a small regional teacher preparation institution located in a rural Mideast town. A more detailed description of the 2007 study is discussed in Chapter 3.

The purposes of this study are to (1) gauge the perceived importance and efficacy of the identified categories of dispositions in a larger population of teacher education students, teacher education faculty, and PK-12 educators and administrators; and to (2) determine the dispositions which may not be common to all programs in the unit, but are identified as essential to teaching Health and Physical Education. While these data are important for the purposes of accreditation, this study will move beyond that which is required for accreditation to determine the dispositions which may not be common to all programs in the unit, but are identified as essential to teaching Health and Physical Education. The outcome of the study will help provide guidance in the preparation of teacher education students in general, teacher education students majoring in Health and Physical Education, and teacher education students who will likely teach health and/or physical education, but who are not specifically seeking certification in those fields. One issue with addressing dispositions in Health and Physical Education is that these are fields that are, in many ways more closely related to allied health professions, rather than to education professions. Much of what is addressed in health and physical education relates more to lifestyle behaviors, rather than to cognitive functions and, therefore, may require dispositions that have not been given consideration by those in the core fields of education. Additionally, all teacher preparation programs struggle with how to address dispositions, particularly when accreditation procedures require the systematic assessments of dispositions across all fields of education. This study will serve as a 
model for identifying dispositions essential to teachers of specific content areas or grade levels, and to administrators, supervisors, counselors, or other non-teaching positions in education.

The research questions include:

1. Building upon prior work of Simpson and Diaz, what are overall general perceptions of the importance and efficacy related to each category of identified dispositions?

2. Are there differences in teacher education students' (both undergraduate and graduate), local school professionals' (including teachers, administrators, and counselors), and teacher education faculty's perception of how well the institution develops the identified dispositions categories in its candidates?

3. What dispositions are perceived to be important specifically to the fields of Health and Physical Education? 
CHAPTER 2 -REVIEW OF THE LITERATURE

\section{The History of NCATE's Dispositions Requirements}

The 1990s marked the beginning of a period of great change in teacher education. Prior to the 1990 s, the three domains of teacher education, commonly recognized as knowledge, skills, and attitudes, were recast as knowledge, skills, and dispositions. In Dispositions in Teacher Education, Larry Freeman notes the swiftness of the change in comparison with other changes in education when he states, "Normally one would expect the teacher education profession to produce a parade of articles and conference presentations discussing and debating the concept of dispositions and then gradually to integrate the notion into the everyday work of teacher education. That is not what happened" (Freeman, 2007, p. 3-4). Freeman continues his discussion by explaining that, in a period of about ten years, the National Council for the Accreditation of Teacher Education (NCATE) enshrined the concept of dispositions into their standards, rules, and regulations that govern the teaching certification in many states (Freeman, 2007). Below is an examination into the history of the infusion of dispositions into teacher education programs, the challenges teacher education institutions have faced as they incorporate dispositions into their programs, and a discussion regarding dispositions specific to the fields of Health and Physical Education.

The current emphasis of dispositions in teacher education emerged from a longstanding concern for quality teacher preparation. In 1954, the National Council for the Accreditation of Teacher Education (NCATE) was created by five organizations for the purpose of ensuring quality teacher education training. The five original organizations associated with NCATE broadly represented the teaching profession at the 
time. They included the Council of Chief State School Officers, the National Education Association, the American Association of Colleges for Teacher Education, and the National Association of State Directors of Teacher Education and Certification. Since 1954, twenty-eight additional national organizations representing educators, policymakers, and the public have joined NCATE to help ensure quality teacher preparation in the United States (NCATE, 15 Years of Growth).

From 1954 until 1995, NCATE's accreditation system was limited to an evaluation of teacher education curricula. In the 1980s and 1990s, the standards-based movement precipitated change in NCATEs accreditation procedure, shifting the focus from curricular evaluation to the evaluation of teacher education candidate performance. NCATE required all of its specialty associations to revise program standards to be performance-based. Additionally, NCATE began to coordinate accreditation efforts with licensing agencies, which helped develop a more coherent system of quality assurance. In 1995, NCATE released its first set of performance-based accreditation standards because, "It is no longer acceptable for the candidates simply to have been exposed to certain topics in the curriculum, or for a faculty member to say, 'I taught the material.' Institutions must demonstrate that candidates know their subject and how to teach it effectively so that students learn" (NCATE, 15 Years of Growth, p. 5).

In 2000, NCATE first introduced the requirement for Teacher Education Institutions to include dispositions in the conceptual framework to systematically assess the development of candidate dispositions. They state, "Dispositions are not usually assessed directly; instead they are assessed along with other performances in candidates' work with students, families, and communities" (NCATE, 2001, p. 19). They defined the 
term in their 2000 standards as, "The values, commitments, and professional ethics that influence behaviors toward students, families, colleagues, and communities and affect student learning, motivation, and development as well as the educator's own professional growth" (NCATE, 2001, p. 53). Taylor and Wasicsko make accurate predictions when they stated in 2000, “... with the national spotlight on teacher quality and increasing pressures from political and business concerns, it appears that dispositions of effective teachers will become of even greater interest..." (Taylor \& Wasicsko, 2000, p.2). They further explain the issues in teacher education will be, "to define what is meant by 'dispositions,' review the research base, find appropriate measurement tools, decide on the implications for selecting and preparing future teachers, and conduct additional research" (Taylor \& Wasicsko, 2000, p.2).

The introduction of this new accreditation requirement spurred numerous discussions among teacher education institutions about the lack of clarity regarding the precise meaning of the term dispositions, about NCATE's expectations for the assessment of dispositions, and how the requirement would change teacher preparation. Wasisko, Callahan, and Wirtz (2004) note, "In the NCATE Standards, dispositions are defined in a nebulous manner that simultaneously touts their importance, yet provides little guidance as to their implementation" (p. 2).

According to the 2001 NCATE standards, to earn an "acceptable" rating the unit must show, "Candidates are familiar with the dispositions expected of professionals. Their work with students, families, and communities reflects the dispositions delineated in professional, state, and institutional standards" (NCATE, 2001, p. 16). To earn a "target" rating, the unit must show the following: 
Candidates work with students, families, and communities in ways that reflect the dispositions expected of professional educators as delineated in professional, state, and institutional standards. Candidates recognize when their own dispositions may need to be adjusted and are able to develop plans to do so (NCATE, 2001, p. 16).

The supporting explanation of the standard indicates the following: Candidates for all professional education roles develop and model dispositions that are expected of educators. The unit articulates candidate dispositions as part of its conceptual framework(s). The unit systematically assesses the development of appropriate professional dispositions by candidates. Dispositions are not usually assessed directly; instead they are assessed along with other performances in a candidate's work with students, families, and communities (NCATE, 2001, p.19).

The language used in the 2001 standards assumes consensus about the dispositions expected of professionals; it assumes the dispositions are clearly delineated in professional, state, and institutional standards, and it assumes familiarity with the assessment of dispositions. However, as discussed in multiple places in this literature review, educators have yet to come to a consensus about what dispositions are, what dispositions should be assessed, and how dispositions should be assessed.

In the 2008 standards, an attempt was made to provide some clarification regarding dispositions assessment. To earn an acceptable rating, institutions must show the following: 
Candidates are familiar with the professional dispositions delineated in professional, state, and institutional standards. Candidates demonstrate classroom behaviors that are consistent with the ideal of fairness and the belief that all students can learn. Their work with students, families, colleagues and communities reflects these professional dispositions (NCATE, 2008, p.20).

The 2008 standards include a description for a "target" rating which states the following: Candidates work with students, families, colleagues, and communities in ways that reflect the professional dispositions expected of professional educators as delineated in professional, state, and institutional standards. Candidates demonstrate classroom behaviors that create caring and supportive learning environments and encourage self-directed learning by all students. Candidates recognize when their own professional dispositions may need to be adjusted and are able to develop plans to do so" (NCATE, 2008, p.20).

The supporting explanation indicates the following:

Candidates for all professional education roles develop and model professional dispositions that are expected of educators. The unit includes as professional dispositions the idea of fairness and the belief that all students can learn. Based on its mission, the unit may determine additional professional dispositions it wants candidates to develop. The unit articulates professional dispositions as part of its conceptual framework. The unit systematically assesses the development of appropriate professional dispositions by candidates. Professional dispositions are not assessed directly; instead the unit assesses dispositions based on observable behavior in educational settings (NCATE, 2008, p. 22). 
In an attempt to provide guidance regarding what to assess, NCATE added the requirement that institutions use assessments with observable behaviors to determine a candidate's disposition for fairness and the belief that all students can learn. However, numerous questions continued to go unanswered. Currently, NCATE requires dispositions to be systematically assessed across the unit. In other words, institutions are required to identify the dispositions that are important to all programs in education, and how they are systematically assessed. This requires institutions to determine a set of dispositions universal to all programs and to develop a means to assess and evaluate them - a difficult task when educators are not in agreement about the precise meaning of the term "disposition".

Additionally, the shift from curricular program evaluation to performance-based evaluation generates several questions. For example, in the past, candidates were credentialed based on passing licensure exam scores and were evaluated based on knowledge. Essentially credentialing candidates required professors to teach coursework, monitor field experiences, and submit existing documentation to show what was taught and candidate success was based on standardized licensure exam scores. With the shift to performance-based assessment, evidence of the program's success is defined in terms of student performance. What is the cost to universities and to students when considering the amount of additional time, energy, and resources required for performance-based assessment? What is the cost when considering the creation of rubrics, the collection and analysis of data, and the time, energy, and resources to determine the best means of evaluating candidate performance, in comparison with primarily evaluating them based on a standardized licensure exam and a description of the program? With performance- 
based assessment, NCATE provides standards to be met, but leaves the interpretation of how to meet the standards to the institution.

\section{What is a Disposition?}

In an attempt to provide clarity in determining what a disposition is, the authors of The Passion of Teaching: Dispositions in the Schools, begin by acknowledging the "sheer volume of research efforts toward identifying what causes or lies behind teachers' actions ..." (Smith, Skarbek, \& Hurst, 2005, p. 2). They include a table with some examples of terms associated with dispositions in the literature from 1963-1995. While their list is in no way exhaustive, it includes a wide variety of terms such as attitudes, personality and characteristics, beliefs, values, expectations, sense of efficacy, conceptions, perceptions, theories, and dispositions (Smith, Skarbek, \& Hurst, 2005).

The variety of terms used in association with dispositions indicates the utter ambiguity of the term in the field. There have been numerous attempts to define the term "disposition", but many of the definitions employ terminology that in no way provide clarity to the definition (Smith, Skarbek, \& Hurst, 2005). In 1985, Katz and Raths defined dispositions as "an attributed characteristic of a teacher, one that summarizes the trend of a teacher's actions in particular contexts" (Katz \& Raths, 1985, p. 301). They credit their definition to the works of Buss and Craik (1983), who believe dispositions are summaries of the frequency of acts (Katz \& Raths, 1985).

Wasicsko, Callahan, and Wirtz (2004) believe a simple way to conceptualize dispositions is to assume the term encompasses everything that is not considered to be knowledge or skill. They explain that most operational definitions of the term dispositions include three constructs that are evident in the literature on teacher 
effectiveness. These areas include teacher behaviors (observable actions), teacher characteristics (attributes or tendencies such as tolerance, open-mindedness, enthusiasm, etc.), and teacher perceptions (attitudes, values, and belief systems such as self-concept, seeing students as able people versus thing orientation, etc.) (Wasisko, Callahan, \& Wirtz, 2004).

Katz and Raths' (1985) definition is frequently referred to in the literature, and "may be most effective in clarifying the dispositions discourse" (Smith, Skarbek, \& Hurst, 2005, p. 2). They compare and contrast between their definition of dispositions and other terms frequently used in education. For example, when examining the relationship between skills and dispositions, they note "to have a disposition considered desirable for teaching, a teacher must also have certain skills" (Katz \& Raths, 1985, p. 302). First, the teacher must possess the skill necessary to analyze the learner's needs, current teaching practices, in order to determine how to best help the student. Next, the teacher must adapt instruction according to the learner's needs. Similarly, Schussler and others point out that dispositions require the use of both knowledge, as well as the awareness to know the appropriate time and manner to apply certain knowledge and skills (Schussler, Bercaw, \& Stooksberry, 2008).

Another frequently used term for which Katz and Raths (1985) offered clarification is "attitudes." In relationship to dispositions, an "attitude" is considered set of beliefs about an object or situation, and is seen as a "pre-disposition" to act. A person may possess an appropriate attitude in a given situation, but not engage in observable acts. Since Katz and Raths view dispositions as patterns of observable behaviors, 
attitudes are considered pre-dispositions because they are not observable (Katz \& Raths, 1985).

Dispositions have also been likened to "habits". Katz and Raths distinguish between habits and dispositions when they say, "We see dispositions as 'habits of mind'—not as mindless habits" (Katz \& Raths, 1985, p. 303). Essentially, habits occur without thought. While some intentional behaviors a teacher exhibits might appear automatic, they are likely not without thought. Teacher dispositions "should be so well learned and understood that they are manifested frequently and thus resemble habits" (Katz \& Raths, 1985, p. 303).

The final term Katz and Raths (1985) compared with disposition is trait. They discuss two facets of traits that are different from dispositions. First, traits describe one's character. They note that traits like "honesty, ambition, courage and forthrightness" depend on the second facet, intensity. If a person is asked a question like, "Where is the nearest restroom?" and a person responds accurately, it is not necessarily a good measure of the person's honesty because the person likely had no reason to be dishonest. Traits depend on situations, where dispositions do not (Katz \& Raths, 1985).

In 1949, Dr. Arthur Combs addressed the human qualities of teachers and other helping professions in theory he called perceptual psychology (Combs, 2006). His research is serves as a foundation for numerous dispositions models (Combs, 1973, 1974; Combs, Soper, Gooding, Benton, Dedrick, \& Usher, 1969; Wasicsko, 2007). Essentially, his work states that people behave according to how the world appears to them; behaviors are indicators of underlying perceptions, attitudes, and values; core perceptions change and develop slowly over time; if one can determine how people perceive themselves, 
behavior can be explained; and one's perceptions can be understood by reading behavior (Combs, et al., 1969).

In the 1960's, Arthur Combs and his associates engaged in a series of studies on the beliefs of effective helpers, their characteristic perceptions of self, other people, the nature of helping, important purposes of helping, and the world in general. The studies are referred to in the literature as "perceptual-field psychology" and are foundational to many interpretations of dispositions in teacher education. Usher (2004) examined Combs' works and reformulated his studies as Five Dispositions of Teacher Effectiveness, which include: empathy, positive view of others, and positive view of himself/herself, authenticity, and meaningful purpose/vision. Usher concludes from perceptual-field psychology that dispositions are learned as a result of experiences that are related to the self, and the five proposed dispositions of effective teachers are "natural outgrowths of the basic human need for self-adequacy" (Usher, 2004). Essentially, given the right experiences, Usher believes the dispositions will develop freely. He states that, "Experiences that involve a physical investment (movement, touch, etc.), a mental effort (thoughts, feelings, etc.) and a spiritual sense (inspiration, release, faith, etc.) are the most potent and contributory experiences for the nurturance of dispositional growth" (Usher, 2004, p.2).

Although Katz and Raths, as well as Combs are frequently cited in the literature as providing some clarity as to what a disposition is, numerous other definitions and clarification statements abound. Examples include the following: 
“...dispositions concern not only what one can do, one's abilities, but also what one is disposed to do. Thus dispositions address the often-noticed gap between our abilities and our actions" (Ritchart, 2001, p.3).

"The construct of 'dispositions in action' is concerned with patterns of thinking and how one is disposed to act. It moves beyond personality traits and minimal behavior expectations. Within this construct, patterns of thought about issues of morals, ethics, and diversity reveal dispositions toward thinking and how they manifest themselves through the actions teachers subsequently take in the classroom" (Thorton, 2006, p.56). “...the qualities that characterize a person as an individual: the controlling perceptual (mental, emotional, and spiritual) qualities that determine the person's natural or unusual ways of thinking and acting" (Usher, 2002, p.2).

“...disposition consists of value or belief, an intention or desire that the value or belief be actualized, and the skills or knowledge necessary to give reality to the intention" (Freeman, 2004, p. 4).

“...the core perceptions (values, attitudes, and beliefs) exhibited by teachers that permit them, when combined with significant knowledge and skills, to be effective in facilitating learning, growth, and development in virtually all the students with whom they interact" (Wasicsko, 2007, p. 60).

“...intellectual, and emotional investments in events, situations, and people. Pre service and in-service educators develop positions toward teaching and learning that direct their work with student, parents, and colleagues. Dispositions are made manifest through intentional, practiced behaviors that can be challenged, developed, and enhanced even as they denote behavioral tendencies that endure 
over time. Because dispositions are not visible, analysis of dispositions must rely upon the actions of the teacher in the classroom. Behaviors signaling effective dispositions are indicators of competence in actual performance over time" (Breese \& Nawrocki-Chabin, p. 33).

In addition to struggling to interpret the term disposition, educators were apparently unsure of the meaning of the term social justice in NCATE's 2000 definition. By addressing social justice, were teacher preparation institutions somehow to make a judgment about candidate moral character? This question is raised by Wilkerson and Lang (2007) when they discuss three issues associated with the assessment of moral and ethical values in teacher education. The first is that unless there is a gross deficit, it is difficult to observe a person's moral and ethical character. Secondly, there are religious overtones to some views of moral and ethical character that may prove problematic, particularly in Health Education. For example, some religions oppose homosexuality, while others do not. Who is to determine the appropriate moral characteristics of a teacher? How does a determination of moral character impact the teaching of morally sensitive areas, such as those in human sexuality? Thirdly, "Focusing on morality and ethics, rather than skill-based standards, is short-sighted, bordering, in our view, on the real immoral action, letting unmotivated teachers in to the profession because of a failure to recognize the codependence of knowledge, skills, and dispositions" (Wilkerson \& Lang, 2007, p. 13).

Other questions raised about social justice include, "How should social justice be conceptualized so that it is more widely accepted as a viable lens through which educators can help student better interpret themselves and their world? How might we 
conceptualize social justices so as to avoid its reduction to political indoctrination?" (Heybach, 2009, p. 239). Heybach (2009) also raises the point that narrow views of social justice limit teachers' abilities to critically examine the world through multiple viewpoints. What is the impact of limited viewpoints on a person's ability to teach diverse populations of students? How can we conceptualize social justice in order to facilitate pedagogical practices that are relevant to multiple populations of students?

In June 2006 NCATE released a statement in defense of their use of the term social justice, stating the term is used as, "one of several illustrative examples of professional dispositions. Critics incorrectly alleged that NCATE has a 'social justice' requirement. It does not. The requirements are spelled out in the Standards themselves where the phrase 'social justice' does not appear" (NCATE, 2006). The purpose of the inclusion of the term social justice was to recognize the disparities in the achievement of students in America, not to "require institutions to inculcate candidates with any particular social or political ideology" (NCATE, 2006). They further clarify their position by stating, "NCATE seeks to ameliorate the achievement gap by ensuring that its institutions are preparing teachers who will be able to help all students learn, regardless of their socioeconomic status, race/ethnicity, and exceptionalities" (NCATE, 2006).

In 2007, NCATE revised their standards, using the term professional dispositions instead of dispositions, and eliminating the use of the term social justice. In the glossary of the 2007 NCATE Standards, professional dispositions are defined as, "professional attitudes, values, and beliefs demonstrated through both verbal and non-verbal behaviors as educators interact with students, families, colleagues, and communities. These positive behaviors support student learning and development" (NCATE, 2008, p. 89-90). 
They attempt to provide further clarification for institutions by stating the assessment of professional dispositions should be "based on observable behaviors in educational settings. The two professional dispositions that NCATE expects institutions to assess are fairness and the belief that all students can learn. Based on their mission and conceptual framework, professional education units can identify, define, and operationalize additional professional dispositions" (NCATE, 2008, p. 90).

NCATE's requirements are vaguely stated and leave a great deal of room for interpretation. In addressing dispositions, institutions should give consideration to how to broaden the perspectives of candidates to teach in a multitude of educational settings and how to best meet the needs of all students. Ladson-Billings' (1995) addresses the importance of culturally relevant pedagogy in teaching diverse populations of students and describes the practices and characteristics of exemplary teachers of African American students. Some of the characteristics and important practices she noted centered on the following:

- Conceptions of self and others (believing that all students are capable of success, viewing pedagogy as an art, viewing themselves as part of the larger community, believing they give back to the community through teaching, and believing that teaching is drawing knowledge out)

- The manner in which social relations are structured (reciprocal connectedness between the teacher and the student, and an atmosphere of community and collaboration)

- Conceptions of knowledge (knowledge is always changing, it must be viewed critically, teachers should show passion about knowledge and learning, teachers 
should build on student knowledge and experiences to make content relevant, assessments and the way success is defined should be varied)

Ladson-Billings (1995) research does not explicitly list a finite set of dispositions for a culturally sensitive pedagogy. However, her work is rich with considerations for structuring teacher education programs, as well as professional development, to address the complexities of teaching students who do not necessarily have similar values, beliefs, and/or backgrounds as the educators who teach them. Additionally her work could provide guidance to teacher preparation institutions that see social justice as an important concept to address.

\section{Dispositions in the State of Maryland}

As the NCATE became more attentive to dispositions, the State of Maryland also began to recognize the need to hold higher education institutions accountable for developing and assessing candidate dispositions. In 1988, the Higher Education Act established the Maryland Higher Education Commission (The Commission) to address the growth and development of higher education in the state. In order to gather information to develop their plan the Commission held a series of public hearings across the state to gain input from various stakeholders. One of the central themes to emerge was the plea for improvement in teacher education, professional preparation, and continuing education for in-service teachers. Two of the objectives of the commission directly related to teacher education:

- To require specific plans by public campuses to improve undergraduate education with an emphasis on arts and sciences core requirements; and 
- To require specific plans by public campuses to improve teacher education (Maryland Public Schools, 1995, p.5).

To address the objectives of the Commission, a task force was charged with recommending a comprehensive approach to preparing teachers that included a solid foundation in academic preparation as well as promising developments in professional practice. The following recommendations resulted from the work of the task force:

- To enhance the liberal arts and sciences preparation of teacher candidates;

- To enhance the clinical, school-based experience;

- To institute outcomes-based instruction and assessment of teacher preparation;

- to integrate teacher education reform and school reform;

- To integrate college-based faculty into the clinical setting;

- To involve the total campus community in the preparation of teacher; and

- To create a professional development ladder for future teachers (Maryland Public Schools, 1995, p. 6).

Additionally, the task force recommended a broad liberal arts and sciences background, a sustained clinical experience, and continuing educational opportunities in alignment with State requirements for recertification (Maryland Public Schools, 1995).

The recommendations of the task force (Task Force I) were accepted by the Commission, and a new task force (Task Force II) was formed to examine the recommendations of Task Force I in order to suggest strategies for implementation. Task Force II developed twenty recommendations, structured around five themes: the undergraduate experience, the pre-intern assessment, the professional development experience (internship), the post-internship assessment, and the continuing professional 
development of teachers (Maryland Public Schools, 1995). For the purposes of this paper, only the relevant recommendations will be examined.

The first five recommendations relate to undergraduate preparation. The four relevant to teacher education and dispositions are discussed below (recommendations 1, 2, 4, and 5):

Recommendation 1: All students pursuing careers in teaching should complete programs with sufficient academic rigor to give them the breadth and depth necessary to effectively teach their subjects.

Recommendation 2: As part of a comprehensive foundation in the liberal arts, all prospective teachers should have substantive math, science, and technology backgrounds (Maryland Public Schools, 1995, p.11).

Each of the above recommendations clearly relate to candidate knowledge, rather than skill or disposition. The rationale behind each of these recommendations is the need for teachers to have a broad knowledge of not only their subject matter, but also the interrelationships between multiple subjects. Such knowledge will allow teachers to be more effective by relating content to multiple subject areas. In the latter part of recommendation one, an undertone of dispositions is implied by the phrase "necessary to effectively teach their subjects". It is widely agreed that candidate knowledge is critically important for teachers and it is somewhat easy to determine when candidates possess knowledge. However, when words like "effectively teach" appear, the level of agreement about what it means to "effectively teach" becomes significantly less clear, and effective teaching becomes much more difficult to assess than content and pedagogical knowledge alone. It is easy to recognize good teaching, but it is difficult to 
identify all of the nuances that make one teacher more effective than another. In Recommendation four, there is evidence of a somewhat clearer example of the slight shift of emphasis from knowledge to a combination of knowledge and observable behavior, which may include dispositions:

Recommendation 4: As an alternative to offering academic content undergraduate degrees, institutions may develop undergraduate education degree programs that:

- are performance-based in design;

- include a performance-based assessment measuring the students' knowledge in academic areas and pedagogy;

- have rigorous academic requirements; and

- require an extended clinical internship in a Professional Development School (Maryland Public Schools, 1995, p.13).

With the addition of performance-based assessment, the possibility of assessing not only candidate skill, but also candidate disposition, increases. Through candidate observations in a real classroom setting, dispositions considered critical to effective teaching may be monitored, assessed, and nurtured when weaknesses are identified.

Recommendation five addresses the importance of college professors modeling good teaching. While this recommendation does not explicitly address candidate dispositions, it has a dramatic impact on what candidates perceive as appropriate instruction, and, thereby, has potential to impact their dispositions to teach effectively. Additionally, this recommendation directly aligns with Bandura's (1997) principles of 
social learning discussed at the end of this chapter. Essentially Bandura's theory stresses the importance of observing desirable behaviors in order to learn to replicate them.

In the discussion following the recommendation, it is noted that, "Campus-wide attention should be given to ensuring the highest quality of instruction to serve as a model for prospective teachers" (Maryland Public Schools, 1995, p. 14). The recommendation states:

Recommendation 5: The implementation of these recommendations should accompany more campus-wide attention to the importance of ensuring the highest quality instruction - across the disciplines in the arts and sciences - that will serve as a model for prospective teachers. In particular, efforts should be made to improve instruction at the introductory levels, especially in math and science (Maryland Public Schools, 1995, p. 15).

Recommendations six through fifteen each pertain to the Professional Development School experience. Each intern is to complete an extensive internship for 100 consecutive days in a school called a Professional Development School (PDS). The idea behind the PDS model is for candidates to intern in cohort groups at least five and have more varied experiences than only interning with a single mentor teacher (Maryland Public Schools, 1995). PDSs are to model current best practices for teaching and learning for pre-K-12 students. They should have numerous experienced teachers and other school personnel. In the PDS model, higher education faculty members are to work closely with practicing teachers to develop new methods of instruction and curricula for both the PK-12 school and the college. With the PDS model, there is an overall theme of collaboration, rather than separation, between higher education and PK-12 schools, 
thereby, providing a pathway for identifying and addressing candidate strengths and weakness in knowledge, skill, and dispositions (Maryland Public Schools, 1995).

The next two recommendations address the internship experience. Currently, the state of Maryland requires an extensive 100 consecutive day internship at a Professional Development School (Maryland Public Schools, 1995).

Recommendation 6: Every teacher candidate should do an extensive internship in a specially designed Professional Development School.

Recommendation 7: The Maryland State Department of Education should develop guidelines for use by university, college, and school system partnerships in the establishment of rigorous standards for admission to a Professional Development School. These basic requirements should include:

- Substantial completion of a bachelor's degree in an academic discipline, academic interdisciplinary, or multidisciplinary program, or performancebased education program;

- Successful completion of a State-approved assessment measuring knowledge in general liberal arts and sciences; and

- Successful completion of a state-approved assessment measuring knowledge in the intended teaching content area (Maryland Public Schools, 1995, p. 17-18).

Each of the requirements of recommendation seven continues to focus primarily on content knowledge, rather than skill or disposition. Recommendation eight, however, has a much greater emphasis on dispositions when the Essential Dimensions of Teaching, 
Maryland's performance-based standards for what teachers should know and be able to do, are examined.

Recommendation 8: Maryland's Essential Dimensions of Teaching and the Interstate New Teacher Assessment and Support Consortium (INTASC) should serve as a framework for the teacher education curriculum. The Professional Development Schools should provide clinical settings for teacher candidates to master the combination of theory and practice inherent in these Essentials (Maryland Public Schools, 1995, p.19).

The Essential Dimensions of Teaching identify ten performance-based standards which include indicators for four learning domains: knowledge, analysis, action, and reflection. The document indicates that learning to teach occurs in a cycle. The candidate must acquire a knowledge base related to the new skill; analyze critical elements of the skill; plan and implement a course of action, and then reflect upon the outcomes of the action. The reflection informs the candidate's knowledge base, and the cycle continues. Ten essential dimensions identified include the following:

1. Demonstrate mastery of appropriate academic disciplines and a repertoire of teaching techniques.

2. Demonstrate an understanding that knowledge of the learner's physical, cognitive, emotional, social, and cultural development is the basis of effective teaching.

3. Incorporate a multicultural perspective which integrates culturally diverse resources, including those from the learner's family and community. 
4. Demonstrate knowledge of strategies for integrating students with special needs in to the regular classroom.

5. Use valid assessment approaches, both formal and informal, which are ageappropriate and address a variety of developmental needs, conceptual abilities, curriculum outcomes, and school goals.

6. Organize and manage a classroom using approaches supported by student learning needs, research, best practice, and expert opinion.

7. Use computer and computer-related technology to meet student and professional needs.

8. Demonstrate an understanding that classrooms and schools are sites of ethical, social, and civic activity.

9. Collaborate with the broad educational community, including parents, businesses, and social service agencies.

10. Engage in careful analysis, problem solving, and reflection in all aspects of teaching (Maryland Public Schools, 1994, p. 4).

Following each of the above essential dimensions is a set of indicators for each of the learning domains (knowledge, analysis, action, reflection). Within the indicators, the emphasis on teacher dispositions begins to emerge, particularly in the action and reflection domains. For example, one of the action indicators for the first essential dimension is "model the attitudes, dispositions, and behaviors related to the subject area(s), e.g. the teacher as scientist, writer, artist, etc." (Maryland Public Schools, 1994). Although the vague language in this indicator likely leads to questions about the attitudes, 
dispositions, and behaviors which should be modeled, it is one of the earliest examples of Maryland's attentiveness to teacher dispositions in pre-service and in-service teachers.

\section{The Impact of Dispositions and Dispositions Requirements}

As institutions have attempted to incorporate systematic assessment of dispositions into their teacher education programs, they have struggled with how to assess them and what exactly they should assess. NCATE charges institutions with assessing observable behavior and advises against evaluating attitudes (NCATE, 2006). Perhaps the reason many have struggled to assess dispositions, rather than attitudes is because dispositions - the observable actions — are greatly influenced by a person's beliefs, values, feelings, and thoughts (Diez \& Raths, 2007). The two seem to be extremely difficult to separate. Helm (2006b) writes, "It is not easy to assess something that is internal by nature, or to determine its existence if one cannot see the disposition in question" (p. 237). She explains this statement using an illustration about two hunters. One asks the other if he had ever seen the game they were about to hunt, and the other responds by telling him, "No, but I'd recognize it if I saw it" (Helm, 2006b, p. 237). The difficulty in distinguishing between the observable and the unobservable is further illustrated by the terminology used in the 1992 INTASC Standards that include, "the teacher realizes, appreciates, has enthusiasm for, believes respects, is sensitive, values, and recognizes. As is clear, this version of the construct of 'disposition' represents beliefs, values, and perceptions rather than a summary of behaviors" (Diez \& Raths, 2007).

Another question raised by many educators is whether or not dispositions are innate, or learned. Is teaching something one is "called" to do, or is good teaching 
something that can be learned? Is it possible to determine which applicants are predisposed to good teaching? (Helm, 2006a). One study conducted by Rinaldo and others (2009) showed candidate perceptions of their own dispositions during initial phases of a teacher education program were lower than their perceptions at later stages of the program. Because of the combination of coursework and field experiences, it is unclear exactly what facilitated the perceived changes. Also, these changes were those perceived by the candidates and were not corroborated by outside examiners. However, the study lends some support for the notion that dispositions can be developed over time (Rinaldo, et al., 2009). Additionally, the quality of the field experiences may be a factor in shaping dispositions. Both Helm (2006a) and Rinaldo and others (2009) allude to the importance of creating experiences where candidates observe desirable dispositions in practicing teachers, and in a realistic teaching environment. The belief in modeling desirable behaviors and providing opportunities and experiences to practice them is part of Bandura's (1997) beliefs about social learning. The modeling of dispositions seems to help make teacher candidates more aware of what is expected of good teachers, thus allowing them to work toward developing their own dispositions (Helm, 2006; Rinaldo, et al., 2009). What are the right conditions for observation? How do we create appropriate opportunities for modeling, practicing, and helping teacher education students become aware of their own dispositions?

Additionally, when considering that the term "disposition" has been defined as a pattern of observable behaviors, the connection between skills and dispositions becomes apparent. For example, if a candidate is learning to modify instruction to meet the needs of diverse learners, then demonstrates in multiple ways that he/she has mastered the skill, 
it can be assumed that in future lessons if the candidate fails to modify instruction to meet learner needs, it is not because of his/her lack of skill, but rather may be due to lack of disposition to put forth the effort to modify instruction. In contrast, a candidate who lacks the skill to modify instruction to meet learner needs does not necessarily lack the desire (disposition) to do so. He/she may simply need additional support in acquiring the skill/skill set.

There are many unanswered questions about dispositions, and the process of addressing dispositions assessments seems to be a "learn as you go" endeavor. In the literature on dispositions, numerous institutions have chronicled their attempts at assessing dispositions and offer advice to institutions on appropriate courses of action for developing systematic assessments. In Dispositions in Teacher Education, Raths (2007) discusses the importance of starting with the identification of dispositional goals that are of a reasonable conceptual size. Many institutions develop long lists of individual observable behaviors to assess. The lists become overwhelming to the observer and should be grouped into more broad categories (Rike, \& Sharp, L. 2008). Other institutions have developed dispositions assessment models based on professional behaviors, self-reflections, ethics and equity, or the active nature of dispositions (Thorton, 2006). Regardless of the nature of the dispositional goal, in clarifying expectations for candidates it is helpful to state specific instances that reflect the goal as well as counter indicators of the goal (Diez \& Raths, 2007). Once the dispositional goal is identified, Raths suggests using the Buss and Craik (1983) model which includes: 
1. After identifying a target disposition, or goal, a panel of educational experts identify numerous examples of acts a teacher candidate might exhibit to exemplify the disposition.

2. The panel of experts rate how typical each of the examples would be of the target disposition identified. Then the list of examples would be narrowed and used in step three (below).

3. Faculty members observe teacher candidates over a period of time and mark the number of times in which one of the acts is observed. Those candidates who most frequently exhibit the acts would have a stronger target disposition than the candidates who do not frequently exhibit the acts (Diez \& Raths, 2007).

The Interstate New Teacher Assessment and Support Consortium (INTASC) followed a similar procedure indicated by Buss and Craik (1983) in the development of the Clinical Experience Rubric (CER). The CER was developed by field experience supervisors and pre-kindergarten through twelfth grade teachers using the Interstate New Teacher Assessment and Support Consortium (INTASC) standards. The rubric developers first identified the most important INTASC dispositions, and then categorized each disposition according to common identified themes. Themes included professionalism, teaching qualities, and relationships with others. Then the team identified indicators and counter indicators associate with each disposition (Flowers, 2006).

Another assessment example includes Likert scales where the 'dispositions', rather than specific acts, are posed for ratings and evaluations for which supervisors rate 
each candidate's two strongest and two weakest dispositions from a list provided (Diez \& Raths, 2007, p. 161). Some universities use portfolios to assess dispositions, particularly those related to reflection (Wenzlaff, 1998).

According to Diez and Raths (2007), each of the examples listed above is not without flaw. Institutions have struggled with teaching raters what is meant by each of the dispositions, thus resulting in low coefficients of agreement among raters. Additionally, raters were reluctant to assign ratings at the lower end of the scales.

Helm (2006b) discusses additional evaluation methods, including interviews, having external sources (such as mentor teachers) use a rubric to evaluate candidates, and evaluation of candidate reflections. She seems to contradict Diez and Raths' statement about the reluctance of raters to assign low scores when she states, "Usually, cooperating teachers are not afraid to evaluate the student teachers fairly and correctly using the scoring rubrics" (p. 2). It should be noted that the extent to which raters were trained is unclear in each of the documents and may contribute to differences in the degree of reluctance to rate candidates correctly.

Regardless of the type of assessment used, institutions may consider Alverno College's five principles in developing dispositions assessments for their candidates: make the invisible visible through active means, (2) assess dispositions in both structured ways and through ongoing observations, (3) assess dispositions over time through a reflective process, (4) make criteria used in the assessment public and explicit, and (5) recognize that assessing dispositions has moral meaning for teacher candidates and for the profession (Sockett, 2006). It should be noted that Alverno is a small, private institution with approximately 2300 undergraduate students and a student-faculty ration 
of 12:1 (U.S. News and World Report). Their principles of dispositions assessments involving ongoing observations may prove difficult for institutions with greater teacherstudent ratios. One of the challenges of addressing dispositions is that attention needs to be given to the context in which the research is conducted. The way a small, private institution addresses dispositions may not be feasible for a larger public institution. The amount of students, the resources, and the opportunities for diverse field experiences are among a few things that may vary significantly among teacher preparation institutions. Each institution should give consideration to their own resources, personnel, number of students, and feasibility of various assessment models.

In addition to the above mentioned assessment and evaluation methods, some universities have developed monitoring systems to identify candidates who display dispositional behaviors identified as undesirable. Teacher educators at St. Bonaventure University, another small institution of about 2,000 undergraduate students (U.S. News and World Report), use a "yellow flag" system in which professors identify candidates for whom they have concerns, document concerns and steps taken to address concerns, and make recommendations for resolving the issue. Copies of the completed yellow flag form are then sent to the chairperson and the candidate, and then either the chairperson or the dean meet with the candidate to discuss the concern and potential solutions. Then, a plan of action is drawn up in the form of a contract. Students who receive three yellow flags are not considered for internship placement (Burke, 2002).

Indiana University South Bend employs a similar system called the "letter of concern". When a faculty member submits the first letter, it is shared with the candidate and goes into the candidate's file. If a second letter is submitted, the candidate meets 
with the dean to discuss his/her future in the program. If the candidate is removed from the program he/she may create a personal and professional development plan to address weaknesses. Upon successful completion of the plan, the student may request to be reinstated into the program (Smith, Skarbek, \& Hurst, 2005). The advantage to using a monitoring system, such as the ones described above, is the opportunities created for conversations with individual students about their dispositions. The systems allow for early intervention, and may help candidates realize why a certain disposition is important, or that another career path might be a better option (Burke, 2002; Smith, Skarbek, \& Hurst, 2005).

Numerous types of dispositions assessments are noted in the literature, including checklists, faculty-faculty conferences, faculty-student conferences, committee review, student contracts, projects, reflections, and exit slips, (Ginsberg \& Whaley, 2006; Da Ros-Voseles, \& Moss, 2007). Additionally, many institutions have indicated specific procedures for developing assessment instruments and assessment systems. Henderson State University began by first establishing a set of clearly identified dispositions supported by research, translating each disposition into observable behaviors, designing a means to assess the dispositions in candidates, determining a mechanism to delay the admission of program applicants who did not demonstrate desirable dispositions, and developing ways to assist candidates with the understanding of dispositions and selfassessment of dispositions. While they were able to successfully meet NCATE standards, they continue to study the reliability of their assessments in an effort to continually improve (Harrison, Smithey, McAffee, \& Weiner, 2006). 
The University of New England approached a dispositions assessment study by asking faculty to generate a list of dispositions they felt were reflective of a professional teacher. The dispositions were then grouped into categories. In each course, the instrument is used as a self-evaluation tool for teacher education candidates. Following the self-evaluation, the instructor of the course also evaluates the students. Instructors are given two answer choices: (a) no reservations about the student answer choices, and (b) reservations exist. Faculty gave feedback to the students regarding their evaluations, and then submitted the evaluations to the researchers. In any case where a faculty member had reservations about a student's dispositions, the situation was brought to the attention of the department chair, who then met with the candidate. Essentially, the researchers noted the need to refine the instrument in order to allow more answer choices for the faculty. They noted faculty support of the instrument, as well as the need to engage in further study to refine the instrument and evaluation system (Hillman, Rothermel, \& Scarana, 2006).

In addition to struggling with what and how to assess teacher education candidates, many institutions have struggled with what to do with candidates who show less than desirable dispositions. Many use evaluations as opportunities to facilitate difficult discussions with students about expectations of teacher candidates. Others have used assessment results to delay advancement of candidates through the program, or to remove students from the program. However, those who have used dispositions as a reason for removing candidates from a program have found themselves involved in lawsuits, as is the case at LeMoyne College in Syracuse, New York (Honawar, 2008; Manzo, 2006). Many institutions fear litigation; however, Diez (2007b) suggests that 
when dispositions are assessed throughout a candidate's experience, when the assessment results are well documented, and when assessment results are used to provide information to help candidates grow, the danger of legal implications becomes less significant.

Regardless of the mechanism of evaluation or how evaluations are used, there are several problems with assessing dispositions that continue to pervade teacher preparation programs:

1. A finite set of dispositions with which to work is necessary to provide structure for evaluation.

2. It is possible to determine that some candidates have stronger dispositions than others, but it is difficult to determine a specific cut score that must be achieved in order to earn licensure.

3. Consideration needs to be given to how dispositions are learned and strengthened (Diez \& Raths, 2007).

Additionally, after determining what dispositions should be assessed and the mechanisms that will be used for assessment, there is still the issue of communicating expectations to teacher education faculty, mentor teachers, and most importantly, teacher education students. In one study, the researchers noted that prior to receiving instruction and engaging in training practices, their top teacher education candidates held much different perspectives of what evaluators considered "competent" and "outstanding" levels of dispositions (Soddard, Braun, Dukes, \& Koorland, 2007).

As clearly stated in the discussion above, one reason institutions have had difficulty developing a finite set of dispositions with which to work is due to the lack of consensus regarding what a disposition is. Another reason is the focus that NCATE 
places on systematically assessing dispositions as a Unit. In other words, institutions are charged with identifying and assessing dispositions which are common to all programs. While it is likely that there are numerous dispositions that should be commonly assessed, consideration should be given to dispositions that are important in specific disciplines, such as Health and Physical Education, which are subjects often taught by classroom teachers, rather than certified content specialists. Are the dispositions required of a typical classroom teacher the same as those required in specialty areas, particularly those related to such areas as allied heath, the arts, business, or career training (such as welding, automotive mechanics, cosmetology, etc.)? Does the concept of a teacher encompass all teachers, or does the concept of a teacher include teachers of core subjects? How does the concept of teacher impact decisions about dispositions assessment in teacher preparation?

As institutions struggle to identify what to assess, consideration should be given to the literature regarding the dispositions that seem to have the most impact on academic success. The results of a study by Hamre and Pianta (2001) suggest that teacher-student relationships are "unique predictors of academic and behavioral outcomes in early elementary school, with mediated effects through eighth grade" (p. 634). A study by Birch and Ladd (1997) indicate the quality of the teacher-student relationship is correlated with levels of school avoidance, student attitude toward school, student cooperation, student self-directedness, and school adjustment. Additionally, Marzano (2003) discusses the importance of the teacher-student relationship in the context of classroom management. 
In a 2007 article, Helm states, "Dedicated teachers, who possess the right dispositions, can be the keys to reach students who do not come from wealth or privilege" (p. 109). Helm's beliefs are consistent with what the Centers for Disease Control and Prevention states about the importance of school connectedness to a child's success. "In the school setting, students feel supported and cared for when they see school staff dedicating their time, interest, attention, and emotional support to them. Students need to feel that adults care about them as individuals as well as about their academic achievement" (Centers for Disease Control and Prevention, 2009, p. 6). Similarly, McCombs (1998) states that student learning and motivation is improved when teachers care about and attend to the needs of each individual learner. When students feel supported by important adults, they are more likely to be engaged in learning. A teacher's ability to maintain a safe, structured, positive psychosocial climate ultimately impacts a student's level of connectedness to the school, and ultimately, their academic success (Centers for Disease Control and Prevention, 2009).

In a study conducted by Wenglinsky (2002), aspects of teacher quality, particularly classroom practices, seemed to have a great impact on student achievement. Classroom practices such as hands-on activities, ability of the teacher to relate information to student experiences, and engagement in professional development to learn how to teach various groups of students seemed to weigh heavily on student achievement. What kinds of experiences are necessary for pre-service teachers to develop the dispositions necessary to impact student achievement this way? How is student achievement defined — as standardized test scores, as student's ability to be a productive member of society, as an individual who has values, morals, and character and will likely 
passes them along to generations to follow, as a person who is well rounded, caring, or considerate? Are there measures of student success we overlook? How does that impact what becomes emphasized in teacher education?

In a 2008 article, Osguthorpe believes that if we assume there is a relationship between moral dispositions of a teacher and the moral development of students, then there are at least three reasons to desire teachers of good moral character. The first is to perpetuate students of good disposition and moral character. The second is that we want teachers to consciously and unconsciously convey good moral character, essentially serving as role-models for students. The third is that we want teachers to provide instruction of morality through the curriculum. Osguthorpe also states that if we assume there is no relationship between a teacher's moral character and the development of morality in students, we should still find teachers of good moral character desirable for three reasons. The first is for authenticity; we want teachers to be what they convey to students. The second is that we want teacher to teach in moral ways, with virtue. The third reason is that we want teachers to show wisdom and the virtue of intellect.

In a 1974 study, Combs describes the effective characteristics of teachers as indicated by the Florida Childhood Education Program, and concludes the need to address teacher effectiveness in terms of a perceptual psychology model. He identifies the following as characteristics of effective teachers:

- Knowledge of the world and of subjects;

- Sensitivity to people and the capacity for empathy;

- Accurate and appropriate beliefs about people and their behavior;

- Positive beliefs about self; 
- Appropriate and congruent beliefs about purposes, goals of society, schools, the classroom, and the teacher's own goals in teaching; and

- The personal discovery of appropriate and authentic ways of teaching In the works of Darling-Hammond, several teacher variables have been found to impact student achievement. While each of the variables in and of themselves may not be considered dispositions, the argument could be made for teachers to have the disposition develop skill and knowledge in the areas she identifies as critical to student achievement. In Darling-Hammond's 2000 article, the following teacher variables were linked with student achievement: general and verbal ability, subject matter knowledge, knowledge about teaching and learning, teaching experience, and passion for teaching. While both subject matter knowledge and pedagogical knowledge are were found by Darling-Hammond to be critical to student achievement, studies by Reynolds (1992) and Lourdusamy, Toh, and Wong (2001) showed that pedagogical content knowledge, or knowledge of how to effectively teach content, is more critical to student achievement than content knowledge alone. Toh, Ho, Chew, and Riley further explain the importance of and distinction between pedagogical content knowledge when they explain that a teacher can only relate a concept well if he or she first understands it well. It is difficult to make content meaningful to students if it is not first meaningful and fully understood by the teacher.

One final question regarding the impact of dispositions on teacher education institutions relates to role-modeling outside the classroom. Should behaviors outside the classroom be considered in evaluations of teachers? One study by Olsein, Clough, and Penning (2009) investigated elementary teachers' Facebook profiles and determined that 
of the $32 \%$ of elementary education majors who participated in the study, only $22 \%$ of those profiles were free of inappropriate content. What guidance is given to institutions for addressing the plethora of available personal information about teacher education candidates made available through social media? If a candidate's behavior in the classroom is not cause for concern and candidate, should evaluations of dispositions be impacted by information gleaned through measures outside of the traditional teacher education setting?

\section{Dispositions at Frostburg State University}

In 2007, Frostburg State University (FSU) prepared an Institutional Report (IR) for NCATE and the Maryland State Department of Education (MSDE) in preparation for an accreditation visit. According to the report, FSU dispositions have always been assessed during candidate internships. The internship evaluation instrument is organized according to FSU's conceptual framework, and includes the following dispositions items:

- Exhibits professional dispositions (e.g., caring, ethical, passionate, accepting diversity, responsible, and ethical behavior)

- Communicates high expectations for all students

- Embraces the belief that all students have the right and ability to learn

- Exhibits enthusiasm for the subject matter he/she teaches

- Supports programs that work to promote safe school, home, and community environments, values the increasingly diverse nature of current and emerging school populations

- Builds effective school, home, and community partnerships 
- Creates powerful learning communities within the classroom and the school

- Treats all students and members of the educational community equitably and respectfully

- Promotes effective social behavior in and among students (Frostburg State University Institutional Report, 2007, p. 39)

Interns are observed and evaluated by University supervisors, as well as mentor teachers. Additionally, at the end of the internship semester, candidates present a portfolio of artifacts from their educational career at FSU. Portfolios showcase various artifacts unique to the candidate's educational experience such as pictures, projects, reflections, self-evaluations, awards, etc. During the portfolio presentation, the candidate explains the relationship of each artifact to the conceptual framework indicator. Portfolio presentations allow candidates to verbally and visually express evidence to support their dispositions. Presentations are evaluated by a team of University professors and mentor teachers (Frostburg State University Institutional Report, 2007).

As a final example of dispositions evaluation at FSU, the Institutional Report discusses the follow-up survey. The office of Unit Assessment at FSU asks principals (employers) and FSU graduates (employees/potential employees) to complete a followup survey to provide further documentation of dispositions in the years immediately following candidate graduation. The data are discussed at Advisory Board meetings and used to facilitate discussion regarding program improvement (Frostburg State University Institutional Report, 2007). 
FSU recognizes the need to formally and systematically evaluate candidate dispositions prior to internship. Currently Frostburg State University is developing a "Professional Dispositions and Responsibilities Rating Form" as well as a "Unit Professional Dispositions/Responsibilities Early Alert Process and Guidelines”. The following dispositions were identified by FSU faculty and local K-12 educators as important and will be systematically assessed beginning Fall 2010:

- Show sensitivity to and respect differences of all individuals;

- Demonstrate commitment to reflection, self-assessment of one's practice, and responsibility for one's own actions;

- Accept and act upon reasonable critical evaluation;

- Demonstrate flexibility;

- Reestablish positive professional relationships;

- Treat all individuals fairly and equally;

- Value and promote critical thinking;

- Demonstrate enthusiasm about and commitment to the profession;

- Demonstrate commitment to professional development;

- Dress appropriately for one's professional contexts;

- Use appropriate communication skills (use of standard English);

- Be punctual for all responsibilities and duties;

- Respect the privacy of individuals and the confidentiality of information;

- Behave with professional integrity;

- Provide a learning-centered emotional environment; 
- Work collaboratively with others, e.g. students, teachers, parents, administrators, and peers; and

- Assume all responsibilities considered to be an integral part of the professional's duties.

\section{Relationship of Dispositions to Health and Overall Academic Success}

The health and well-being of students, faculty, and staff is critical to the academic success of the nation's youth. According to the Centers for Disease Control and Prevention "schools cannot achieve their primary mission of education if students and staff are not healthy" (Centers for Disease Control and Prevention, Coordinated School Health). Poor school performance is associated with health-related factors such as hunger, physical and emotional abuse, and chronic illness. Risky health behaviors such as substance use, violence, and physical inactivity affect student attendance, grades, test scores, and ability to pay attention in class and are consistently linked to academic failure. The CDC states, "Leading national education organizations recognize the close relationship between health and education, as well as the need to embed health into the educational environment for all students" (Centers for Disease Control and Prevention, Student Health and Academic Achievement).

The CDC states that, "school health programs and policies may be one of the most efficient means to prevent or reduce risk behaviors and prevent serious health problems among students" (Centers for Disease Control and Prevention, Coordinated School Health). They provide a framework for planning and coordinating school health activities called Coordinated School Health (CSH). CSH requires the coordinated efforts of eight critical components: health education, physical education, nutrition services, 
health services, family and community involvement, healthy and safe environment, mental and social services, and staff wellness (Centers for Disease Control and Prevention, Coordinated School Health). While health and physical educators comprise $1 / 4$ of the eight critical components involved in $\mathrm{CSH}$, multiple school and community members - including non-health and physical educators, administrators, and counselors - are a part of a well-functioning coordinated school health program. Since coordination of services is critical in $\mathrm{CSH}$, it is likely that particular dispositions are required for collaboration, communication, coordination, and cooperation among multiple groups in CSH (Marx, Northrop, \& Wooley, 1998).

\section{Staff Wellness and Academic Achievement}

Staff wellness is one of the eight critical components of CSH of particular interest to dispositions in teacher education. In the past when school districts addressed health, their primary focus was on student health problems. "Schools were identified as places for motivating students to lead healthy lifestyles and teachers were identified as the agents for showing them how to adopt and maintain healthy behaviors. However, teachers who lack good health cannot be healthy role models for their students" (School Employee Wellness, p. 6). Teachers notoriously suffer higher rates of burnout than other professions. "Compared with other professions, they show high levels of exhaustion and cynicism...this intense stress leads to low employee morale and high turnover" (School Employee Wellness, p. 6). Given the potential impact of employee wellness on student achievement, perhaps the dispositions for teachers and school administrators to maintain personal levels of health and well-being should become more of an emphasis in teacher preparation programs. 


\section{Dispositions, School Connectedness, Health and Academic Achievement}

A student's engagement, bonding, belonging, attachment, and/or commitment related to school is sometimes referred to as their "school connectedness" (Center for School Mental Health Analysis and Action, 2005). School connectedness is critical to the academic achievement of students, as well as to their overall health status. According to CDC, "students who feel a genuine sense of belonging at school tend to are more likely to do well in school, stay in school, and make healthy choices." (Centers for Disease Control and Prevention, Helping Your Child Feel Connected to School). The dispositions of teachers could potentially play a critical role in increasing feelings of school connectedness among students. The $\mathrm{CDC}$ recommends teachers strive to do the following:

- Create processes that engage students, families, and communities and that facilitate academic achievement.

- Provide opportunities for families to be actively involved in their children's academic and school life.

- Provide students with the academic, emotional, and social skills they need to engage in school.

- Use effective classroom management and teaching methods to foster a positive learning environment.

- Participate in professional development opportunities to enhance your abilities to meet the diverse needs of your students. 
- Promote open communication, trust, and caring among school staff, families, and community partners (Centers for Disease Control and Prevention, 2009, p. $2-3)$

Each of the above recommendations implies the need for certain dispositions. For example, suggestions the CDC provides for the third strategy are to "use classroom and extracurricular activities to explore and discuss empathy, personal strengths, fairness, kindness, and social responsibility" and to "allow and encourage students to identify, label, express, and assess their feelings" (Centers for Disease Control and Prevention, 2009 , p. 2). In order to do these things, teachers would likely need to have a variety of interpersonal dispositions to allow a climate of caring, acceptance, and open communication among students. Numerous other dispositions, (such as acceptance of others, involvement in school activities, connecting with parents, flexibility, advocacy, engaging in ongoing professional development, and dedication) are imbedded within the six strategies for fostering school connectedness and should be given consideration by those involved in facilitating school improvement.

\section{Dispositions in Health and Physical Education}

In the 2008 version of NCATE's Professional Standards, the phrase "knowledge, skills, and dispositions needed to help students learn" repeatedly appears. Many disciplines require students to develop knowledge and skills to be successful, and much of what is considered "learning" is cognitive. However, Health and Physical Education are unique fields when compared with typical educational settings. Much of the focus is on changing personal behaviors, such as eating and activity habits, making appropriate decisions, and setting personal goals (Centers for Disease Control, 2007). The content is 
important for students to know, and the skills are important for students to be able to do, but in health and physical education, the ultimate goal is to support and promote currently existing healthy student behaviors, as well as facilitate a change in unhealthy behaviors. No other subjects in school equate "learning" with changes in or maintenance of personal behaviors, and because of this uniqueness, there may be differences in the dispositions required for teaching general education and those required for teaching health education. For example, in the state of Maryland, health education is required each year in grades kindergarten through eighth grade, and for one semester in high school. Generally speaking, elementary health education is taught by the elementary classroom teacher not a health education specialist. Those who teach elementary school health education may or may not have significant training in health education and may or may not have the dispositions to specifically teach health education. When the term "teacher" is used, does one think of a health and/or physical educator, or does one think of a reading, math, or science teacher first. When one thinks of classes he or she had, does Health or Physical Education come to mind first? When one thinks of dispositions required for educators, do the fields of Health and Physical Education come to mind? Below is a discussion of the dispositions that may be specific to Health and Physical Education according to the leading professional organizations.

In the 2008 National Initial Physical Education Teacher Education Standards issued by the National Association for Sport and Physical Education (NASPE), Standard 2.2 states that candidates should "achieve and maintain a health-enhancing level of fitness throughout the program" (National Association for Sport and Physical Activity, 2008, p.1). The emphasis placed upon the disposition to serve as a model of health- 
fitness is apparent, and follows the logic of the importance of sending clear and consistent health enhancing messages to students (Marx, Wooley, \& Northrop, 1998). Standard 6 of NASPE's National Initial Physical Education Teacher Education Standards relates to professionalism. Element 6.1 states that candidates will, "demonstrate behaviors that are consistent with the belief that all students can become physically educated individuals"; Element 6.2 states that candidates will, "participate in activities that enhance collaboration and lead to professional growth and development"; and, Element 6.3 states that candidates will, "demonstrate behaviors that are consistent with the professional ethics of highly qualified teachers" (National Association for Sport and Physical Activity, 2008, p.3). Each of these elements resembles the language found in NCATE's 2008 Professional Standards, and clearly relates generally to all fields of education. However, Element 6.4 states that candidates will, "communicate in ways that convey respect and sensitivity" (National Association for Sport and Physical Activity, 2008, p.3). While this element can be related to general education, it may become critically important in health and physical education because of the personal nature of what is being communicated to students. For example, the way the teacher communicates the results of fitness tests, the way the teacher encourages and motivates the student to participate in physical activities, or the way the teacher counsels the student regarding personal activity behaviors, will logically impact the student's attitude toward changing unhealthy behaviors because of the potential for the student to feel embarrassed or belittled. Since much of the feedback in Physical Education is done verbally, and since student performance is visible to all students in the class, how does the way the teacher sends feedback impact the student? 
Similarly, the 2008 NCATE Health Education Teacher Preparation Standards issued by the American Association for Health Education (AAHE) indicate the need for ethical and compassionate communication, as well as advocacy, collaboration, and ethical behaviors. Standard VII relates to being a resource person in health education and specifies that an acceptable indicator Key Element B is for candidates to "demonstrate professional and ethical practices when responding to requests for information" (American Association for Health Education, 2008, p. 11). Under the same standard, Key Element D states that candidates should "describe ways to establish effective consultative relationships with others involved in a Coordinated School Health Program" (National Association for Sport and Physical Activity, 2008, p.12). Indicators identified as meeting this requirement include "demonstrate the dispositions and skills required for effective communication (e.g. listening, empathizing, being approachable, problem solving, mediating, and negotiating) with other school staff, students, parents, and community stakeholders" and "demonstrate professional and ethical practices when consulting and handling sensitive issues related to student disclosure and confidentiality" (National Association for Sport and Physical Activity, 2008, p.12).

Additionally, the 2008 Standards emphasize the importance of communication and advocacy for health education in Standard VIII. Key Element B requires candidates to "apply a variety of communication methods and techniques" as evidenced by their ability to, "apply conflict resolution skills as needed"; "demonstrate appropriate techniques to communicated about emerging health issues"; and "demonstrate multiple strategies for communicating health information to families, colleagues, community members, and other stakeholders" (National Association for Sport and Physical Activity, 
2008, p.13-14). Key Element C requires candidates to advocate for health education and seek opportunities to do so. Key Element D explicitly states that candidates should demonstrate professionalism as evidenced by demonstrating "dispositions for professional working relationships with others" and showing "ethical professional behaviors consistent with the Unified Code of Ethics for Health Education Professionals" (National Association for Sport and Physical Activity, 2008, p.14). While communication, advocacy, collaboration, and ethical behaviors are likely important in any field of education, the degree to which they are important and the circumstances in which they are needed are likely different for health and physical education, or others in the school system who address serious health and wellness issues with students.

In conclusion, there are numerous questions related to the assessment of dispositions, but before any assessment questions can be answered, professionals in the fields of education need to come to a consensus about which dispositions should be assessed. Of particular interest to this study is determining whether or not there are dispositions unique to Health and Physical Education that should be assessed both in Health and Physical Education teacher certification programs and in other programs where graduates are likely, but not certified, to teach Health and/or Physical Education. Once there is clarity in the field about which dispositions are important, institutions should consider how to develop and assess them within individual teacher education programs, and possibly across the entire Unit. There are currently separate teacher preparation standards for Health Education and for Physical Education. They are treated as two separate entities, yet they are related fields. Are the dispositions of effective Health Educators similar to the dispositions of effective Physical Educators, or are they 
different? Should the Health and Physical Education Professional organizations work in tandem with one another to address questions related to dispositions in these unique fields, or should they work separately? What overlap exists between what is important in Health Education and what is important in Physical Education with respect to dispositions? What differences are there? Perhaps the answers to each of these questions depends on philosophical perspective of the purpose of Health Education versus the purpose of Physical Education, but at this point there are many unchartered areas of research related to these questions.

\section{Dispositions and Certification Practices in Maryland}

In order to monitor the quality of teachers, states typically offer two general options for certification: traditional certification through an accredited teacher education program, and alternative certification. Typically, alternative certification programs are designed for those who have a bachelor's degree in a field other than education and are interested in becoming certified to teach. The alternative certification candidate generally completes required coursework and fieldwork, passes a licensure exam, and is then certified by the state's department of education (U. S. Department of Education, 2004). In the state of Maryland, those seeking initial teacher certification essentially have three options. They may complete a Maryland approved teacher education program, an alternative certification program, or meet the fieldwork and coursework requirements for alternative certification through transcript analysis. All Maryland teachers, regardless of the initial certification route taken, must earn passing scores on the Praxis II exam(s) for their content area(s) (Maryland Public Schools, Profile 6). Additionally, in the state of Maryland, any teacher who is currently certified may take the Praxis II exam in another 
content area-without ever having taken coursework in that content area- to become certified in another teaching field (Baltimore County Public Schools).

While licensure exams provide some continuity in certification requirements, the problem with them is that they are primarily designed to assess content and pedagogical knowledge, rather than also assessing performance and disposition. Additionally, "minimum passing scores are generally set at a level that is lower than the national median scores for these assessments, bringing into question their utility for determining the quality of teacher preparation" (U.S. Department of Education, 2006, p. 2). While multiple pathways to certification allow school systems to fill vacant positions with credentialed teachers, a comparison of each certification route reveals a lack of consistency in requirements. All routes to initial certification require passing scores on licensure exams, coursework, and field experience, but the regulations for coursework and field experience seem to vary significantly for alternative certification and traditional certification. For example, in the state of Maryland, the standards for transcript analysis include a minimum of a bachelor's degree in the certification area or a minimum number of credits in specified areas, as well as a supervised field experience or a minimum of one year satisfactory teaching experience (Code of Maryland Regulations 13a.12.02.06 \& 13a.12.02.18). The regulations include no indication of the length of the field experience or proof that the field experience or coursework meets any formalized standards. In contrast, all traditional teacher certification programs in the state of Maryland with 2000 or more students must be accredited through the National Council for Accreditation of Teacher Education (NCATE) and approved by the Maryland State Department of Education (Maryland Public Schools, Profile 6). NCATE requires teacher preparation 
institutions to meet both unit standards and individual program standards, to provide evidence of performance, and be evaluated by an accreditation team (NCATE, About NCATE). NCATE uses the term "unit" to refer to those responsible for coordinating teacher preparation at an institution. All teacher preparation programs are part of the "unit", and are therefore subject to the 2008 unit standards which address the following areas (NCATE, Glossary):

- Candidate knowledge, skills, and professional dispositions

- Assessment system and unit evaluation

- Field experience and clinical practice

- Diversity

- Faculty qualifications, performance, and development

- Unit governance and resources

In addition to providing evidence that all programs meet the unit standards, each individual program within the unit must meet program standards and submit Specialized Program Area (SPA) report for national recognition. The SPA reports require the submission of at least six sample assessments with rubrics and data to prove SPA standards are met (NCATE, Program Standards and Report Forms). The process of becoming accredited and maintaining accreditation is extensive, but it is designed to ensure quality of teacher preparation programs (NCATE, About NCATE).

Given the extensive process the State of Maryland requires for approval of teacher education programs to ensure teacher quality for traditional teacher certification, it seems as though there is a disparity in the requirements for alternative certification and traditional certification. Teacher education institutions are required to prove candidates 
have the appropriate knowledge, skills, and dispositions through reports and data which showcase assessments, coursework, and field experiences, whereas alternatively certified candidates simply provide evidence that coursework and fieldwork have been completed. Alternatively certified candidates are not required to submit assessment samples or data, or prove that they are adequately prepared according to SPA standards. Given the current alternative certification requirements in the state of Maryland, it is possible for a person to complete coursework at an institution which has lost its accreditation, and then become certified through an alternative route. The exact same coursework and field experiences which failed to meet requirements for traditional certification would adequately meet requirements for alternative certification. If the purpose of credentialing teachers is to ensure quality, then it seems as though the certification system is flawed. Requiring teacher licensure exams helps address minimal standards for content and pedagogical knowledge, but without the assessment of skill and dispositions do states risk endorsing teachers who may or may not truly have the skill and dispositions to teach?

Alternatively, given the lack of long-range research in the area of dispositions, are there differences in the dispositions of alternatively certified teachers versus those trained traditionally? Do internships in PDS schools make a difference in the development of dispositions? What are the policy implications for certification if there is no difference, or if alternatively certified candidates' dispositions are better than traditionally certified candidates?

The term "dispositions" or "professional dispositions" has emerged as an area of emphasis in the accreditation of teacher education institutions, and is defined by NCATE as, "professional attitudes, values, and beliefs demonstrated through both verbal and non- 
verbal behaviors as educators interact with students, families, colleagues, and communities. These positive behaviors support student learning and development" (NCATE, Glossary). While the language used in NCATE's definition is vague, the last statement emphasizes they are behaviors that support student learning and development. Behaviors are observable actions, and therefore lend themselves to assessments requiring observation of performance, rather than traditional examinations, such as Praxis. Alternative certification in the state of Maryland currently requires candidates to complete a field experience, but does not provide guidance as to behaviors, or evidence of behaviors, that should be demonstrated during the field experiences (Code of Maryland Regulations 13a.12.02.06 \& 13a.12.02.18). Traditional certification currently requires institutions of higher education to provide evidence of candidate dispositions assessments related to the ideal of fairness and the belief that all students can learn (NCATE, 2008).

\section{Social Cognitive Theory and Dispositions}

Breese and Nawrocki-Chabin (2007) apply Bandura's (1997) stages of modeling and reinforcement to the notion of developing and nurturing dispositions in teachers and teacher education candidates. Bandura's stages include attention to the modeled behavior, remembering and recalling observed behaviors, reproducing the behaviors, and, motivation and reinforcement of the behavior (Bandura 1997). According to Breese and Nawrocki Chabin (2007), Bandura's theoretical principles provide a framework for addressing dispositions in education. In stage one, candidates is made aware of appropriate teacher behaviors. In stage two, the candidate is encouraged to recall those behaviors observed, for example, in the context of observing a mentor teacher. In stage 
three, the candidate models the observed behavior, and in stage four, the candidate is encouraged and to continue applying the behavior. The role of the mentor or professor is to not only model and provide opportunities for practicing behaviors, but to facilitate candidate self-evaluation in order to motivate the candidate to further develop and use the behavior, thus facilitating self-efficacy (Breese \& Nawrocki-Chabin, 2007).

\section{Systems Theory and Dispositions}

In considering theory related to dispositions, one cannot ignore the complexity of dispositions. Often the assessment dispositions are reduced to a finite checklist, and are not treated as the complex systems they are. "When states and/or teacher education programs focus on standardization (as opposed to standards) in their assessment systems, reductionism is a real problem. Standardization means that the same elements must be present in the evaluation of each candidate. Given the expense of evaluation systems, only a limited number of elements are likely to be included" (Diez, 2007, p. 188). Diez (2007) further explains that typically the evaluation system addresses the elements that are easiest to measure, rather than what is most crucial. Often times the critical elements are the most difficult to assess.

When consideration is given to systems theories, it is easy to see why the assessment of dispositions seems to be so problematic. Combs (1973) discusses educational accountability from the perspective of closed/behavioralistic systems and from open/humanistic systems. A behavioralist reduces assessment to a simple, straightforward precise process, whereas a humanist views assessment as large, complex processes which are more appropriate for addressing perceptual behavior. Combs (1973) says perceptions are expressed in behavior, but the "relationship is not one-to-one. A 
given set of perceptions may produce many varieties of behavior" (p. 19). Behaviors occur for any number of reasons, and to assume that a particular behavior is a manifestation of any one perception (disposition) puts the attention in the wrong place. Open/humanistic systems, which are appropriate for assessing dispositions, focus on processes, rather than ends, and therefore cannot be reduced to observing behaviors in isolation (Combs, 1973).

Diez, (2007b) believes that knowledge, skills, and dispositions function together in teaching and are difficult to address as separate, independent functions. She says that having a list of specific dispositions makes it easy to prove to an accreditation team that they are assessed; however, institutions should give consideration to whether it is adequate to simply meet the standard. She suggests the need to thoughtfully explore dispositions in the context of teaching and learning (Diez, 2007b). Her statements are reflective of open systems, where dispositions should be treated as more complex structures than they are typically treated. 


\section{CHAPTER 3 - METHODOLOGY}

\section{Design}

The purposes of this study are to (1) gauge the perceived importance and efficacy of the identified categories of dispositions in a larger population of teacher education students, teacher education faculty, and PK-12 educators and administrators; and to (2) determine the dispositions which may not be common to all programs in the unit, but are identified as essential to teaching Health and Physical Education. A non-experimental research design is employed to determine if there are differences among perceptions in each group. The statistical method employed is a one-way analysis of variance (ANOVA). A frequency distribution histogram is used to illustrate the dispositions identified as essential to teaching Health and Physical Education.

\section{Prior Research}

In 2007, Simpson and Diaz conducted an unpublished research study. A group of 12 educators representing faculty members from a small Mid-Atlantic regional teacher education institution, teacher education graduates, a college of education dean, elementary faculty, secondary faculty, guidance counselors, and PK-12 administrators, assembled to brainstorm dispositions important to those in educational professions. Participants were given a short break after they identified the following 102 dispositions that serve as the basis for the conceptual maps produced through Concept Mapping/Pattern Matching.

1. Commitment to the profession

2. Enthusiasm for your subject matter

3. Overall Genuineness 
4. Caring about students

5. Patience

6. Fairness

7. Flexibility

8. Initiative

9. Organization

10. Open to suggestions or criticisms

11. Professional Attire

12. Perseverance

13. Punctuality

14. "Whatever it takes" attitude

15. Responsibility to complete

16. Cooperative Spirit

17. Willing to work with others no matter what situation

18. Discrete

19. Respect confidentiality

20. Self Confidence

21. Friendly, but NOT Friends With (Appropriate interaction)

22. Integrity to yourself first

23. Having an independent nature

24. Enjoy having fun

25. Energetic

26. Creative 
27. Honest

28. Empathetic

29. Not dumbing down (rigorous)

30. Challenging others

31. An awareness or perception of students' needs

32. Community Awareness

33. Tolerant

34. Down to Earth Nature / Modest

35. Dedicated

36. Compassionate

37. Awareness of Socioeconomic Issues

38. Awareness of Cultures

39. Finding Unique Qualities in Each Student

40. Thirst for Knowledge

41. Dedication to self-renewal / Lifelong Learner

42. Risk Taker

43. Willing to let your students view you as Human

44. Being Authentic / Including owning up to mistakes

45. Respectful of others

46. Accepting (beyond just tolerant)

47. Time Management

48. Communicating courageously - (not avoidant)

49. Assertive 
50. Knowing when to use which disposition appropriately

51. Being able to think on your feet

52. Making decisions with students in mind

53. Being Forgiving

54. Thick-Skinned

55. Community / School Participation

56. Reflective / Intrapersonal

57. Willing to follow code of ethics even though don't agree

58. Serving as good role model for students, colleagues, parents

59. Control emotions

60. Seeing the good in everyone

61. Optimistic

62. Team Player

63. Collaborative

64. Willingness to take "lost souls" underneath your wing

65. Being willing to parent

66. It's OK to be wrong

67. Meeting professional deadlines

68. Being malleable

69. Articulate

70. Being an entertainer

71. Being able to adapt when things don't go as planned

72. Being level headed in emergency situations 
73. Conscientious

74. Having a life.

75. Balance in life roles

76. Knowing your limits.

77. Resourcefulness

78. Being able to say "no."

79. Being able to set goals for yourself and completing them.

80. Belief in yourself

81. Intrinsic Motivation

82. Having appropriate expectations-level for others

83. Friendliness

84. Positivity

85. Being Willing to Listen

86. Being Willing to Take Time to Listen

87. Sense of Humor / Being able to laugh at yourself

88. Awareness of your surroundings (eyes back of head)

89. Ability to multitask

90. Being able to "go with flow"

91. Not easily distracted

92. Courteous

93. General neatness

94. Paying Attention

95. Good Personal Hygiene 
96. Professional Appearance

97. Not taking student actions personally

98. Don't provoke students/learners

99. Even tempered

100. Don't see administrator as the enemy

101. Sensitivity

102. Willing to ask for help when needed

During the break, the researchers made one copy of the dispositions list for each participant and cut each list into strips of one disposition per strip. Following the break, each participant was given a packet containing all of the dispositions, each on an individual strip of paper. Directions given to the participants were:

1. Work independently.

2. Organize the dispositions into groups ("clusters") that seem to go together.

3. Give each cluster a name to represent the dispositions included in the cluster.

4. Write the name of each cluster on an individual envelope.

5. Place each disposition in the envelope of the corresponding cluster.

6. Place each of the cluster envelopes into a large manila envelope. Seal it and turn it in to the researcher.

A few weeks after the brainstorming and categorizing activity, participants were sent a list of each of the dispositions identified in the focus group and were asked to rate the relevant importance of each item as related to the dispositions desired of teacher education candidates. Additionally, participants rated how well the institution develops each disposition in program candidates. The data were analyzed using a concept 
mapping pattern matching program to determine dispositions participants conceptually related to one another. The results are visually illustrated in the scatter plot below (see figure 1).

Figure 1. Scatterplot of Items.

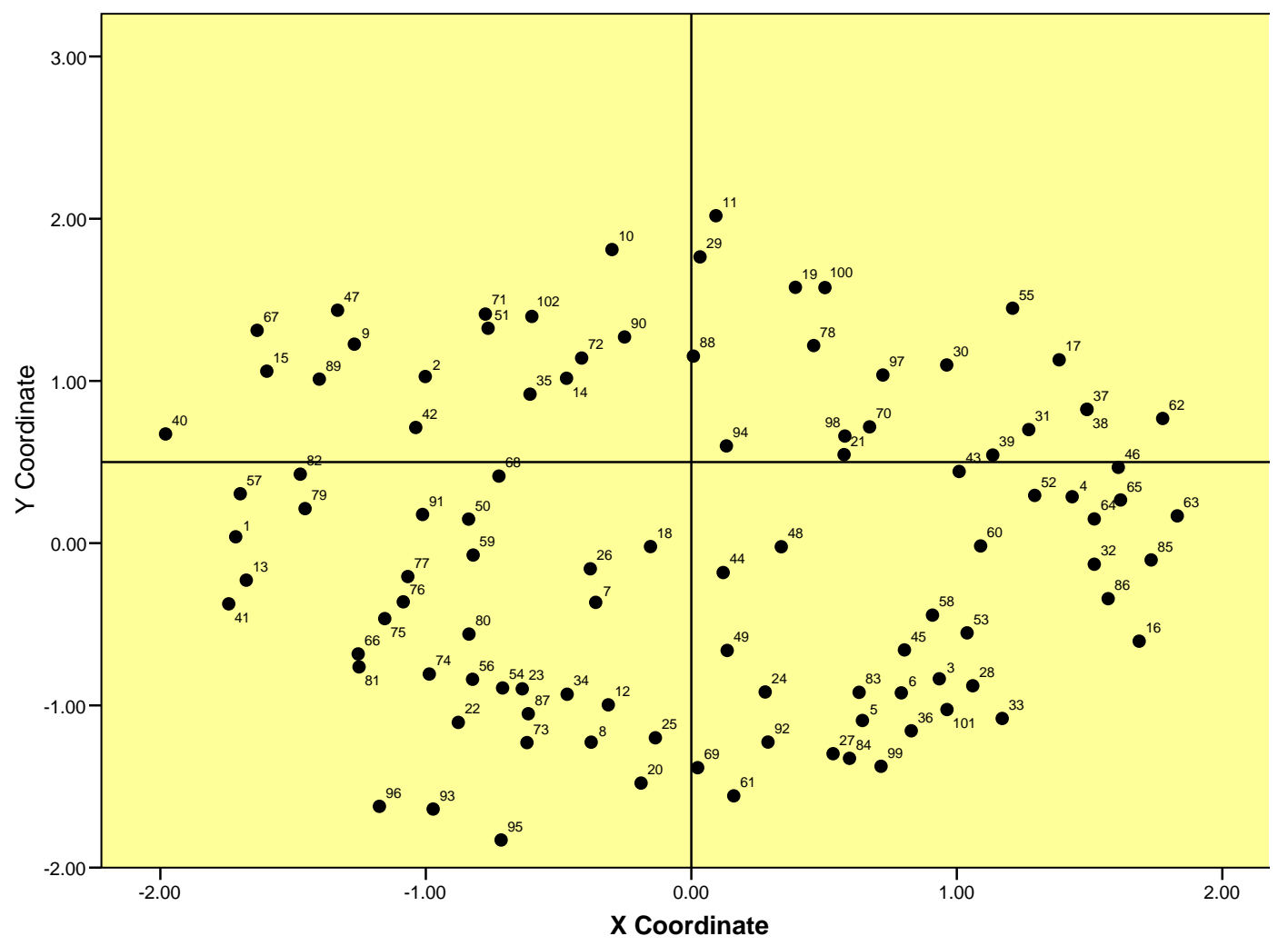

Results were organized into ten different conceptual clusters. Below are listed the ten cluster as named by the researchers named and the respective dispositions represented within each cluster.

1. Cluster 1: Responds to Students' Social and Educational Needs

a. Caring about student

b. Cooperative spirit 
c. Awareness or perception of students' needs

d. Community awareness

e. Awareness of socioeconomic issues

f. Awareness of cultures

g. Finding unique qualities in each student

h. Willing to let your students view you as human

i. Accepting (beyond just tolerant)

j. Making decisions with student in mind

k. Seeing the good in everyone

1. Team player

m. Collaborative

n. Willingness to take "lost souls" underneath your wing

o. Being willing to parent

p. Being willing to listen

q. Being willing to take the time to listen

2. Cluster 2: Builds Rapport with Entire Educational Community (Including students, parents, etc.)
a. Willing to work with others no matter what the situation
b. Friendly, but NOT "friends with" (appropriate interaction)
c. Challenging others
d. Community/School participation
e. Being an entertainer
f. Paying attention 
g. Not taking student actions personally

h. Don't provoke students/learners

3. Cluster 3: Exhibits Personable Qualities that Make One Approachable to Students
a. Overall genuineness
b. Patience
c. Fairness
d. Honest
e. Empathetic
f. Tolerant
g. Compassionate
h. Respectful of others
i. Being forgiving
j. Serving as a good role-model for students, colleagues, parents
k. Friendliness
1. Positivity
m. Even tempered
n. Sensitivity

4. Cluster 4: Communicates Enthusiasm to Students
a. Initiative
b. Self confidence
c. Enjoy having fun
d. Energetic 

e. Assertive
f. Optimistic
g. Articulate
h. Courteous

5. Cluster 5: Exhibits Psychosocial Maturity
a. Flexibility
b. Discrete
c. Creative
d. Being authentic/including owning up to mistakes
e. Communicating courageously (not avoidant)
f. Knowing when to use which disposition appropriately
g. Control emotions
h. Being malleable
i. Not easily distracted

6. Cluster 6: Exhibits Appropriate Appearance and Personal Hygiene
a. General neatness
b. Good personal hygiene
c. Professional appearance

7. Cluster 7: Demonstrates Awareness of One's Own Strengths and Limitations
a. Perseverance
b. Integrity to yourself first
c. Having an independent nature
d. Down to earth nature/modest 
e. Thick skinned

f. Reflective/intrapersonal

g. It's okay to be wrong

h. Conscientious

i. Having a life

j. Balance in life roles

k. Knowing your limits

1. Resourcefulness

m. Belief in yourself

n. Intrinsic motivation

o. Sense of humor/being able to laugh at yourself

8. Cluster 8: Responds Appropriately to Challenging Situations
a. Open to suggestions or criticisms
b. Professional attire
c. "Whatever it takes"
d. Respect confidentiality
e. Not dumbing down (rigorous)
f. Dedicated
g. Being able to think on your feet
h. Being able to adapt when things don't go as planned
i. Being level-headed in emergency situations
j. Being able to say "no"
k. Awareness of your surroundings (eyes in the back of your head) 
1. Being able to "go with the flow"

m. Don't see the administrator as the enemy

n. Willing to ask for help when needed

9. Cluster 9: Effectively Manages Resources
a. Enthusiasm for your subject matter
b. Organization
c. Responsibility to complete
d. Risk Taker
e. Time management
f. Meeting professional deadlines
g. Ability to multitask

10. Cluster 10: Exhibits Professionalism
a. Commitment to the profession
b. Punctuality
c. Thirst for knowledge
d. Dedication to self- renewal/lifelong learner
e. Willing to follow code of ethics even though you don't agree
f. Being able to set goals for yourself and completing them
g. Having appropriate expectation levels for others

\section{Research Questions}

This study explores the following research questions: 
1. Building upon prior work of Simpson and Diaz, what are overall general perceptions of the importance and efficacy related to each category of identified dispositions?

2. Are there differences in teacher education students' (both undergraduate and graduate), local school professionals' (including teachers, administrators, and counselors), and teacher education faculty's perception of how well the institution represented develops the identified dispositions categories in its candidates?

3. What dispositions are perceived to be important specifically to the fields of Health and Physical Education?

\section{Independent Variable}

The independent variable in this study is the role of the participant in education. Roles include undergraduate and graduate education majors at the institution, PK-12 professionals working in PDS schools (including teachers, counselors, and administrators), and teacher education professionals who are involved with teacher preparation programs.

\section{Dependent Variable}

Two separate sets of single-factor, independent-measures ANOVA analyses were conducted for each of the ten dispositions clusters. In the first set of analyses, the dependent variable is the relative importance of each disposition cluster to all educators. For the second set of analyses, the dependent variable is the perception of well the institution's curriculum develops each disposition cluster in its teacher education candidates. Ten different clusters analyzed in each question include: 
- Responding to students' social and educational needs

- Building rapport with entire educational community

- Exhibiting personable qualities that make you approachable to students

- Communicating enthusiasm to students

- Exhibiting psychosocial maturity

- Exhibiting appropriate appearance and hygiene

- Demonstrates awareness of one's own strengths and limitations

- Is capable of responding appropriately to challenging situations

- Effectively manages resources

- Professionalism

\section{One-Way, Independent Measures ANOVA}

To address the first two research questions [(1) Building upon prior work of Simpson and Diaz, what are overall general perceptions of the importance and efficacy related to each category of identified dispositions? And (2) Are there differences in how teacher education students, local school professionals, and teacher education faculty rate the importance and efficacy of identified dispositions categories?], participants were asked to: (1) rate the relative importance of each of the ten dispositions clusters as they relate to teachers and other education professionals, and (2) rate how well the institution's curriculum helps students develop each cluster of dispositions. For each question, a oneway, independent-measures analysis of variance was used to analyze ratings for each of the ten clusters of dispositions. The mean and standard deviation was used to answer the first research question. The F-ratio was used to determine statistically significant 
differences among the three groups of respondents, which provided data to answer the second research question. Data were analyzed using SPSS software.

The between-treatments variance was calculated to determine how much variance there is between the responses of the three groups of participants. The within-treatments variance was calculated to determine how much variance there is among members within each individual group. Once the total variability in between-treatments and withintreatments is determined, the F-ratio was calculated to determine whether there are statistically significant differences in perceptions about dispositions among the three populations at the alpha .05 level. When F-ratio indicated significant differences, the Scheffé test was conducted to determine which mean differences are significant and which are not.

\section{Frequency Distribution}

To address the third research question (What dispositions are perceived to be important specifically to Health and Physical Education?), respondents were asked to list the specific dispositions important for teaching Health and Physical Education in the PK12 setting. Responses were categorized according to the existing ten dispositions clusters, the frequency of responses in each cluster will be tabulated, and clusters will be ranked according to frequency of responses. Mean ratings of the importance of each disposition cluster to all fields of education were used to rank each cluster. Rankings of the importance of each cluster to Health and Physical Education and the importance of each cluster to all fields of education were compared and discussed. The results may be used to provide support for the need for further research in dispositions specific to certain fields of education. 


\section{Hypotheses}

The hypotheses include:

1. There is a significant difference at the alpha $=.05$ level in the perceived importance of responding to students' social and educational.

2. There is a significant difference at the alpha $=.05$ level in the perceived importance of building rapport with the entire educational community.

3. There is a significant difference at the alpha $=.05$ level in the perceived importance of exhibiting personable qualities that make a teacher approachable to students.

4. There is a significant difference at the alpha $=.05$ level in the perceived importance of communicating enthusiasm to students.

5. There is a significant difference at the alpha $=.05$ level in the perceived importance of exhibiting psychosocial maturity.

6. There is a significant difference at the alpha $=.05$ level in the perceived importance of exhibiting appropriate appearance and hygiene.

7. There is a significant difference at the alpha $=.05$ level in the perceived importance of demonstrating awareness of one's own strengths and limitations.

8. There is a significant difference at the alpha $=.05$ level in the perceived importance of the capability of responding appropriately to challenging situations.

9. There is a significant difference at the alpha $=.05$ level in the perceived importance of effectively manages resources. 
10. There is a significant difference at the alpha $=.05$ level in the perceived importance of professionalism.

11. There is a significant difference at the alpha $=.05$ level in the perceived development of the disposition to respond to students' social and educational needs.

12. There is a significant difference at the alpha $=.05$ level in the perceived development of the disposition to build rapport with the entire educational community.

13. There is a significant difference at the alpha $=.05$ level in the perceived development of the disposition to exhibit personable qualities that make a teacher approachable to students.

14. There is a significant difference at the alpha $=.05$ level in the perceived development of the disposition to communicate enthusiasm to students.

15. There is a significant difference at the alpha $=.05$ level in the perceived development of the disposition to exhibit psychosocial maturity.

16. There is a significant difference at the alpha $=.05$ level in the perceived development of the disposition to exhibit appropriate appearance and hygiene.

17. There is a significant difference at the alpha $=.05$ level in the perceived development of the disposition to demonstrate awareness of one's own strengths and limitations.

18. There is a significant difference at the alpha $=.05$ level in the perceived development of the disposition to respond appropriately to challenging situations. 
19. There is a significant difference at the alpha $=.05$ level in the perceived development of the disposition to effectively manage resources.

20. There is a significant difference at the alpha $=.05$ level in the perceived development of the disposition to be professional.

The hypothesis for each of the twenty ANOVA procedures states the means of all groups are not equal. Expressed mathematically: $\mathrm{H}_{1}: \mu_{1} \neq \mu_{2} \neq \mu_{3}$

\section{Null Hypotheses}

The following null hypotheses guide the analysis of data for this study.

1. There is no significant difference at the alpha $=.05$ level in the perceived importance of responding to students' social and educational needs.

2. There is no significant difference at the alpha $=.05$ level in the perceived importance of building rapport with the entire educational community.

3. There is no significant difference at the alpha $=.05$ level in the perceived importance of exhibiting personable qualities that make a teacher approachable to students.

4. There is no significant difference at the alpha $=.05$ level in the perceived importance of communicating enthusiasm to students.

5. There is no significant difference at the alpha $=.05$ level in the perceived importance of exhibiting psychosocial maturity.

6. There is no significant difference at the alpha $=.05$ level in the perceived importance of exhibiting appropriate appearance and hygiene. 
7. There is no significant difference at the alpha $=.05$ level in the perceived importance of demonstrating awareness of one's own strengths and limitations.

8. There is no significant difference at the alpha $=.05$ level in the perceived importance of the capability of responding appropriately to challenging situations.

9. There is no significant difference at the alpha $=.05$ level in the perceived importance of effectively manages resources.

10. There is no significant difference at the alpha $=.05$ level in the perceived importance of professionalism.

11. There is no significant difference at the alpha $=.05$ level in the perceived development of the disposition to respond to students' social and educational.

12. There is no significant difference at the alpha $=.05$ level in the perceived development of the disposition to build rapport with the entire educational community.

13. There is no significant difference at the alpha $=.05$ level in the perceived development of the disposition to exhibit personable qualities that make a teacher approachable to students.

14. There is no significant difference at the alpha $=.05$ level in the perceived development of the disposition to communicate enthusiasm to students.

15. There is no significant difference at the alpha $=.05$ level in the perceived development of the disposition to exhibit psychosocial maturity. 
16. There is no significant difference at the alpha $=.05$ level in the perceived development of the disposition to exhibit appropriate appearance and hygiene.

17. There is no significant difference at the alpha $=.05$ level in the perceived development of the disposition to demonstrate awareness of one's own strengths and limitations.

18. There is no significant difference at the alpha $=.05$ level in the perceived development of the disposition to respond appropriately to challenging situation.

19. There is no significant difference at the alpha $=.05$ level in the perceived development of the disposition to effectively manage resources.

20. There is no significant difference at the alpha $=.05$ level in the perceived development of the disposition to be professional.

The null hypothesis for each of the twenty ANOVA procedures states the means of all groups are equal. Expressed mathematically: $\mathrm{H}_{0}: \mu_{1}=\mu_{2}=\mu_{3}$

\section{Instrument}

The results of the 2007 unpublished study conducted by Lisa Simpson and Sebastian Diaz (described at the beginning of this chapter) were used to design an electronic survey for this research. The survey includes a series of questions to determine participants' role, educational and teaching experiences, attitudes toward Health and Physical Education, perceptions about dispositions, and perceptions about how well the institution develops dispositions in its candidates. Three primary questions provided data to answer the research questions: 
- The items below reflect general types of dispositions that PK-12 educators may possess. Please rate the relative importance of each of these items as they relate to teachers and other education professionals.

- The items below reflect general types of dispositions that PK-12 educators may possess. Please rate how well the institution's College of Education curriculum helps students develop these dispositions.

- The prior question asked you to consider general categories of dispositions in relation to all areas of PK-12 education. For this question below, consider more specifically the area of Health and Physical Education. List below (up to 10) specific dispositions that you believe are necessary for teaching Health and Physical Education in the PK-12 setting. Please list very specific dispositions as opposed to general categories.

A number of additional questions are included for the purpose of providing the researcher with additional supporting documentation to guide further research. For example:

- List up to 10 specific dispositions that are most important for students to have before starting a teacher education program.

- How important is Health Education to a PK-12 student's overall education?

- How important is Physical Education to a PK-12 student's overall education?

\section{Population and Sample}

The population includes teacher preparation programs at regional universities within the Mid-Atlantic Region. The sample includes all students who were enrolled at the selected institution in the Spring 2011 in courses specific to teacher education majors, 
all students have taken selected required education courses between Summer 2009 and Spring 2011 and who still had active email accounts; PK-12 faculty and administration who currently work in one of the institution's Professional Development Schools and who have worked with the institution's teacher education students, all the institution's College of Education faculty members who prepare teacher education majors, and the dean of the College of Education. The sample for this study included approximately 1200 people.

\section{Human Subjects Clearance}

Applications for Institution Review Board approval have been submitted to the institution surveyed and to West Virginia University. Approval was granted by both review boards.

\section{Procedure of Analysis for ANOVA}

The following steps were utilized to conduct inferential Analyses of Variance (ANOVA):

1. Identify the procedure for analysis as a one-way ANOVA;

2. Determine significance levels;

3. Format and enter data into SPSS;

4. Conduct ANOVA with SPSS;

5. Test to ensure assumptions of ANOVA are met;

6. On significant f-test results, perform Scheffè's post hoc analysis;

7. Specify which main effects were significant; and

8. Present findings, conclusions, and recommendations. 


\section{Procedure of Analysis for Frequency Distribution}

The following steps define the procedure for analysis of frequency distributions.

1. Identify the procedure for analysis as a frequency distribution.

2. Categorize specific dispositions for teaching Health and Physical Education listed by each respondent into one of the 10 dispositions clusters used in the survey, noting any response which does not seem to belong to any of the ten previously determined clusters.

3. Tally the number of responses in each of the ten dispositions clusters and the number that do not belong to any of the ten clusters.

4. Present findings.

5. Compare and discuss findings with data from ratings of the relative importance of each cluster of dispositions as they relate to all teachers and education professionals.

6. Present conclusions and recommendations. 


\section{CHAPTER 4 - RESULTS}

\section{Overview of Chapter}

This chapter presents findings from the analysis of data to address each of the 3 research questions. It begins with a review of the problem statement and research questions, and is followed by a presentation of data. Data analyses include descriptive statistics, one-way ANOVA, and frequency distributions. The chapter closes with a presentation of the respondent demographics, the limitations of the study, and a summary of the analysis.

\section{Results of Analysis}

\section{Statement of problem.}

The purposes of this study are to (1) gauge the perceived importance and efficacy of the identified categories of dispositions in a larger population of teacher education students, teacher education faculty, and PK-12 educators and administrators; and to (2) determine the dispositions which may not be common to all programs in the unit, but are identified as essential to teaching Health and Physical Education (HPE). While these data are important for the purposes of accreditation, this study will move beyond that which is required for accreditation to determine the dispositions which may not be common to all programs in the unit, but are identified as essential to teaching Health and Physical Education. The outcome of the study will help provide guidance in the preparation of teacher education students in general, teacher education students majoring in Health and Physical Education, and teacher education students who will likely teach health and/or physical education, but who are not specifically seeking certification in 
those fields. Additionally, all teacher preparation programs struggle with how to address dispositions. This study will serve as a model for identifying dispositions essential to all fields of education, and to teachers of specific content areas or grade levels.

\section{Research question}

Research questions are listed below. Questions one and three were not inferential questions, whereas research question two was inferential.

1. Building upon prior work of Simpson and Diaz, what are overall general perceptions of the importance and efficacy related to each category of identified dispositions?

2. Are there differences in how teacher education students (both undergraduate and graduate), local school professionals (including teachers, administrators, and counselors), and teacher education faculty rate the importance and efficacy of identified dispositions categories?

3. What dispositions are perceived to be important specifically to the fields of Health and Physical Education?

\section{Hypotheses.}

Each of the hypotheses refers to differences between three treatment groups: teacher education students, teacher education faculty, and PK-12 professionals. The hypotheses include:

1. There is a significant difference at the alpha $=.05$ level in the perceived importance of responding to students' social and educational needs.

2. There is a significant difference at the alpha $=.05$ level in the perceived importance of building rapport with the entire educational community. 
3. There is a significant difference at the alpha $=.05$ level in the perceived importance of exhibiting personable qualities that make a teacher approachable to students.

4. There is a significant difference at the alpha $=.05$ level in the perceived importance of communicating enthusiasm to students.

5. There is a significant difference at the alpha $=.05$ level in the perceived importance of exhibiting psychosocial maturity.

6. There is a significant difference at the alpha $=.05$ level in the perceived importance of exhibiting appropriate appearance and hygiene.

7. There is a significant difference at the alpha $=.05$ level in the perceived importance of demonstrating awareness of one's own strengths and limitations.

8. There is a significant difference at the alpha $=.05$ level in the perceived importance of the capability of responding appropriately to challenging situations.

9. There is a significant difference at the alpha $=.05$ level in the perceived importance of effectively manages resources.

10. There is a significant difference at the alpha $=.05$ level in the perceived importance of professionalism.

11. There is a significant difference at the alpha $=.05$ level in the perceived development of the disposition to respond to students' social and educational needs. 
12. There is a significant difference at the alpha $=.05$ level in the perceived development of the disposition to build rapport with the entire educational community.

13. There is a significant difference at the alpha $=.05$ level in the perceived development of the disposition to exhibit personable qualities that make a teacher approachable to students.

14. There is a significant difference at the alpha $=.05$ level in the perceived development of the disposition to communicate enthusiasm to students.

15. There is a significant difference at the alpha $=.05$ level in the perceived development of the disposition to exhibit psychosocial maturity.

16. There is a significant difference at the alpha $=.05$ level in the perceived development of the disposition to exhibit appropriate appearance and hygiene.

17. There is a significant difference at the alpha $=.05$ level in the perceived development of the disposition to demonstrate awareness of one's own strengths and limitations.

18. There is a significant difference at the alpha $=.05$ level in the perceived development of the disposition to respond appropriately to challenging situations.

19. There is a significant difference at the alpha $=.05$ level in the perceived development of the disposition to effectively manage resources.

20. There is a significant difference at the alpha $=.05$ level in the perceived development of the disposition to be professional. 
The hypothesis for each of the twenty ANOVA procedures states the means of all groups are not equal. Expressed mathematically: $H_{1}: \mu_{1} \neq \mu_{2} \neq \mu_{3}$

\section{Null Hypotheses.}

Each of the null hypotheses refers to differences between three treatment groups: teacher education students, teacher education faculty, and PK-12 professionals. The null hypotheses include:

1. There is no significant difference at the alpha $=.05$ level in the perceived importance of responding to students' social and educational needs.

2. There is no significant difference at the alpha $=.05$ level in the perceived importance of building rapport with the entire educational community.

3. There is no significant difference at the alpha $=.05$ level in the perceived importance of exhibiting personable qualities that make a teacher approachable to students.

4. There is no significant difference at the alpha $=.05$ level in the perceived importance of communicating enthusiasm to students.

5. There is no significant difference at the alpha $=.05$ level in the perceived importance of exhibiting psychosocial maturity.

6. There is no significant difference at the alpha $=.05$ level in the perceived importance of exhibiting appropriate appearance and hygiene.

7. There is no significant difference at the alpha $=.05$ level in the perceived importance of demonstrating awareness of one's own strengths and limitations. 
8. There is no significant difference at the alpha $=.05$ level in the perceived importance of the capability of responding appropriately to challenging situations.

9. There is no significant difference at the alpha $=.05$ level in the perceived importance of effectively manages resources.

10. There is no significant difference at the alpha $=.05$ level in the perceived importance of professionalism.

11. There is no significant difference at the alpha $=.05$ level in the perceived development of the disposition to respond to students' social and educational.

12. There is no significant difference at the alpha $=.05$ level in the perceived development of the disposition to build rapport with the entire educational community.

13. There is no significant difference at the alpha $=.05$ level in the perceived development of the disposition to exhibit personable qualities that make a teacher approachable to students.

14. There is no significant difference at the alpha $=.05$ level in the perceived development of the disposition to communicate enthusiasm to students.

15. There is no significant difference at the alpha $=.05$ level in the perceived development of the disposition to exhibit psychosocial maturity.

16. There is no significant difference at the alpha $=.05$ level in the perceived development of the disposition to exhibit appropriate appearance and hygiene. 
17. There is no significant difference at the alpha $=.05$ level in the perceived development of the disposition to demonstrate awareness of one's own strengths and limitations.

18. There is no significant difference at the alpha $=.05$ level in the perceived development of the disposition to respond appropriately to challenging situation.

19. There is no significant difference at the alpha $=.05$ level in the perceived development of the disposition to effectively manage resources.

20. There is no significant difference at the alpha $=.05$ level in the perceived development of the disposition to be professional.

The null hypothesis for each of the twenty ANOVA procedures states the means of all groups are equal. Expressed mathematically: $\mathrm{H}_{0}: \mu_{1}=\mu_{2}=\mu_{3}$

\section{Overview of Statistical Results}

The following table summarizes the descriptive findings for Research Question 1.

Table 1. Descriptive Results for Importance and Efficacy.

\begin{tabular}{ll}
\hline Research Question & \multicolumn{1}{c}{ Result } \\
\hline $\begin{array}{l}\text { RQ1 Part 1: What are the overall general perceptions of the } \\
\text { importance related to categories of dispositions? }\end{array}$ & $\begin{array}{l}\text { All } 10 \text { categories are "Extremely } \\
\text { Important" }\end{array}$ \\
\hline $\begin{array}{l}\text { RQ1 Part 1: What are the overall general perceptions of the } \\
\text { importance related to categories of dispositions? }\end{array}$ & $\begin{array}{l}\text { The efficacy of all } 10 \text { categories is } \\
\text { "Good" }\end{array}$ \\
\hline
\end{tabular}


The following table summarizes the results for the first part of Research Question 2, which focuses on the perceived importance of the items comprising the clusters.

Table 2. Results of Importance Ratings.

RQ2 Part 1: Are there differences in how pre-service teachers, in-service teachers, and teacher education faculty rate the importance of identified dispositions categories?

\begin{tabular}{lcc}
\hline Cluster & Result & p-Value \\
\hline $\begin{array}{l}\text { Educator responds to students' social and educational } \\
\text { needs }\end{array}$ & Not Significant & 0.812 \\
\hline Educator builds rapport with entire educational community & Not Significant & 0.986 \\
\hline $\begin{array}{l}\text { Educator exhibits personable qualities that make him/her } \\
\text { approachable to students }\end{array}$ & Significant & 0 \\
\hline Educator communicates enthusiasm to students & Significant & 0.025 \\
\hline Educator exhibits psychosocial maturity & Not Significant & 0.691 \\
\hline $\begin{array}{l}\text { Educator exhibits appropriate appearance and personal } \\
\text { hygiene }\end{array}$ & Significant & 0 \\
\hline $\begin{array}{l}\text { Educator demonstrates awareness of one's own strengths } \\
\text { and limitations }\end{array}$ & Significant & 0.002 \\
\hline $\begin{array}{l}\text { Educator is capable of responding appropriately to } \\
\text { challenging situations }\end{array}$ & Not Significant & 0.065 \\
\hline Educator effectively manages resources & Significant & 0.004 \\
\hline Educator exhibits professionalism & Not Significant & 0.938 \\
\hline
\end{tabular}


The following table summarizes the results for the second part of Research

Question 2, which focuses on the perceived efficacy of the items comprising the clusters.

Table 3. Results of Efficacy Ratings.

RQ2 Part 2: Are there differences in how pre-service teachers, in-service teachers, and teacher education faculty rate the efficacy of identified dispositions categories?

\begin{tabular}{llc}
\hline Cluster & \multicolumn{1}{c}{ Result } & p-Value \\
\hline $\begin{array}{l}\text { Educator responds to students' social and educational } \\
\text { needs }\end{array}$ & Not Significant & 0.243 \\
\hline Educator builds rapport with entire educational community & Not Significant & 0.062 \\
\hline $\begin{array}{l}\text { Educator exhibits personable qualities that make him/her } \\
\text { approachable to students }\end{array}$ & Not Significant & 0.257 \\
\hline Educator communicates enthusiasm to students & Not Significant & 0.754 \\
\hline $\begin{array}{l}\text { Educator exhibits psychosocial maturity } \\
\text { hygiene }\end{array}$ & Not Significant & 0.385 \\
\hline $\begin{array}{l}\text { Educator demonstrates awareness of one's own strengths } \\
\text { and limitations }\end{array}$ & Not Significant & 0.448 \\
\hline $\begin{array}{l}\text { Educator is capable of responding appropriately to } \\
\text { challenging situations }\end{array}$ & Significant & 0.008 \\
\hline Educator effectively manages resources & Not Significant & 0.064 \\
\hline Educator exhibits professionalism & Not Significant & 0.116 \\
\hline
\end{tabular}

\section{Results for Research Question 1}

The first research question was, "Building upon prior work of Simpson and Diaz, what are overall general perceptions of the importance and efficacy related to each category of identified dispositions?" Ten dispositions clusters were identified in the prior work of Simpson and Diaz. Using a four level Likert scale, participants were asked to: (1) rate the relative importance of each of the ten dispositions clusters as they relate to teachers and other education professionals, and (2) rate how well the institution's College of Education curriculum helps students develop each of the ten clusters of dispositions.

The mean and standard deviation of the Likert scale items were used to answer the first research question. The Likert scale levels and corresponding numerical values 
used to rate the relative importance of each cluster included: "Extremely Important" = 4, "Important" = 3, "A Little Important" = 2, and "Not Important At All" = 1. The mean scores for the relative importance ratings of each cluster ranged from 3.6273 to 3.8773 out of 4 , indicating that each of the 10 clusters is considered to be "Extremely Important". Additionally, the standard deviation was less than .5 for all ten of the relative importance ratings (see Table 4).

The Likert scale levels and corresponding numerical values used to rate the efficacy of each cluster included: "Excellent" = 4, "Good" = 3, "Adequate" = 2, and "Poor" $=1$. The mean scores for the efficacy ratings of each cluster ranged from 3.0942 to 3.4555 out of 4 , indicating that the development of each of the 10 clusters of dispositions in the institution's candidates is considered to be "Good". Additionally, the standard deviation was less than .9 for all ten of the relative efficacy ratings (see Table 5).

Table 4. Relative Importance Descriptive Statistics.

\begin{tabular}{llcccc}
\hline Cluster Description & N & Minimum Maximum & Mean & SD \\
\hline $\begin{array}{l}\text { Educator responds to students' social and educational } \\
\text { needs }\end{array}$ & 220 & 2 & 4 & 3.827 & 0.341 \\
\hline $\begin{array}{l}\text { Educator builds rapport with entire educational } \\
\text { community }\end{array}$ & 220 & 2 & 4 & 3.718 & 0.461 \\
\hline $\begin{array}{l}\text { Educator exhibits personable qualities that make } \\
\text { him/her approachable to students }\end{array}$ & 220 & 2 & 4 & 3.846 & 0.387 \\
\hline $\begin{array}{l}\text { Educator communicates enthusiasm to students } \\
\text { Educator exhibits psychosocial maturity }\end{array}$ & 220 & 1 & 4 & 3.868 & 0.389 \\
\hline $\begin{array}{l}\text { Educator exhibits appropriate appearance and } \\
\text { personal hygiene }\end{array}$ & 220 & 3 & 4 & 3.800 & 0.401 \\
\hline $\begin{array}{l}\text { Educator demonstrates awareness of one's own } \\
\text { strengths and limitations }\end{array}$ & 220 & 2 & 4 & 3.800 & 0.412 \\
\hline $\begin{array}{l}\text { Educator is capable of responding appropriately to } \\
\text { challenging situations }\end{array}$ & 220 & 3 & 4 & 3.845 & 0.449 \\
\hline Educator effectively manages resources & 220 & 2 & 4 & 3.627 & 0.367 \\
\hline Educator exhibits professionalism & 220 & 2 & 4 & 3.877 & 0.342 \\
\hline
\end{tabular}


Table 5. Relative Efficacy Descriptive Statistics.

\begin{tabular}{lccccc}
\hline Cluster Description & N & Minimum Maximum & Mean & SD \\
\hline $\begin{array}{l}\text { Educator responds to students' social and educational } \\
\text { needs }\end{array}$ & 191 & 1 & 4 & 3.304 & 0.727 \\
\hline $\begin{array}{l}\text { Educator builds rapport with entire educational } \\
\text { community }\end{array}$ & 191 & 1 & 4 & 3.147 & 0.781 \\
\hline $\begin{array}{l}\text { Educator exhibits personable qualities that make } \\
\text { him/her approachable to students }\end{array}$ & 191 & 1 & 4 & 3.236 & 0.796 \\
\hline $\begin{array}{l}\text { Educator communicates enthusiasm to students } \\
\text { Educator exhibits psychosocial maturity }\end{array}$ & 191 & 1 & 4 & 3.440 & 0.677 \\
\hline $\begin{array}{l}\text { Educator exhibits appropriate appearance and } \\
\text { personal hygiene }\end{array}$ & 191 & 1 & 4 & 3.230 & 0.820 \\
\hline $\begin{array}{l}\text { Educator demonstrates awareness of one's own } \\
\text { strengths and limitations }\end{array}$ & 191 & 1 & 4 & 3.382 & 0.792 \\
\hline $\begin{array}{l}\text { Educator is capable of responding appropriately to } \\
\text { challenging situations }\end{array}$ & 191 & 1 & 4 & 3.309 & 0.728 \\
\hline Educator effectively manages resources & 191 & 1 & 4 & 3.094 & 0.878 \\
\hline Educator exhibits professionalism & 191 & 1 & 4 & 3.456 & 0.779 \\
\hline
\end{tabular}

\section{Results for Research Question 2}

\section{Omnibus test and post-hoc comparisons for relative importance.}

The following results were obtained for Research Question 2 regarding respondents' ratings of relative importance:

1. When comparing mean ratings of "Responds to Social and Educational Needs" for relative importance among teacher education faculty, teacher education students, and PK-12 professionals, no significant difference was found $(\mathrm{F}=.209$; $\mathrm{df}=2 ; \mathrm{p}<0.813)$

2. When comparing mean ratings of "Builds Rapport" for relative importance among teacher education faculty, teacher education students, and PK-12 professionals, no significant difference was found $(\mathrm{F}=.014 ; \mathrm{df}=2 ; \mathrm{p}<0.987)$. 
3. When comparing mean ratings of "Personable Qualities" for relative importance among teacher education faculty, teacher education students, and PK-12 professionals, significant difference was found $(\mathrm{F}=8.551 ; \mathrm{df}=2 ; \mathrm{p}<.001)$. When comparing the three groups, Scheffè's post-hoc analyses yielded 1 of 3 comparisons as being statistically significant. Teacher education faculty differed from teacher education students.

4. When comparing mean ratings of "Enthusiasm" for relative importance among teacher education faculty, teacher education students, and PK-12 professionals, significant difference was found $(\mathrm{F}=3.749 ; \mathrm{df}=2 ; \mathrm{p}<0.026)$. When comparing the three groups, Scheffè's post-hoc analyses yielded 1 of 3 comparisons as being statistically significant. Teacher education faculty differed from teacher education students.

5. When comparing mean ratings of "Psychosocial Maturity" for relative importance among teacher education faculty, teacher education students, and PKprofessionals, no significant difference was found $(\mathrm{F}=.371 ; \mathrm{df}=2 ; \mathrm{p}<0.692)$.

6. When comparing mean ratings of "Appearance and Personal Hygiene" for relative importance among teacher education faculty, teacher education students, and $\mathrm{PK}-12$ professionals, significant difference was found $(\mathrm{F}=12.039 ; \mathrm{df}=2$; $\mathrm{p}<.001)$. When comparing the three groups, Scheffè's post-hoc analyses yielded 2 of 3 comparisons as being statistically significant. Teacher education faculty differed from teacher education students. Teacher education faculty differed from PK-12 personnel. 
7. When comparing mean ratings of "Self-Awareness" for relative importance among teacher education faculty, teacher education students, and PK-12 professionals, significant difference was found $(\mathrm{F}=6.181 ; \mathrm{df}=2 ; \mathrm{p}<0.003)$. When comparing the three groups, Scheffè's post-hoc analyses yielded 2 of 3 comparisons as being statistically significant. Teacher education faculty differed from teacher education students. Teacher education faculty differed from PK-12 personnel.

8. When comparing mean ratings of "Responds to Challenging Situations" for relative importance among teacher education faculty, teacher education students, and $\mathrm{PK}-12$ professionals, no significant difference was found $(\mathrm{F}=2.775 ; \mathrm{df}=2$; $\mathrm{p}<0.066)$.

9. When comparing mean ratings of "Manages Resources" for relative importance among teacher education faculty, teacher education students, and PK-12 professionals, significant difference was found $(\mathrm{F}=5.697 ; \mathrm{df}=2 ; \mathrm{p}<0.005)$. When comparing the three groups, Scheffè's post-hoc analyses yielded 2 of 3 comparisons as being statistically significant. Teacher education faculty differed from teacher education students. Teacher education faculty differed from PK-12 personnel.

10. When comparing mean ratings of "Professionalism" for relative importance among teacher education faculty, teacher education students, and PK-12 professionals, no significant difference was found $(\mathrm{F}=.064 ; \mathrm{df}=2 ; \mathrm{p}<0.939)$. Omnibus test and post-hoc comparisons for efficacy. 
The following results were obtained for Research Question 2 regarding respondents' ratings of efficacy:

1. When comparing mean ratings of "Responds to Social and Educational Needs" for efficacy among teacher education faculty, teacher education students, and PK-12 professionals, no significant difference was found $(\mathrm{F}=1.427 ; \mathrm{df}=2 ; \mathrm{p}<0.244)$.

2. When comparing mean ratings of "Rapport" for efficacy among teacher education faculty, teacher education students, and PK-12 professionals, no significant difference was found $(\mathrm{F}=2.821 ; \mathrm{df}=2 ; \mathrm{p}<0.063)$.

3. When comparing mean ratings of "Personal Qualities" for efficacy among teacher education faculty, teacher education students, and PK-12 professionals, no significant difference was found $(\mathrm{F}=1.370 ; \mathrm{df}=2 ; \mathrm{p}<0.258)$.

4. When comparing mean ratings of "Enthusiasm" for efficacy among teacher education faculty, teacher education students, and PK-12 professionals, no significant difference was found $(\mathrm{F}=.283 ; \mathrm{df}=2 ; \mathrm{p}<0.755)$.

5. When comparing mean ratings of "Psychosocial Maturity" for efficacy among teacher education faculty, teacher education students, and PK-12 professionals, no significant difference was found $(\mathrm{F}=.958 ; \mathrm{df}=2 ; \mathrm{p}<0.386)$.

6. When comparing mean ratings of "Appearance and Personal Hygiene" for efficacy among teacher education faculty, teacher education students, and PK12 professionals, no significant difference was found $(\mathrm{F}=.807 ; \mathrm{df}=2$; $\mathrm{p}<0.449)$. 
7. When comparing mean ratings of "Self-Awareness" for efficacy among teacher education faculty, teacher education students, and PK-12 professionals, a significant difference was found $(\mathrm{F}=4.892 ; \mathrm{df}=2 ; \mathrm{p}<0.009)$. When comparing the three groups, Scheffè's post-hoc analyses yielded 1 of 3 comparisons as being statistically significant. Teacher education students differed from PK-12 personnel.

8. When comparing mean ratings of "Response to Challenges" for efficacy among teacher education faculty, teacher education students, and PK-12 professionals, no significant difference was found $(\mathrm{F}=2.784 ; \mathrm{df}=2 ; \mathrm{p}<0.065)$.

9. When comparing mean ratings of "Manages Resources" for efficacy among teacher education faculty, teacher education students, and PK-12 professionals, no significant difference was found $(\mathrm{F}=2.176$; $\mathrm{df}=2 ; \mathrm{p}<0.117)$.

10. When comparing mean ratings of "Professionalism" for efficacy among teacher education faculty, teacher education students, and PK-12 professionals, no significant difference was found $(\mathrm{F}=1.413 ; \mathrm{df}=2 ; \mathrm{p}<0.247)$. 
ANOVA results for relative importance and efficacy are displayed in Table 6 and

Table 7, respectively.

Table 6. ANOVA Results for Relative Importance Ratings.

\begin{tabular}{|c|c|c|c|c|}
\hline Cluster Description & F Value & df & p Value & $\begin{array}{l}\text { Post Hoc Results } \\
\text { (If Applicable) }\end{array}$ \\
\hline $\begin{array}{l}\text { Educator responds to students' social and } \\
\text { educational needs }\end{array}$ & 0.209 & 2 & 0.812 & \\
\hline $\begin{array}{l}\text { Educator builds rapport with entire } \\
\text { educational community }\end{array}$ & 0.014 & 2 & 0.986 & \\
\hline $\begin{array}{l}\text { Educator exhibits personable qualities that } \\
\text { make him/her approachable to students }\end{array}$ & 8.551 & 2 & 0.000 & $\begin{array}{l}\text { FSU Faculty Differ } \\
\text { from FSU Students }\end{array}$ \\
\hline $\begin{array}{l}\text { Educator communicates enthusiasm to } \\
\text { students }\end{array}$ & 3.749 & 2 & 0.025 & $\begin{array}{l}\text { FSU Faculty Differ } \\
\text { from FSU Students }\end{array}$ \\
\hline Educator exhibits psychosocial maturity & 0.371 & 2 & 0.691 & \\
\hline $\begin{array}{l}\text { Educator exhibits appropriate appearance } \\
\text { and personal hygiene }\end{array}$ & 12.039 & 2 & 0.000 & $\begin{array}{l}\text { FSU Faculty Differ } \\
\text { from PK-12 } \\
\text { Professionals; FSU } \\
\text { Faculty Differ from } \\
\text { FSU Students } \\
\end{array}$ \\
\hline $\begin{array}{l}\text { Educator demonstrates awareness of one's } \\
\text { own strengths and limitations }\end{array}$ & 6.181 & 2 & 0.002 & $\begin{array}{l}\text { FSU Faculty Differ } \\
\text { from PK-12 } \\
\text { Professionals; FSU } \\
\text { Faculty Differ from } \\
\text { FSU Students }\end{array}$ \\
\hline $\begin{array}{l}\text { Educator is capable of responding } \\
\text { appropriately to challenging situations }\end{array}$ & 2.775 & 2 & 0.065 & \\
\hline Educator effectively manages resources & 5.697 & 2 & 0.004 & $\begin{array}{l}\text { FSU Faculty Differ } \\
\text { from PK-12 } \\
\text { Professionals; FSU } \\
\text { Faculty Differ from } \\
\text { FSU Students }\end{array}$ \\
\hline Educator exhibits professionalism & 0.064 & 2 & 0.938 & \\
\hline
\end{tabular}


Table 7. ANOVA Results for Relative Efficacy Ratings.

\begin{tabular}{|c|c|c|c|c|}
\hline Cluster Description & F Value & df & p Value & $\begin{array}{l}\text { Post Hoc Results } \\
\text { (If Applicable) }\end{array}$ \\
\hline $\begin{array}{l}\text { Educator responds to students' social and } \\
\text { educational needs }\end{array}$ & 1.427 & 2 & 0.243 & \\
\hline $\begin{array}{l}\text { Educator builds rapport with entire } \\
\text { educational community }\end{array}$ & 2.821 & 2 & 0.062 & \\
\hline $\begin{array}{l}\text { Educator exhibits personable qualities that } \\
\text { make him/her approachable to students }\end{array}$ & 1.37 & 2 & 0.257 & \\
\hline $\begin{array}{l}\text { Educator communicates enthusiasm to } \\
\text { students }\end{array}$ & 0.283 & 2 & 0.754 & \\
\hline Educator exhibits psychosocial maturity & 0.958 & 2 & 0.385 & \\
\hline $\begin{array}{l}\text { Educator exhibits appropriate appearance } \\
\text { and personal hygiene }\end{array}$ & 0.807 & 2 & 0.448 & \\
\hline $\begin{array}{l}\text { Educator demonstrates awareness of one's } \\
\text { own strengths and limitations }\end{array}$ & 4.892 & 2 & 0.008 & $\begin{array}{c}\text { FSU Students differ } \\
\text { from PK-12 } \\
\text { Personnel } \\
\end{array}$ \\
\hline $\begin{array}{l}\text { Educator is capable of responding } \\
\text { appropriately to challenging situations }\end{array}$ & 2.784 & 2 & 0.064 & \\
\hline Educator effectively manages resources & 2.176 & 2 & 0.116 & \\
\hline Educator exhibits professionalism & 1.413 & 2 & 0.246 & \\
\hline
\end{tabular}

\section{Reliability test.}

In order to determine reliability, Cronbach's Alpha statistics were computed for each set cluster data. Items used to measure relative importance yielded Alpha $=0.838$, while the respective measure for reliability of items addressing efficacy yielded Alpha $=0.951$. Both of these results are within an acceptable range for reliability.

\section{Results for Research Question 3}

To address the third question, participants were asked to list specific dispositions important to teaching Health and Physical Education (HPE) and those important to any area of education. Each response was then analyzed and placed into one of the 10 categories of dispositions to which it most closely belonged. The researcher noted 
several responses related to being healthy, fit, in shape, or active, particularly when participants were asked to consider dispositions important for teaching HPE. These responses were interpreted as part of being a role-model rather than as part of "Appropriate Appearance and Personal Hygiene" and thus were included as part of the category "Qualities that Make One Approachable to Students", which included "rolemodel" in the original 2007 study.

When comparing the responses for all areas of education with the responses for those specific to Health and Physical Education, it appears as though there are similarities in the distribution of responses by cluster (see Figure 2). Upon closer investigation, the specific responses within some clusters showed some variability in what is considered important to all areas of education in comparison with what is considered to be important specifically to Health and Physical Education. Clusters with obvious differences in what is perceived to be important to all areas of education in comparison with dispositions perceived to be important specifically to Health and Physical Education are discussed below.

The greatest difference was seen in the cluster for "Personable Qualities that Make One Approachable to Students". Only 1\% of the responses for dispositions important to all educators related to being healthy or fit. In contrast, almost $30 \%$ of the responses for dispositions important to HPE in this category related to being health or fit (see Figure 3). 
Figure 2. Importance Dispositions by Category.

Importance Dispositions by Category

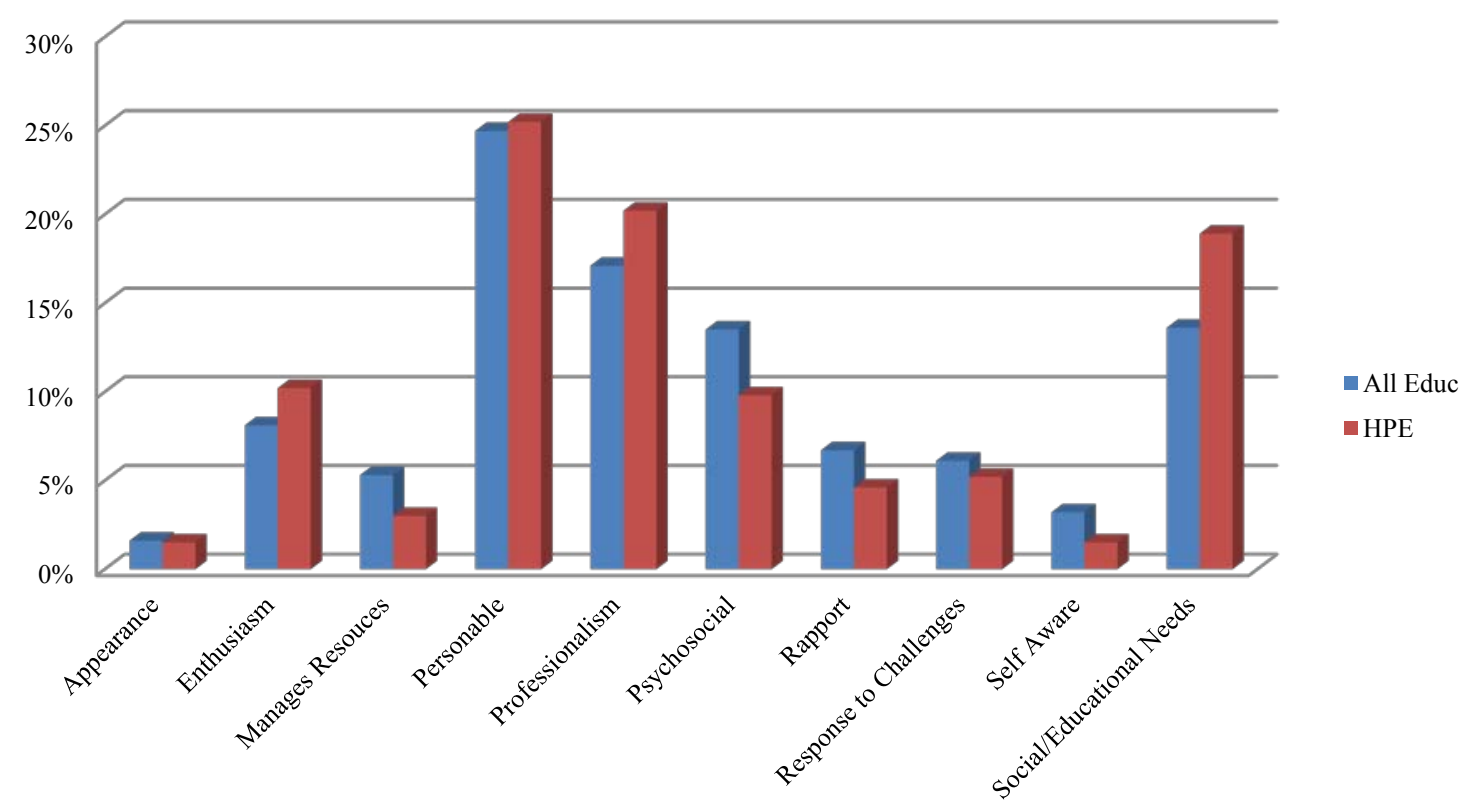

Figure 3. Personable Qualities.

\section{Personable Qualities}

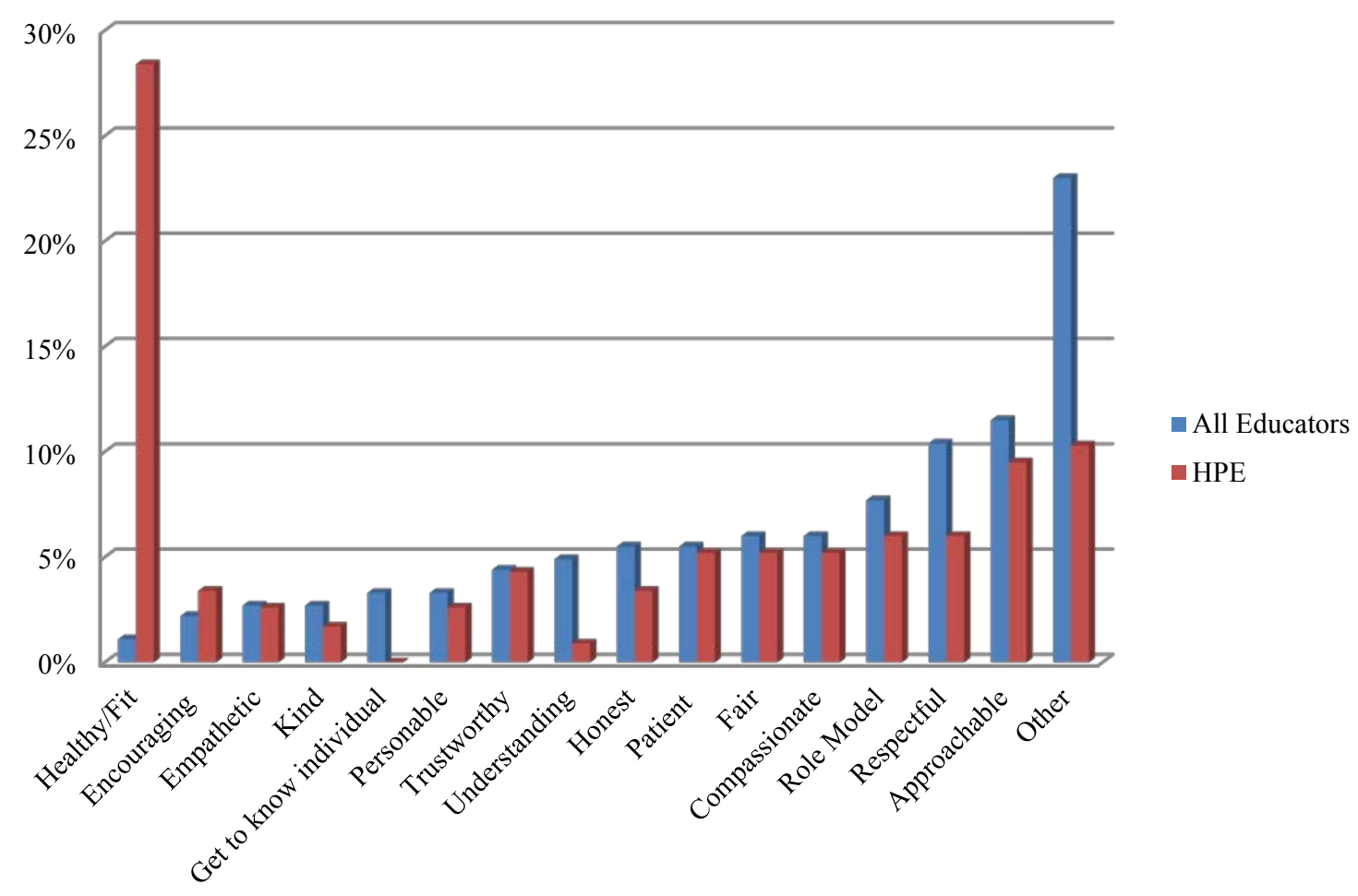


Differences in specific dispositions within the category of "Professionalism" included dedication, knowledge, and general professionalism. Dedication accounted for $14 \%$ of responses in this category for all educators and only $5 \%$ for HPE. Knowledge accounted for only $17 \%$ of responses for all educators and $36 \%$ for HPE. Many of the HPE responses related to specific health-related topics such the body and how it works, health as well as fitness, how exercise enhances brain function, health and safety, nutrition, etc. The disposition of being generally professional accounted for $29 \%$ of the responses for all educators and only $19 \%$ of the responses for HPE (see Figure 4).

Figure 4. Professionalism.

\section{Professionalism}

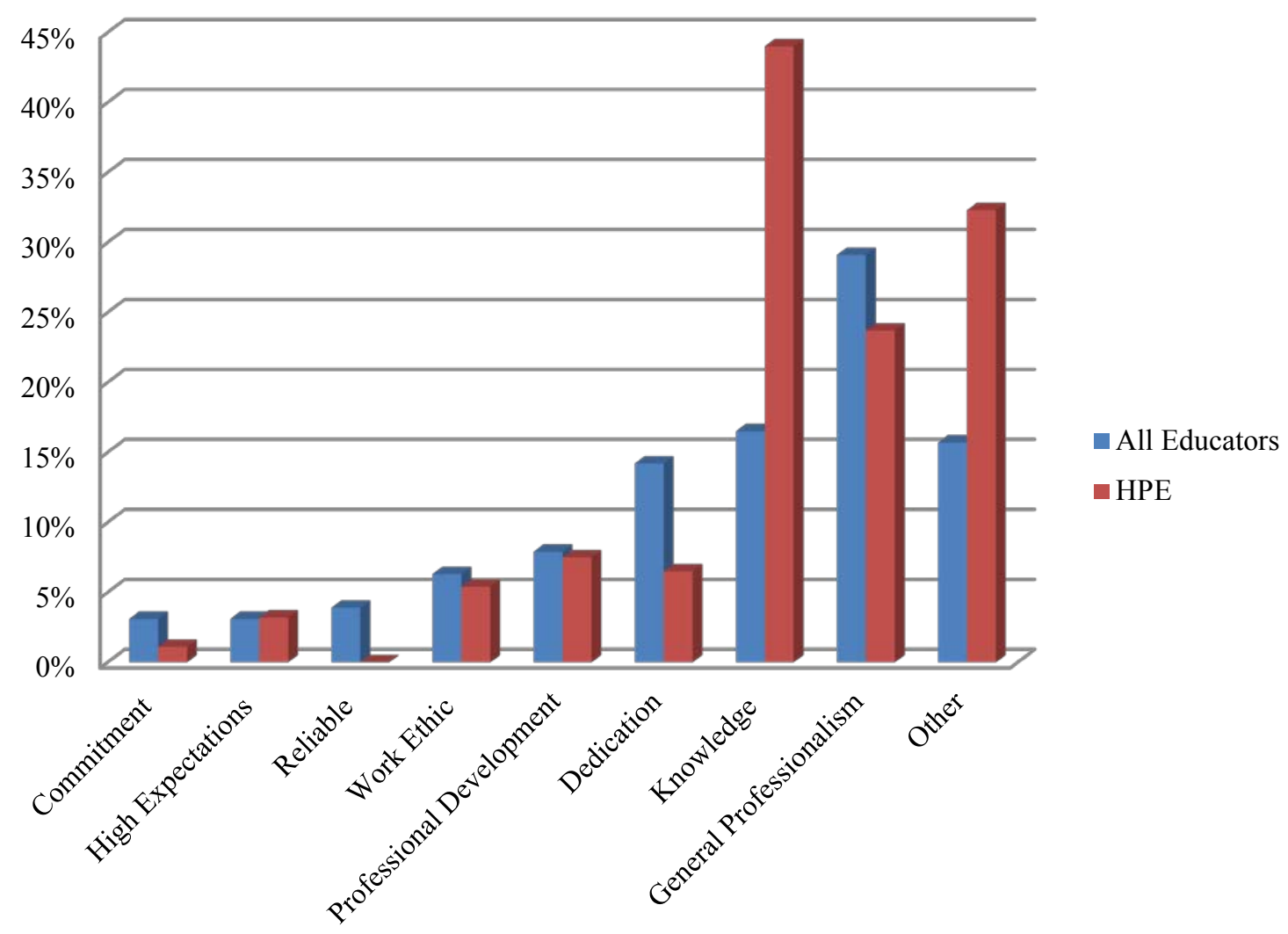

Specific dispositions within the "Response to Social and Educational Needs" category that varied between the all educators and HPE included awareness, listening, 
and likes kids. Awareness seemed to be more important to HPE (11\% of the responses) than to all educators ( $2 \%$ of the responses); listening (7\%) was more important to all educators than to HPE (1\%); and liking kids accounted for $11 \%$ of the responses for all educators and $0 \%$ for HPE (see Figure 5).

Figure 5. Response to Social/Educational Needs.

\section{Response to Social/Educational Needs}

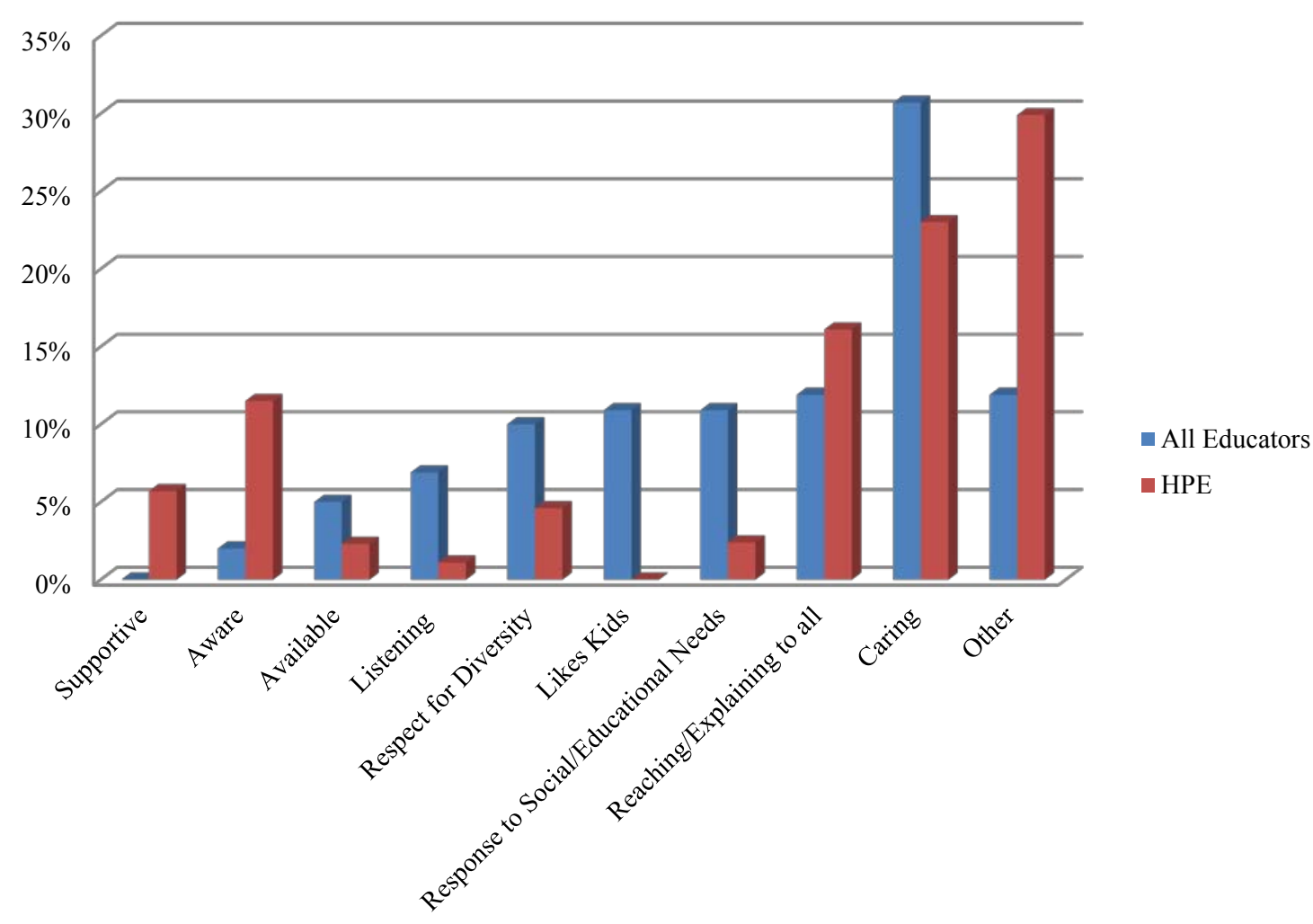

With the cluster "Response to Challenges", the disposition to maintain a safe environment seemed to be far more important to HPE (21\%) than to all educators $(6 \%)$. For the purposes of this study, a safe environment included emotional as well as physical safety. For example, minimizing bullying, promoting safety, safe physical environment, etc. were included as maintaining a safe environment. Other differences in this group 
were evident in the area of general response to challenges, with $8 \%$ of the HPE responses falling in this area as opposed to $24 \%$ of all educator responses in this same area. For both HPE and all educators, managament/discipline accounted for a large number of the dispositions identified as important, with $38 \%$ and $29 \%$ respectively (see Figure 6).

Figure 6. Response to Challenges.

\section{Response to Challenges}

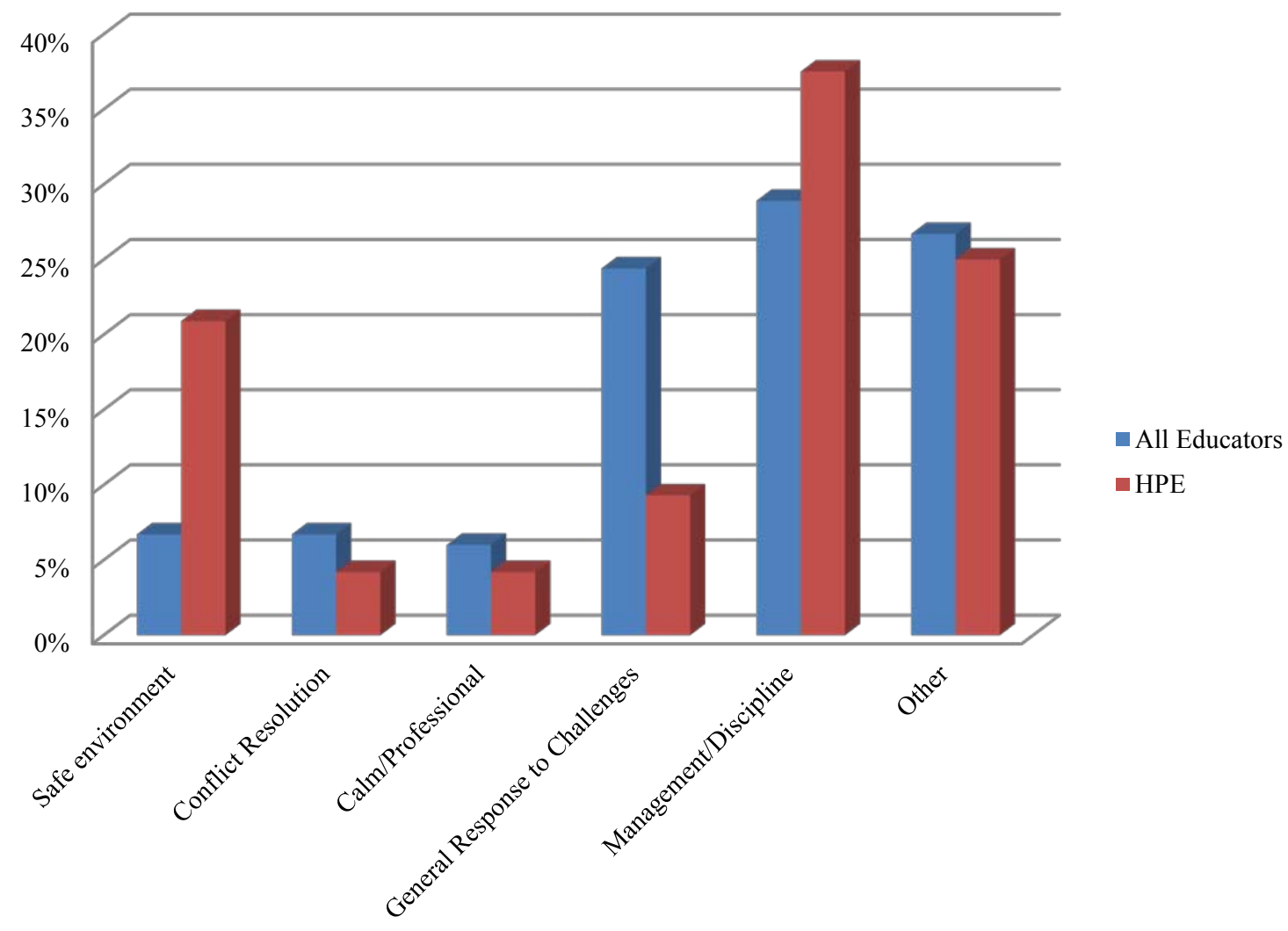

Within the cluster for "Psychosocial Maturity", participants identified the need for Health and Physical Educators to be mature much more frequently than they identified maturity for all areas of education. Many used the word "mature" in reference to addressing sensitive topics in Health and Physical Education, such as puberty, reproduction, and sexually transmitted infections (see Figure 7). 
Figure 7. Psychosocial Maturity.

\section{Psychosocial Maturity}

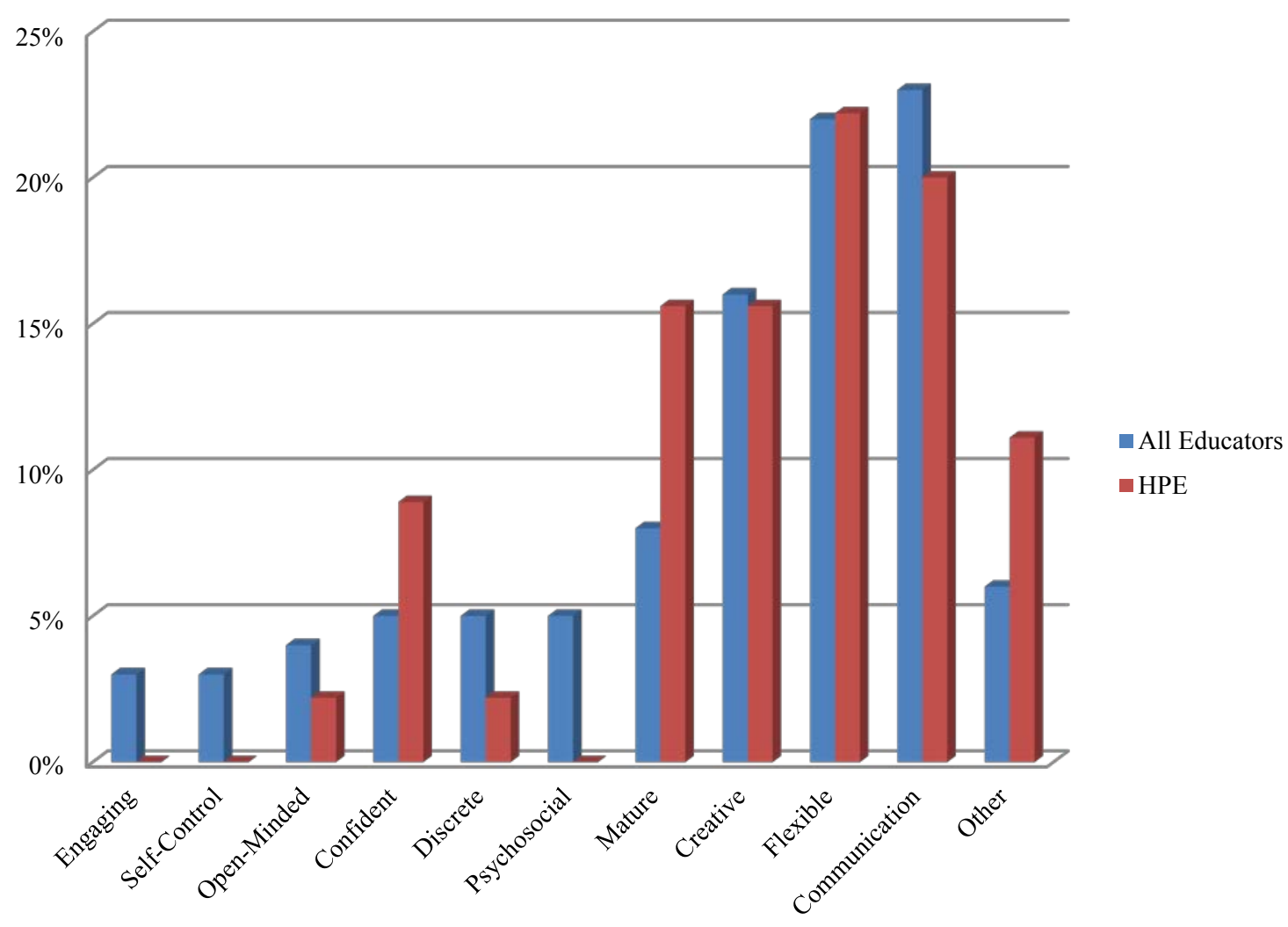

\section{Other Analyses}

\section{Demographics.}

Of the 270 respondents, $10 \%$ are teacher education faculty or staff members, $25.5 \%$ are PK-12 educators, but not currently teacher education students, $13 \%$ are both PK-12 educators and teacher education students, and 51.5\% are teacher education students. Teacher education faculty or staff includes any person who taught at least one course in an education program or who is in an administrative role in an education program. For the purposes of data analysis, responses from participants were both teacher education students and PK-12 professionals were classified PK-12 professionals. 
The researcher assumed that most respondents would identify more with their full-time career rather than graduate school (for which most are enrolled part-time). The majority of respondents identified their areas of expertise as either Early Childhood/Elementary or Elementary (see Figure 8). Of the 21 "other" responses, 13 of them were content specific (math, social studies, language arts, etc.) or specifically state "middle school".

Figure 8. Respondent Certification Area, or Undergraduate/Graduate Major.

\section{Major or Certification}

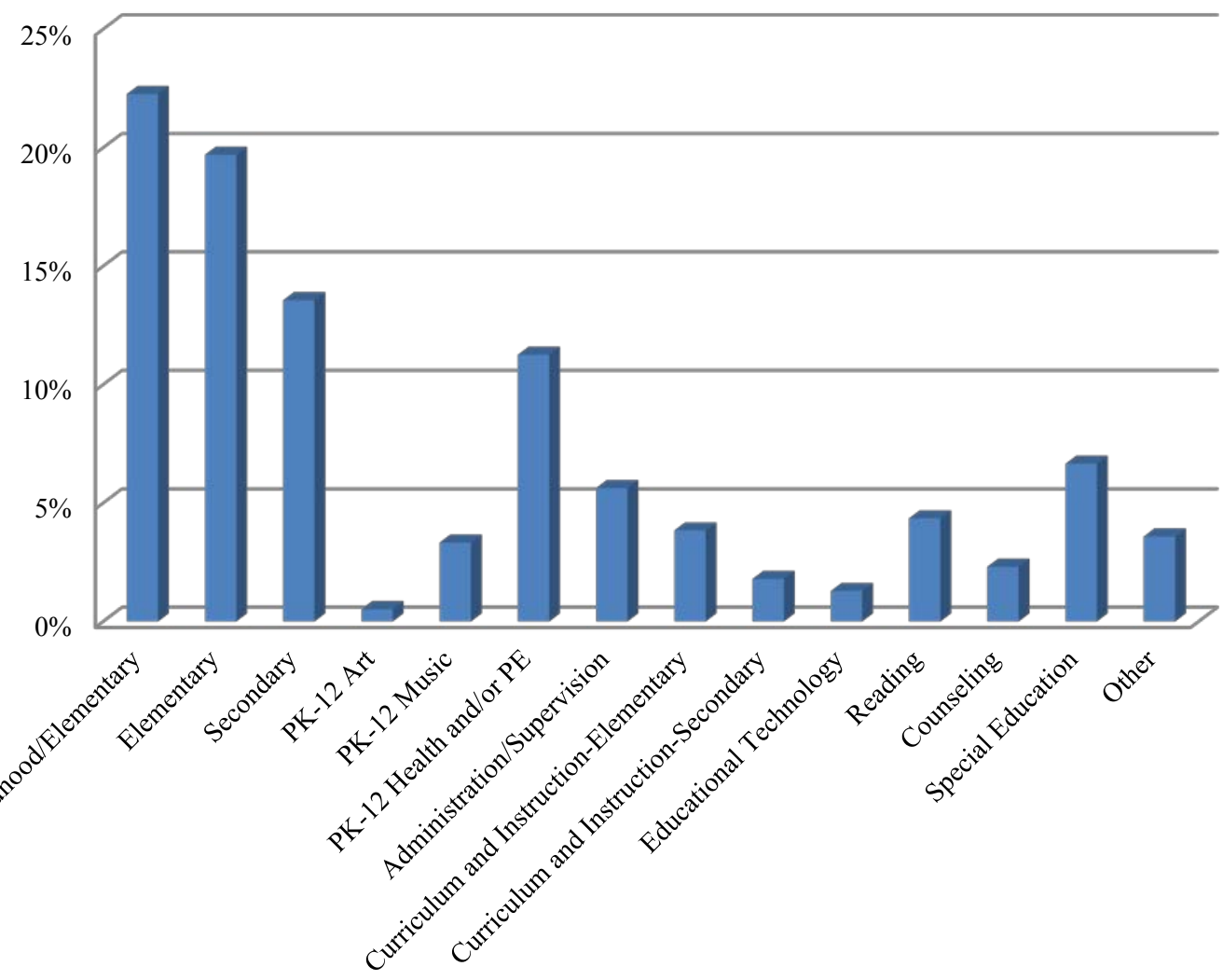

\section{Limitations.}

This study includes the following limitations:

1. Self-report bias may have led to exaggerations in responses 
2. Undefined terminology, such as "dispositions" and "psychosocial maturity" may have resulted in a lack of clarity for some questions

3. Names of clusters may have been somewhat unclear or misleading because specific dispositions belonging to each cluster were not identified. A few examples of dispositions representing the cluster may have provided more clarity.

4. The return rate was between $22 \%$ and $23 \%$, and there was variability in the size of the treatment groups. A greater response rate would improve the credibility of the results.

5. Analysis of responses for research question 3 required interpretation of some responses when the dispositions listed were not dispositions that appeared in the 2007 Simpson and Diaz study. For example, "healthy" was interpreted to be equivalent to being a role-model for Health and Physical Education, and was classified as such.

6. Redundancy of questions may have resulted in respondent fatigue, thus compromising the validity of the survey.

7. When the survey was sent to local board of education personnel, a principal informed the researcher of the correct protocol for approval to send surveys to the school system's employees. As a result, the researcher contacted the appropriate personnel to secure approval. There was no official suspension of the study, but failure to initially follow protocol may have resulted in a reduction of responses from the school system's employees. 
8. No questions in the survey forced the ranking of clusters of dispositions for importance and efficacy. Forced ranking may have provided data to illustrate subtle differences in importance. For example, a participant may have rated 5 clusters "extremely important", but there is no indication of which cluster is the most important.

9. The sample used in this study is representative of a small teacher education institution located in a rural region in western Maryland. The results may not be generalizable to larger urban teacher education institutions.

\section{Summary of Analysis}

Participants of this study generally perceive each of the 10 clusters of dispositions as "extremely important" and they feel the development of each of the clusters at the institution is "good". The ANOVA tests indicated significant differences in perceptions of relative importance among teacher education faculty, teacher education students, and PK-12 personnel in five of the ten clusters, and significant differences in the perceptions of efficacy among those groups in one of the ten clusters.

When participants were asked to name dispositions specific to Health and Physical Education and those generally needed in all fields of education, the importance of general dispositions clusters seems to be about the same. However, the frequency of specific dispositions named within each cluster varied considerably for some. For example, participant responses indicate it is more important for Physical Educators to be disposed to being healthy and fit in comparison with all other field of education. Other dispositions identified more frequently for Health and Physical Education included knowledge, maturity, and maintaining a safe environment. 
The conclusions, implications, and recommendations for future research drawn from the data analysis will be discussed in detail in Chapter 5. 


\section{CHAPTER 5 - CONCLUSIONS, IMPLICATIONS AND RECOMMENDATIONS}

\section{Review of Chapters 1-4}

Concern for teacher quality has led to considerable changes in teacher credentialing over the last decade, particularly in the area of educator dispositions. Teacher education institutions have struggled with task of addressing disposition requirements for accreditation primarily because of the enormous insufficiency of research in the field and the lack of guidance from accreditation agencies (Honawar, 2008; Shussler, 2008; Edwards \& Edick, 2006; Diez \& Raths, 2007). The ambiguity surrounding the term "disposition", coupled with the rapid pace at which standards for dispositions were imposed on teacher education institutions, has resulted in enormous amount of uncertainty and incongruence with respect to addressing the requirements. Furthermore, discussions among teacher education institutions have gone beyond the scope of merely meeting standards for accreditation to the identification of numerous needs, some of which include the following: the identification of key dispositions for educator effectiveness in each field of education and in all fields collectively; whether or not dispositions are inherent or learned; how to develop, assess, and evaluate dispositions; and what to do when candidates demonstrate dispositional deficiencies (Taylor \& Wasisko, 2000; Wasisko, Callahan, \& Wirtz 2004; Smith, Skarbek, \& Hurst, 2005; Helm, 2006; Diez \& Raths, 2007; Helm, 2006; Sockett, 2006; Burke, 2002; Hillman, Rotherman, \& Scarana, 2006; Honowar, 2008; Manzo, 2006). Foundational to addressing many of the questions surrounding dispositions is to first determine how the term will be defined and conceptualized in education, and to 
identify the dispositions important to all educators and to each field of education. The purposes of this study were to (1) gauge the perceived importance and efficacy of the identified categories of dispositions in a larger population of teacher education students teacher education faculty, and PK-12 educators and administrators; and (2) to determine the dispositions which may not be common to all programs in the unit, but are identified as essential to teaching Health and Physical Education.

The 2007 Simpson and Diaz study identified ten conceptual clusters of dispositions that were used as the foundation to develop the survey for this study. The ten clusters are listed below:

- Responding to students' social and educational needs

- Building rapport with entire educational community

- Exhibiting personable qualities that make you approachable to students

- Communicating enthusiasm to students

- Exhibiting psychosocial maturity

- Exhibiting appropriate appearance and hygiene

- Demonstrates awareness of one's own strengths and limitations

- Is capable of responding appropriately to challenging situations

- Effectively manages resources

- Professionalism

The survey for this research required participants to rate the relative importance and efficacy of each of the ten clusters. Participants were also asked to list specific dispositions critical to all fields of education and dispositions critical to teaching Health and Physical Education. The following questions were the focus of the research: 
1. Building upon prior work of Simpson and Diaz, what are overall general perceptions of the importance and efficacy related to each category of identified dispositions?

2. Are there differences in how the institution's teacher education students (both undergraduate and graduate), local school professionals (including teachers, administrators, and counselors), and teacher education faculty at the institution rate the importance and efficacy of identified dispositions categories?

3. What dispositions are perceived to be important specifically to the fields of Health and Physical Education?

\section{Conclusions}

This dissertation has been an exploration into an important aspect of teacher education which historically has not received adequate attention (Honawar, 2008; Shussler, 2008; Edwards \& Edick, 2006). The task of defining and conceptualizing what a disposition is and identifying the dispositions important to all fields education, as well as to specific disciplines, is the cornerstone to determining the most appropriate responses to the plethora of questions about dispositions that have emerged in the last decade (Diez \& Raths, 2007; Taylor \& Wasisco, 2000; Smith, Skarbek, \& Hurst 2005).

Three general findings of this study were (1) each of the 10 clusters of dispositions included in the research is important to all fields of education, but the degree of importance for some varies among treatment groups; (2) the institution's teacher education curriculum develops dispositions well; (3) the degree of importance of specific dispositions to individual fields of education vary. 
The major implications of this study, discussed further below, include (1) the lack of understanding of the term "disposition" renders the ability to consistently and appropriately address dispositions virtually impossible; (2) the variability in opinions regarding relative importance of each disposition may be due to the frame from which respondents operate; (3) accreditation standards do not address the "extremely important" dispositions; (4) alternative certification requirements in the state of Maryland do not address dispositions at all; (5) variability in the specific dispositions important in some fields of education indicates a "one size fits all" approach to development, assessment, and certification does not meet the specific needs of each certification area; and (6) the identification of areas with the lowest efficacy rates may be due to the advance nature of the disposition.

\section{What is a disposition?}

Much of the literature on dispositions has centered on determining what is meant by the term "disposition". For example, the authors of The Passion of Teaching: Dispositions in Schools (2005) include a table of a wide variety of terms used in association with "disposition" in the literature. Dispositions have been described as attitudes, personalities and characteristics, beliefs, values, sense of efficacy, conceptions, perceptions, theories, and disposition (Smith, Skarbek, \& Hurst, 2005). The elusive nature of the term creates difficulty for those who make attempt to assess and evaluate them. Dispositions in and of themselves are not seen. What can be seen is the result of the disposition, i.e. the actions which demonstrate a disposition exists. Therefore it is generally agreed upon that the sum total of actions over time is indicative of a person's disposition. The critical point of emphasis is the consistency of actions over time. If a 
person demonstrates the disposition to be respectful on Monday, but on most other days is disrespectful, then his is likely disposed to be disrespectful because the pattern of behavior demonstrates disrespect, rather than respect.

The lack of understanding in the field regarding what a disposition is became apparent when survey participants were asked to list specific dispositions important to Health and Physical Education and important to all areas of education. An abundance of participant responses related to knowledge or skill, rather than to disposition. While some dispositions may be dependent upon a person's knowledge or skill, some responses did not use words typically associated with disposition. For example, some stated a "willingness to learn", while others stated "content knowledge". "Knowing content" falls under the domain of "knowledge". However, a "willingness" to learn the content is more indicative of a person's disposition. Similarly, some respondents stated differentiated instruction, alternative assessment, classroom management, and discipline, which require both knowledge and skill in order for a teacher to become disposed to using them. At times there is a fine line between truly not being disposed to do something and not having the knowledge or skill needed to do it, which is particularly true of teachers in training.

All educators, including higher education, PK-12 personnel, and teacher education students, need to clearly understand what a disposition is, what dispositions are important, and what the pattern of behaviors "looks like" when a disposition is demonstrated. Without clear understanding, there will not only be a disconnection between theory and practice, there will also not be a solid foundation for solutions to the questions surrounding teacher dispositions. If we don't fully understand a problem, it makes it difficult to solve it (Smith, Skarbek, \& Hurst, 2005). 
This research has clearly defined 10 clusters of dispositions, each of which is identified as extremely important. The cluster groups identified could serve as the foundation for model to teach what a disposition is, to identify behaviors a candidate might show to demonstrate each disposition, to design dispositions development activities, and to design dispositions assessments.

\section{Variability in perceptions of importance.}

Teacher education faculty, teacher education students, and PK-12 personnel collectively rated each of the ten clusters as "Extremely Important" or "Important" for all educators. Five of the ten clusters, however, showed significant differences between treatment groups. The five clusters where significance was found include (1) Personal Qualities, (2) Enthusiasm, (3) Appearance and Personal Hygiene, (4) Awareness of One's Own Strengths and Limitations, and (5) Managing Resources. In each of these 5 clusters, the post-hoc analyses showed significant ratings between teacher education faulty and teacher education students. The latter three of the 5 clusters also showed significant differences between teacher education faculty and PK-12 personnel. In contrast, there were no significant differences between PK-12 personnel and teacher education students in any of the ratings for relative importance, indicating a general agreement among these two groups regarding the level of importance of each of the ten clusters.

The fact that there is so much variability between teacher education faculty and the other two groups could lead to issues associated with areas of focus for improvement for candidates. For example, there were significant differences between teacher education faulty and PK-12 professionals and between teacher education faculty and teacher education students in relative importance ratings for Personal Hygiene and 
Appearance. The teacher education faculty mean rating was 3.44, the PK-12 mean score was 3.8182, and the teacher education student mean score was 3.857. Both PK-12 professionals and teacher education students rated Appearance and Personal Hygiene much higher than teacher education faculty. Perhaps the teacher education faculty operate from the perspective that in the grand scheme of teaching, appearance is much more important to the adults in a school than it is to truly being effective with students, and therefore rated the cluster Appearance and Personal Hygiene as somewhat less important than the other two groups. In contrast, teacher education students, particularly as interns, are challenged with gaining the respect from adults in the school when, often times, they more closely resemble a high school student than a teacher. Professional appearance can help widen the gap for candidates to set them apart from the students they teach. PK-12 personnel would likely follow the same line of thinking. Many mentor teachers work hard to give each of their interns a competitive edge over other graduates. Professional appearance not only makes an initial impression on those in positions to hire teachers, it also impacts the perceptions of parents or other influential members of the community. Therefore, it is possible both teacher education students and PK-12 professionals perceive the Personal Appearance and Hygiene as more important than the teacher education faculty because of their perspective frames of reference. Differing perspectives can lead to issues with respect to what to emphasize and how to evaluate.

Additionally, it is likely that the perspective of the teacher education faculty is impacted because they work so diligently to develop teacher candidates. Their initial contact with candidates is usually when students are 18-19 years-old, when their attitudes, actions and behaviors more closely resemble a high school student, rather than 
a teacher. Teacher education faculty members facilitate and observe the transformation process that (somehow) turns high school students into teachers. It is a unique time of life for students which often times requires a tremendous amount of personal growth. Perhaps the teacher education faculty differences in ratings are indicative of underlying beliefs they have developed about which dispositions can be developed and which are inherent. Neither teacher education students, nor PK-12 professionals, have had the opportunities to make observations about the developmental processes of becoming a teacher, and therefore may not have given consideration to beliefs about which dispositions can be developed and which are inherent. There is a tremendous period of growth that can only be seen by those working closely with students during all phases of teacher training. While PK-12 personnel work closely with candidates, they are not engaged with them during initial phases of teacher education; the PK-12 personnel consider the "end product", and what is needed to be successful in the schools, rather than the dispositions one might believe are foundational to a teacher education candidate.

Teacher education faculty mean ratings for relative importance were lower than the other two groups in 7 out of the 10 clusters, and in 4 out of the 5 clusters where significant differences were indicated. Perhaps teacher education faculty truly feel dispositions are not as important as other aspects of teaching (knowledge and skill), particularly during developmental stages of teacher training. For example, during the initial phases of a teacher education candidate's experience, an enormous amount of time and energy is spent learning the depth of content required to teach, how to address the standards, how to develop lessons and assessments to align with standards, and how to overcome the nervousness that often accompanies initial teaching experiences. 
Candidates are not expected to have the wherewithal to address student behaviors, manage resources well, or demonstrate an awareness of strengths and limitations, until they have had several teaching experiences.

Perhaps teacher education faculty feel knowledge and skill are foundational to some or all dispositions to teach. For example, for the disposition to manage resources, candidates would need to have considerable knowledge of what resources are available, and they would need skill in using resources prior to developing a disposition to manage resources. If a school has a traveling computer lab, but the student is unaware it exists, finds out it needs to be reserved a month in advance, or needs training to use it, then managing resources is more dependent on knowledge of existing resources and procedures necessary to use them. In contrast, a veteran teacher may be fully aware of available resources, skilled in the use of those resources, and as a result, rate the disposition to uses those resources as "extremely important" to successful teaching.

Additionally, if the participant held the belief that some dispositions are more easily developed than others, or that some are more related to a person's personality, then it is possible that ratings may have been impacted. For example, if a participant was using the frame of reference of teacher training when completing the survey, those dispositions which are difficult to develop in candidates would likely be more important to possess at any level. The variation in ratings between treatment groups supports the literature regarding the need to clearly identify the dispositions, which are critically important to education professionals. Those with an interest in teaching generally feel dispositions are important, but the variability in the opinions regarding the degree of importance of each dispositions cluster, combined with minimal guidance from 
accrediting bodies who simultaneously tout their importance, means teacher preparation faculty are left to make blind decisions about managing dispositions development and assessment in teacher education programs, which dispositions should be required for entry into and/or completion of a teacher education program, etc.

If teacher education faculty perception of what is important is not truly what is the most important in the field, then teacher education candidates are possibly not being prepared as well as they could be. On the other hand, if teacher education faculty beliefs and actions are on target with the true needs of teacher education candidates, or if teacher education faculty have a better understanding of the developmental processes and complexities of the relationships between knowledge, skills, and dispositions in teaching, then it is quite possible that the needs of our candidates are being met. For example, the disposition cluster for Personal Qualities that Make One Approachable showed significant ratings for importance between teacher education faculty and teacher education students, with mean ratings of 3.6 and 3.9143 respectively. Research shows that school connectedness is critical to the academic achievement and overall health of a school aged child (Centers for Disease Control and Prevention, Helping Your Child Feel Connected to School). If school connectedness is in any way impacted by a the approachability of a teacher, then consideration should be given to the importance of developing skills and dispositions needed for candidates to be more approachable, and therefore may require modifications to teacher education programs to address approachability in more depth.

Despite significant differences in perceptions of importance for five of the ten clusters of dispositions, mean scores for each of them were either "important" or 
"extremely important". Further investigation is needed to determine the reasons for significant differences and to determine whether or not program curricula adequately address the development of the most critical dispositions.

\section{Accreditation standards.}

Currently Maryland teacher preparation institutions are governed by NCATE standards for accreditation. In October 2010, NCATE and TEAC (the Teacher Education Accreditation Council) announced that they are merging into one new accrediting body called the Council for the Accreditation of Educator Preparation (CAEP). The goals for CAPE are to create a unified teacher accreditation agency for the nation, raise the performance of teacher education candidates, and raise the standards of evidence that support claims of quality (CAEP, 2010). New standards for accreditation will be developed in 2012, then shared with teacher preparation institutions for comment, and completed in 2013. Teacher preparation institutions will begin applying the new standards for accreditation visits scheduled for spring 2015 or later (NCATE, Update on CAEP Transition). During the process of developing new standards for accreditation, the importance addressing a variety of educator dispositions should be considered. As discussed below, NCATE's current dispositions requirements are not in alignment with the dispositions participants of this study deemed important.

When participants of this study were asked to rate the importance of each cluster, overall mean score ratings indicate that participants feel each cluster is "extremely important" or "important" for educators. In order for teacher education institutions to meet current NCATE standards for accreditation, they must systematically assess only two dispositions: fairness and the belief that all students can learn. Given the results of 
this study, it is clear that NCATE's dispositions requirements do not adequately address many of the dispositions/clusters of dispositions participants feel educators should possess, such as professionalism, building rapport, caring and compassion, selfconfidence, self-control, flexibility, creativity, approachability, etc. In the 2007 Simpson and Diaz study, the disposition of "fairness" is one of 14 specific dispositions belonging to the cluster of "Personal Qualities that Make One Approachable to Students". Of the 102 specific dispositions named in the study, "the belief that all students can learn" was not explicitly identified, but would be categorized as "Responds to Students' Social and Educational Needs". NCATE's requirements neglect to address 8 of the 10 clusters of dispositions rated "important" or "extremely important" by participants in this study, and about 100 specific dispositions identified in the 2007 study.

\section{Certification.}

Similarly, many state boards of education allow teachers to become certified through alternative routes, one of which is the transcript analysis (sometimes called “credit count"). The original purpose of alternative certification was to provide a means for credentialing teachers in a time of teacher shortage. Usually transcript analysis requires applicants to complete fieldwork and a certain number of credits in specific areas and earn passing scores on licensure exams.

Since the results of this study show general agreement that dispositions are extremely important to educators, then it seems as though all certification pathways should include the evaluation of dispositions. Currently in the state of Maryland, the only standard assessment for all routes to certification is the licensure exam. However, licensure exams assess knowledge; they do not assess dispositions or skills. The 
coursework required for certification by way of transcript analysis in Maryland are not standardized, thus there is no assurance that dispositions or skills are developed and assessed. Additionally since many of higher level college courses have several prerequisites attached to them, candidates seeking alternative certification may have difficulty completing certification requirements through existing courses, and, therefore, may have to rely on independent special topics courses. Special topics courses are not generally part of teacher education accredited programs, and therefore do not require submission of assessments and data to demonstrate standards for knowledge, skills, and dispositions are met, as is required for teacher education programs to be nationally recognized by NCATE.

Additionally the standards for field experiences for multiple certification routes vary. Those candidates who complete an accredited program in Maryland must complete a 100 consecutive day internship. Internship data are submitted to accreditation teams to demonstrate candidates have the appropriate knowledge, skills, and dispositions (Maryland Public Schools, 2006). In contrast, the Code of Maryland Regulations simply require alternative certification candidates to complete a field experience or one year of satisfactory teaching. The internship data or proof of knowledge, skills, and dispositions are not submitted (Code of Maryland Regulation 13a.12.02.06 and 13a.12.02.18).

While NCATE's standards for dispositions do not address each of the dispositions participants of this study identified as important, they at least require the disposition for fairness and the belief that all children can learn. Alternative certification via transcript analysis in the state of Maryland does not require the assessment of any dispositions to teach, so it appears as though there is a significant double-standard in certification 
requirements. It is unclear why requirements for traditional certification eligibility require completion of an "accredited teacher education program" if the alternative route simply requires a bachelor's degree and coursework that is not subject to the scrutiny of an accreditation agency or to standards that address knowledge, skills, and dispositions in a similar manner. Candidate knowledge is assessed through the Praxis II exams (which are required for both alternative certification and traditional certification), but skills and dispositions are not. If the purpose of alternative certification is to put "credentialed" teachers in classrooms, it seems as though two thirds of the credentials required for those who are traditionally certified are irrelevant for those who are alternatively certified through transcript analysis. The amount of time, energy, and resources students, faculty, and administration commit to meeting standards for accreditation and to ensure high quality educators are being developed seems to pale in comparison to what is required for alternative certification.

If alternative certification routes continue to exclude requirements for the evaluation dispositions, a person who is removed from teacher preparation program because of dispositional deficiencies could potentially become certified through an alternative certification route - completely bypassing the issue with his/her dispositional deficiencies, and thereby render the efforts of teacher preparation institutions to improve teacher quality meaningless. A teacher who is "credentialed" through alternative certification may or may not have the critical dispositions to teach, but without assessments the dispositions of credentialed teachers is unknown. If Breese and Nawrocki-Chabin's (2007) beliefs about dispositions and social cognitive theory are on target, guidance and nurturing of dispositions is critical. Without a system for developing 
candidate awareness of dispositions, and without a person observing, assessing, and monitoring their development, is there an increased risk of credentialing a teacher whose dispositions are not as developed as one would expect of a new teacher? Without equitable standards and practices for certification in place, states cannot be sure that all “credentialed" teachers, have been screened for dispositional deficiencies. Additionally, without assessments of all teachers, it is unclear whether alternative or traditional certification routes produce candidates who have the appropriate dispositions to teach.

If dispositions are truly important in education, every effort should be made to ensure all teachers develop the dispositions necessary to meet the needs of diverse populations of students. If alternative certification and traditional certification produce teachers of the same quality, then should teacher education institutions challenge certification practices? The amount of time, energy, and finances it takes a teacher education institution to prove to accreditors that assessments and data meet standards for credentialing teachers, seems excessive when compared with the minimal requirements for teachers to be credentialed through alternative certification. Which method is the most effective? States should determine an acceptable standard for teacher quality and then determine equitable pathways for certification. While alternative certification routes may be necessary, the expectations for applicant knowledge, skills, and dispositions should be comparable to the expectations for graduates of an accredited teacher education institution, and vice versa.

Teacher education institutions should take a leadership role and challenge the state departments of education to tighten standards for certification to ensure all teachers are qualified, not only in the area of knowledge, but also in the areas of disposition and 
skill. Teacher education institutions and state boards of education must devote resources to determine the most significant dispositions required for all educators and for specific fields of education, and to determine equitable standards for certification to address knowledge, skills and dispositions.

\section{Specific fields and dispositions needed.}

When respondents were asked to list specific dispositions important to Health and Physical Education and to list specific dispositions important to all areas of education, the purpose was to determine if there is a possibility that a "one size fits all" approach to dispositions expectations is appropriate, or if there are different dispositional needs for teaching Health and Physical Education. While the data show a very clearly aligned pattern of frequency by category of disposition between all areas of education and Health and Physical Education, when the frequency of specific dispositions within each category is examined, there appears to be some obvious differences. The most dramatic difference is seen within the category of Personable Qualities that Make One Approachable to Students. A large number of responses to what is important in Health and Physical Education included variations of being healthy and fit, but being healthy and fit did not appear with frequency for what is important to all educators. This is a very clear indication that respondents expect HPE teachers to "practice what they preach". They want to be taught how to be healthy by a teacher who is actually healthy.

While current NASPE Standards for Physical Education dictate some degree of fitness and skill is needed in physical education candidates, it is up to individual programs to determine the level of fitness and types skills expected. In contrast AAHE 
Standards for Health Education do not reflect any requirements for candidates to serve as healthy role-models.

In order to meet NASPE Standards, the institution surveyed has begun collecting assessment data on a variety of candidate skills, such as throwing, catching, fielding, striking, various dance steps, etc. They have also begun assessing candidate fitness using FitnessGram assessments for cardiovascular endurance, muscular endurance, muscular strength, and flexibility. At this point, candidates who do not demonstrate acceptable levels of skill and fitness are required work to improve scores and be reevaluated at a later time. Consideration is being given to consequences for those who demonstrate significant deficiencies.

Other large differences in the frequency of the identification of specific dispositions important to HPE versus all areas of education include knowledge, and safe environment, both of which were more frequently identified for HPE; and professionalism, dedication, likes kids, and general response to challenges, which were more frequently identified for all areas of education.

\section{Implications}

The results of this research have numerous implications for teacher education, accreditation, and certification. It is important to understand that these are interrelated but below I will spend time on each.

\section{Implications for teacher education.}

First, all teacher education institutions need to clearly operationalize a definition of dispositions. Then institutions need to ensure that higher education faculty, PK-12 personnel, and education students are fully aware of what a disposition is. Each 
institution should then clearly identify dispositions important for their programs (individually and collectively), and the school systems it serves. This research can be used as a guide for discussion about important dispositions and can be used foundational document to be modified based on the individual needs of programs and institutions. Once a core set of dispositions has been identified, then lessons and assessments can be developed to monitor dispositions. Institutions should involve stakeholders in discussions about policies and procedures for monitoring dispositions and determining consequences for candidates who demonstrate deficiencies.

The lines of communication between PK-12 and higher education are critically important for improving the development and monitoring the progress of dispositions in candidates. Additionally, improved communication will help ensure each group is kept abreast of current needs and changes as they develop. Expectations for candidates need to be clearly articulated to both the candidates and to the mentor teachers, and consistency and clarity in terminology used needs to be a priority in order to streamline efforts for improvement.

Additionally, when considering the complex nature of dispositions, as alluded to by Diez (2007) and Combs (1973), teacher preparation institutions should reevaluate the way they address dispositions. While checklists and structured rubrics provide data sets for accreditors, the open systems theory suggests there are numerous factors that impact behavior and a behavior is not necessarily indicative of a person's dispositions (Combs, 1973). When considering teacher quality, should we evaluate dispositions based on the whole teacher and his/her ability to be effective, rather than easily identifiable, simplistic, observable behaviors that tend to require less difficulty in evaluating? 
If consideration is given to Bandura's principles of social learning in relationship to teacher training, institutions should create opportunities to model dispositions, have candidates identify them, practice them, and self-evaluate their performance for motivation for improvement and self-efficacy. Additionally, questions for consideration include the following:

- What kind of teacher educator and mentor teacher professional development is needed to ensure awareness of the types of dispositions expected of candidates?

- What kind of teacher educator and mentor teacher professional development is needed to determine the best methods for create opportunities for candidates to observe, identify, practice, and self-evaluate dispositions?

- What information do mentor teachers need to have regarding each candidate's unique dispositions prior to the internship experience?

- What are the best ways to ensure that mentors are able to model desirable dispositions for teacher candidates?

- What are the implications when the number of mentor teachers within the PDS network is limited for specialty areas (such as Health, Physical Education, Art, Music) and when the mentor teachers within the PDS network do not have the desired dispositions? How will modeling take place? What are the potential solutions?

\section{Implication for teacher education accreditation.}

Accreditation standards should be restructured to reflect what is important for teacher quality. Clearly participants of this study feel numerous dispositions are 
important, rather than only fairness and the belief that all students can learn.

Accreditation agencies need to facilitate further research and training in the area of dispositions and provide examples to institutions for how to develop, assess, and monitor dispositions.

Given the lack of guidance from NCATE, teacher preparation institutions are faced with the challenge of how to address deficiencies. What guidance is given to institutions when candidates show deficiencies? How are data to be used? Should candidates be dismissed from programs? Should they be delayed from progressing through programs? At what point are decisions for dismissal/delayed progression determined? What should be done when a candidate shows little evidence of having essential dispositions that are considered innate, or slow-developing? What happens if the dispositional deficiencies of a candidate will take more than the few years to develop? What guidance is given to teacher preparation institutions for reflecting dispositional deficiencies - should they be reflected in grades, letters of recommendation, or in other ways? Many questions regarding the management of dispositions are unanswered.

\section{Implications for certification practices.}

Requirements for certification need to be completely reevaluated. The disparities between the requirements for traditional certification and alternative certification should be minimized or completely eliminated. The results of this study indicate the perception that dispositions are important for educators. Discussions about certification practices should likely center on developing policies and procedures for ensuring all routes to certification address dispositions. Additionally, the original purpose of alternative certification should be considered. Its original purpose was to credential teachers during 
a time when there was a shortage of traditionally qualified candidates. With differences in requirements for various certification routes, it is unclear whether states requirements achieve their purpose of ensuring quality, particularly if quality of the teacher is measured in terms that span beyond content and pedagogical knowledge.

In the state of Maryland, any certified teacher who can pass the Praxis II exam required for another area of certification, is granted certification in that area. Given the indication from this research that there are dispositions unique to teaching in some fields of education (such as being a healthy role model in Health and Physical Education), this is a practice that needs to be reevaluated. A poorly performing teacher who is certified in one content area should never be permitted or encouraged to take the Praxis II exam to become certified in non-tested subject area simply to, for example, avoid being fired or move to a more desirable teaching position. In this case, the alternative certification route may solve an administrator's dilemma with potentially terminating an employee and moving to a different content area may meet the desires of the employee, but consideration should be given to the likelihood that the employee who is ineffective because of dispositions will likely be equally ineffective in a non-tested area - not because of lack of knowledge, but because of skill-related or dispositions-related deficiencies which are not apparent with licensure exam results. Additionally, the poorly performing employee could potentially transfer into a position for which there is an abundance of high quality candidates who have gone through extensive training, and have met the standards of performance expected for knowledge, skills, and dispositions in a traditional accredited teacher certification program. If the emphasis on certifying 
teachers truly is teacher quality, then teacher quality standards should be consistent for alternative certification and for traditional teacher education programs.

\section{Efficacy and the possibility of advanced dispositions.}

Respondents generally feel the institution's teacher education programs prepare candidates well. Overall mean ratings for each cluster ranged from 3.09 to 3.5 out of 4 , with standard deviations of less than 1 for each cluster. Some of the major specific dispositions to frequently emerge within the category of "Response to Challenges" were classroom management/behavior management/discipline, general response to challenges, maintaining calm/professional attitude, and managing conflict. While participants recognize the importance of "Response to Challenges", the dispositions within the category seem to be among the more advanced dispositions which come with a great deal of real-world experiences. While any quality teacher education program addresses classroom and behavior management, it is virtually impossible for new candidates to balance nervousness, mechanics of teaching, and classroom management or other challenging situations. Generally, when undergraduates teach their first lessons, they teach them in a contrived setting with peers playing the role of the PK-12 learner. In the beginning of a teacher education candidate's experience, the focus is on lesson structure, delivery, and procedure. Classroom management techniques are taught throughout programs, but are given much less consideration as candidates acquire basic teaching skills. Gradually, classroom management becomes more of a focus and candidates begin "practicing" management techniques through role-play, practice teaches, and experiences with P-12 learners during field experiences. During their final semesters, undergraduate students seeking initial certification complete a 100 day internship in the public schools. 
It is during these 100 days when students are given the most authentic opportunities to develop classroom management/behavior management/disciplinary skills and dispositions, as well as respond to authentic challenges which require decision-making, conflict resolution, and a calm, professional attitude. Unfortunately, while the importance of "Responding to Challenges" is acknowledged by all three treatment groups, it is likely the last of the dispositions to develop in candidates because of the need for candidates to first gain experiences and build confidence in teaching. The same could be said for graduate programs where practicum experiences occur toward the end of the candidates' experiences. Regardless of the possible reasons for "Responding to Challenges" receiving the lowest ratings, further discussion among the institution's teacher education faculty and stakeholders could help further clarify issues associated with developing some dispositions as well as solutions to address needs.

The second and third lowest efficacy mean ratings were for the cluster related to building rapport with the entire educational community and for managing resources. Each of these dispositions clusters seem to be the types of dispositions that develop after the basic skills of teaching are mastered. It is logical for both of these clusters would receive lower ratings.

\section{Recommendations for Future Research}

The exploratory nature of this research lends itself to numerous follow up studies. Below are recommendations for future areas of research:

1. What is the impact of teacher dispositions on students?

Participants in this study clearly feel dispositions are important for teachers. However, the connection between what we think is important and what actually is 
important for effectiveness in the classroom should be explored. An interesting study would use a broad definition of teacher effectiveness to examine the impact of teacher dispositions on the student as a person, as well as on students' standardized test scores. For example, what impact do teacher dispositions have on student confidence, attitude about learning, socializing with others, assertiveness, creativity, work ethic, etc.

\section{What are the dispositions that should be minimally required for admission into a} teacher education program?

One question raised by educators is whether or not dispositions are innate or learned (Helm, January/February 2006). If some dispositions are both innate and considered essential to working in education, then minimal admissions requirements could serve to reduce the number of candidates who are either dismissed from or drop out of a program. Additionally, if some dispositions can be learned, but develop over long periods of time, then consideration should be given to the likelihood that the applicant will be able to develop the essential dispositions to teach.

\section{What are the dispositions unique to various fields of education?}

NCATE requires dispositions to be systematically assessed across all teacher education programs in the unit. However this research study indicated differences in dispositions important in Health and Physical Education in comparison to all fields of education. Further research is needed to explore each aspect of education to determine unique dispositions that may make one more effective. For example, there are likely vast differences in the dispositions required to teach kindergarten, to teach high school calculus, to serve as an administrator or supervisor, and to teach students who have behavioral disorders. This research would serve to inform teacher education institutions 
and provide guidance for program assessments. Additionally, the results will have implications for specialized program standards for accreditation and would allow them to clearly delineate the types of dispositions critical to individual fields of education.

4. Are there differences in the dispositions of traditionally trained teachers and alternatively trained teachers? Are there differences in teachers who have field experiences in PDS schools versus non-PDS schools?

Alternative certification routes were intended to help place qualified teachers in classrooms. This dissertation clearly indicated that teacher dispositions are perceived to be important by those who work/plan to work in education. Currently, alternative certification in the state of Maryland does give consideration to teacher disposition. If research indicates that teacher effectiveness is compromised because alternatively certified teachers are dispositionally deficient, then policies for alternative certification need to be revised to address dispositions and support should be provided to help improve deficiencies of those currently in the field. If, research shows that alternatively certified candidates have comparable or more desirable dispositions than those traditionally trained, then current traditional certification practices and accreditation policies should be reevaluated. 


\section{References}

American Association for Health Education. (2008). 2008 NCATE health education teacher preparation standards. Retrieved January, 24, 2010 from http://www.aahperd.org/aahe/events/accreditation/upload/aahe-and-ncate-2008standards.pdf.

Baltimore County Public Schools Offices. Frequently asked questions about certification. Retrieved November 21, 2011 from http://www.bcps.org/offices/personnel/certification/faq.html

Bandura, A. (1997). Self-efficacy: The exercise of control. New York: Freeman.

Birch, S. H., \& Ladd, G. W. (1997). The teacher-child relationship and children's early school adjustment. Journal of School Psychology, 3, 5, 61-79.

Breese, L. \& Nawrocki-Chabin, R. (2007). Social cognitive perspective. In Dispositions in teacher education, eds. M. E. Diez and J. Raths, 31-52. Charlotte, NC: Information Age Publishing.

Burke, P. (2002). A mechanism for monitoring dispositions in pre-service teachers. Childhood Education, 78, 4, 224-225.

Buss, D. \& Craik, K. (1983). The act frequency approach to personality. Psychological Review, 90, 105-126.

Center for School Mental Health Analysis and Action. (2005). Enhancing student connectedness to schools. Retrieved March 24, 2011 from http://csmh.umaryland.edu/resources/CSMH/briefs/CaringConnectednessBrief.pd f.

Centers for Disease Control and Prevention. (2007). National Health Education Standards, second edition. Retrieved on January 24, 2010 from http://www.cdc.gov/HealthyYouth/SHER/standards/index.htm.

Centers for Disease Control and Prevention. (2009). School connectedness: strategies for increasing protective factors among youth. Retrieved on March 26, 2011 from http://cdc.gov/healthyyouth/adolescenthealth/pdf/connectedness.pdf

Centers for Disease Control and Prevention. Coordinated school health. Retrieved on March 22, 2011 from http://cdc.gov/healthyyouth/cshp/index.htm.

Centers for Disease Control and Prevention. Helping your child feel connected to school. Retrieved on March 24, 2011 from http://cdc.gov/healthyyouth/AdolescentHealth/pdf/connectedness_parents.pdf. 
Centers for Disease Control and Prevention. Student health and academic achievement. Retrieved on March 22, 2011 from http://cdc.gov/healthyyouth/health_and_academics/index.htm.

Code of Maryland Regulation 13a.12.02.06. Retrieved on November 22, 2011 from http://www.dsd.state.md.us/comar/comarhtml/13a/13a.12.02.06.htm

Code of Maryland Regulation 13a.12.02.18. Retrieved on November 22, 2011 from http://www.dsd.state.md.us/comar/comarhtml/13a/13a.12.02.18.htm

Combs, A. W. (1973). Educational accountability from a humanistic perspective. Educational Researcher, 2, 9, 19-21.

Combs, A. W. (1974). Humanizing the education of teachers. Theory Into Practice, 18, 2, 123-129.

Combs, A. W. (2006). Being and Becoming: A Field Approach to Psychology. New York: Springer Publishing Company.

Combs, A. W., Soper, D. W., Gooding, C. T., Benton, J. A., Dickman, J. F., \& Usher, R. H. (1969). Florida studies in the helping professions. Retrieved November 27, 2011 from http://fieldpsychtrust.org/florida_studies.pdf.

Council for the Accreditation of Educator Preparation. (2010). NCATE and TEAC form new accrediting body: the council for the accreditation of educator preparation (CAEP). Retrieved on November 1, 2011 from http://www.caepsite.org/documents/102210_newsrelease_caep.pdf

Darling-Hammond, L. (2000). Teacher quality and student achievement: A review of state policy evidence. Education Policy Analysis Archives, 8, 1.

Da Ross-Voseles, D., and Moss, L., (2007). The role of dispositions in the education of future teachers. YC Young Children, 62, 5, 90-98.

Diez, M. (2007a). Assessing dispositions: contexts and questions. In Dispositions in Teacher Education, eds. M. E. Diez and J Raths, 183-201. Charlotte, NC: Information Age Publishing.

Diez, M. (2007b). The role of coaching in working with dispositions. In In Dispositions in Teacher Education, eds. M. E. Diez and J Raths, 203-218. Charlotte, NC: Information Age Publishing. 
Diez, M. (2007c). Looking back and moving forward: three tensions in the teacher dispositions discourse. Journal of Teacher Education, (8)5, 388-396.Diez, M., \& Raths, J. (2007).

Edwards, S., Edick, N. (2006). Dispositions matter: Findings for at-risk teacher candidates. The Teacher Educator, 42, 1, 1-14.

Flowers, C. (2006). Confirmatory factor analysis of scores on the Clinical Experience Rubric: a measure of dispositions for pre-service teachers. Educational and Psychological Measurement, 66, 3.

Freeman, L. (2007). An overview of dispositions in teacher education. In Dispositions in teacher education, eds. M. E. Diez and J. Raths, 3-29. Charlotte, NC: Information Age Publishing.

Frostburg State University Institutional Report. Retrieved January 14, 2009 from http://www.frostburg.edu/colleges/coe/unit_information/FSU\%20IR.pdf.

Ginsberg, R., \& Whaley, D. (2006). The disposition on dispositions. The Teacher Educator, 41,4, 269-275.

Harme, B. K., \& Pianta, R. C.(2001). Early teacher-child relationships and the trajectory of children's school outcomes through eighth grade. Child Development, 72, 62538.

Harrison, J., McAffee, H., Smithey, G., \& Weiner, C. (2006). Assessing candidate disposition for admission into teacher education: can anyone teach? Action in Teacher Education, 27, 4.

Helm, C. (2006a). Teacher dispositions as predictors of good teaching. The Clearing House, 79,3, 117-118.

Helm, C. (2006b). The assessment of teacher dispositions. The Clearing House, 79, 6, 237-240.

Helm, C. (2007). Teacher dispositions affecting self-esteem and student performance. The Clearing House, 80, 3, 109-110.

Heybach, J. (2009). Rescuing social justice in education: A critique of the NCATE controversy. Philosophical Studies in Education. 40, 234-245.

Hillman, S., Rothermel, D. \& Sarano, G. The assessment of pre-service teachers' dispositions. The teacher educator, 41, 4, 234-246.

Honawar, V., (2008). Teacher education community is striving to interpret candidate 'dispositions'. Education Week, 27, 28, 1-13. 
Katz, L., \& Raths, J. (1985). Dispositions as goals for teacher education. Teaching \& Teacher Education, 1, 4, 301-307.

Ladson-Billings, G. (1995). Toward a theory of culturally relevant pedagogy. American Education Research Journal, 32, 3, 465-491.

Lourdusamy, A., Toh, K. A., \& Wong, J. (2001). What counts in teacher education: student teachers' perspective in two settings. Journal of Applied Research in Education, 5, 1, 35-44.

Lund, J., Wayda, V., Woodard, R., \& Buck, M. (2007). Professional Dispositions: What are we teaching prospective physical education teacher? Physical Educator, 64, 1, $38-47$.

Manzo, K. (2006). Teacher hopeful runs afoul of 'dispositions'. Education Week, 25, 1, 5-15.

Marx, E., Northrop, D., \& Wooley, S. (1998). Health is academic. New York, NY: Teachers College Press.

Maryland Public Schools (1994). Essential dimensions of teaching. Retrieved January 19, 2009 from http://www.marylandpublicschools.org/nr/rdonlyres/2c7ffcc4-3f21-4b62-9406311b06cdf2db/1500/edot1994.pdf

Maryland Public Schools (1995). Maryland higher education commission teacher education task force. Retrieved January 19, 2009 from http://www.marylandpublicschools.org/NR/rdonlyres/2C7FFCC4-3F21-4B629406-311B06CDF2DB/1496/Redesign_Teacher_Ed.pdf.

Maryland Public Schools (2006). Teacher preparation approval and accreditation advisory committee final report. Retrieved January 19, 2009 from http://www.marylandpublicschools.org/NR/rdonlyres/2C7FFCC4-3F21-4B629406-311B06CDF2DB/12564/TeachPrepAdvisoryFinalReport.pdf.

Maryland Public Schools. (n.d.). Retrieved November 27, 2011, from Professional Development Schools: Implementation Manual: http://www.msde.maryland.gov/NR/rdonlyres/75608A85-6909-4BE3-A4D8D08C759D0A5A/2930/ImplementationManualReprint2004.pdf

Maryland State Department of Education. Maryland program approval of college/university based teacher preparation programs. Retrieved November 23, 2011 from http://marylandpublicschools.org/MSDE/divisions/certification/progapproval/Pro gram_Approval_Section.htm. 
Maryland State Department of Education. Profile 6. Retrieved on November 22, 2011 from http://marylandpublicschools.org/MSDE/divisions/certification/certification_bran ch/ inf/apply/docs/obtain_6.htm

Marzano, R. J. (2003). Classroom management that works: Researched-based strategies for every teacher. Alexandria, VA: ACSD.

McCombs, B. L. (1998). Integrating metacognition, affect, and motivation in improving teacher education. In M. Lambert \& B. L. McCombs (Eds.), Reforming schools through learner-centered education, 379-408. Washington DC: APA.

National Association of Sport and Physical Education. (2008). National Initial Physical Education Teacher Education Standards. Retrieved January, 24, 2010 from http://www.aahperd.org/naspe/grants/accreditation/upload/2008-National-InitialPETE-Standards.pdf.

National Council for Accreditation of Teacher Education. 15 years of growth. Retrieved January 19, 2009 from http://ncate.org/documents/15YearsofGrowth.

National Council for Accreditation of Teacher Education. (2001). Professional standards for the accreditation of schools, colleges, and departments of education. Washington, DC: NCATE.

National Council for Accreditation of Teacher Education. (2006). A statement from NCATE on professional dispositions. Retrieved January 19, 2009 from http://www.ncate.org/public/0616_messageawise.asp?ch=150.

National Council for Accreditation of Teacher Education. (2008). Professional standards for the accreditation of schools, colleges, and departments of education. Washington, DC: NCATE.

National Council for Accreditation of Teacher Education (2011). Update on CAEP transition. Retrieved on November 1, 2011 from http://ncate.org/Public/Newsroom/NCATENewsPressReleases/tabid/669/EntryId/ 159/Update-on-CAEP-Transition-October-2011.aspx.

National Council for Accreditation of Teacher Education. About NCATE. Retrieved November 23, 2011 from http://ncate.org/Public/AboutNCATE/tabid/179/Default.aspx.

National Council for Accreditation of Teacher Education. Glossary. Retrieved November 22,2011 from http://ncate.org/Standards/NCATEUnitStandards/NCATEGlossary/tabid/477/Def ault.aspx. 
National Council for Accreditation of Teacher Education. Glossary. Retrieved January 19, 2009 from http://ncate.org/institutions/glossary.asp?ch=4\#U.

National Council for Accreditation of Teacher Education. Program Standards and Report Forms. Retrieved on November 23, 2011 from http://ncate.org/Standards/ProgramStandardsandReportForms/tabid/676/Default.a spx\#AAHE

Olsen, J., Clough, M., \& Penning, K. (2009). Prospective elementary teachers gone wild? An analysis of Facebook self-portrayals and expected dispositions of preservice elementary teachers. Contemporary Issues in Technolgy and Teacher Education, 9,4.

Osguthorpe, R. (2008). On the reasons we want teachers of good disposition and moral character. Journal of Teacher Education. 59, 4, 288-299.

Raths, J. (2007). Experiences with dispositions in teacher education. In Dispositions in Teacher education, ed. M. E. Diez and J. Raths, 15-30

Reynolds, A. (1992). What is competent beginning teacher? A review of literature. Review of Educational Research, 62, 1, 1-35.

Rike, C., and Sharp, K. (2008). Assessing preservice teachers' dispositions: a critical dimension of teacher preparation. Childhood Education, 84, 3.

Rinaldo, V., Dening, S., Sheeran, T., Cramer-Benjamin, R., Bermette, P., Foote, C., \& Smith, R. (2009). Developing the intangible qualities of good teaching: a selfstudy. Education, 130, 1, 42-52.

Ritchhart, R. (2001). From IQ to IC: a dispositional view of intelligence. Roeper Review, 23, 3, 143-151.

School Employee Wellness. School employee wellness: a guide for protecting the assets of our nation's schools. Retrieved on March 24, 2011 from http://www.schoolempwell.org/articles/EntireGuide.pdf.

Schussler, D., Bercaw, L., \&Stooksberry, L., (2008). The fabric of teacher candidate dispositions: what case studies reveal about teacher thinking. Action in Teacher Education, 29, 4.

Shiveley, J., \& Misco, T. (2010). But how do I know about their attitudes and beliefs?: A four-step process for integrating and assessing dispositions in teacher education. The Clearing House, 83, 1, 9-14.

Smith, R., Skarbek, J., \& Hurst D. (2005). The passion of teaching: dispositions in the 
schools. Lanham, MD: Scarecrow Education.

Sockett, H., (2006). Teacher dispositions: building a teacher education framework of moral standards. Washington, DC: American Association for Colleges of Teacher Education.

Stoddard, K., Braun, B., Dukes, L. III; \& Koorland, M. A. (2007). Building professional dispositions in pre-service special educators: Assessment and instructional tactics. Journal of University Teaching \& Learning Practice, 4, 1, $27-39$.

Taylor, R. \& Wasisko, M. The dispositions to teach. Retrieved January 14, 2009 from http://www.nku.edu/ education/educatordispositions/resources/The Dispositons to

Thorton, H. (2006). Dispositions in action: do dispositions make a difference in practice? Teacher Education Quarterly, 33, 2, 53-68.

Toh, K. A., Ho, B.T., Chew, M. K. C., \& Riley, J. P. (2003). Teaching, teacher knowledge, and constructivism. Educational Research for Policy and Practice. 2, 195-204.

Usher, D. (2004). Dispositions-centered programs for teacher education. Presented at the Third Annual Symposium on Teacher Educator Dispositions, Eastern Kentucky University, Richmond, KY.

U.S. Department of Education. (2004). Alternative routes to certification. Retrieved on January 3, 2009 from http://www2.ed.gov/admins/tchrqual/recruit/altroutes/report.pdf.

U.S. Department of Education. (2004). New No Child Left Behind flexibility: highly qualified teachers. Retrieved on November 27, 2011 from http://www2.ed.gov/nclb/methods/teachers/hqtflexibility.pdf

U.S. Department of Education. (2006). The secretary's fifth annual report on teacher quality. Retrieved on January 3, 2009 from http://www2.ed.gov/about/reports/annual/teachprep/2006-title2report.pdf.

U. S. Department of Education. (2011). Teacher shortage areas nationwide listing 199091 through 2011-2012. Retrieved on November 21, 2011 from http://www2.ed.gov/about/offices/list/ope/pol/tsa.pdf

U.S. News and World Report. Retrieved on November 27 from http://colleges.usnews.rankingsandreviews.com/best-colleges/alverno-college$\underline{3832}$ 
U.S. News and World Report. Retrieved on November 27 from http://colleges.usnews.rankingsandreviews.com/best-colleges/st.-bonaventureuniversity-2817

Villegas, A. M. (2007). Dispositions in teacher education: A look at social justice. Journal of Teacher Education, 58, 5, 30-380.

Wasicsko, M. (2007). Dispositions - a perceptual approach. In Dispositions in teacher education, ed. M. E. Diez and J Raths, 53-89. Charlotte, NC: Information Age Publishing.

Wasicsko, M., Callahan, C., \& Wirtz, P., (2004). Integrating dispositions into the conceptual framework: four a priori questions. KCA Journal, 23, 1.

Wenzlaff, T., (1998). Dispositions and portfolio development: is there a connection?. Education, 118, 4, 564-572.

Wilkerson, J., \& Lang, S. (2007). Five standards-based steps to valid measurement using the DAATS model. Thousand Oaks: Corwin Press. 
Appendix A: Survey Instrument 


\section{Dispositions in Teacher Education}

\section{Dispositions in Teacher Education}

This survey addresses dispositions that are desired both for Teacher Education students and practicing PK-12 professionals.

\section{* 1. Which of the following BEST describes you?}

$\bigcirc$

Undergraduate student not admitted to Phase I

Undergraduate student admitted to Phase I

Undergraduate student admitted to Phase II

Undergraduate student admitted to Phase III

$\bigcirc$ Graduate student in a Master of Arts in Teaching program (MAT)at FSU

Graduate student in a Master of Education Program at FSU, not currently employed full time by a school system

Graduate student in a Master of Education Program, currently employed full time by a school system

$\bigcirc$ Teacher in a local school, yet NOT enrolled in a graduate program at FSU

$\bigcirc$ PK-12 School guidance counselor

$\bigcirc$ PK-12 School administrator or supervisor

$\bigcirc$ FSU Faculty member

$\bigcirc$ Other (please specify below)

Other (please specify)

* 2. Which of the following BEST describes your major or area of teaching certification? (choose all that apply)

Early Childhood/Elementary

$\square$ Curriculum and Instruction-Elementary

Elementary

$\square$ Curriculum and Instruction-Secondary

Secondary

Educational Technology

PK-12 Art

Reading

PK-12 Music

School Counseling

PK-12 Health and/or Physical Education

Special Education

Administration and Supervision

Other (please specify below)

Other (please specify) 


\section{Dispositions in Teacher Education}

* 3. Are you currently working at a local elementary, middle, or secondary school?

Yes

No 


\section{Dispositions in Teacher Education}

\section{Dispositions in Teacher Education}

* 1. Which of the following grade levels are taught at your school? (check all that apply)

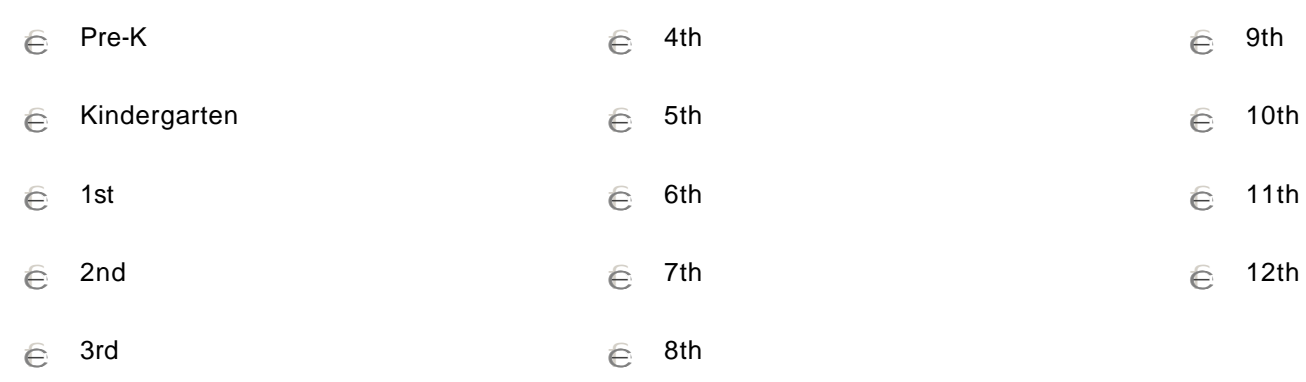

* 2. How many years have you worked in a public school system?
1-2 years
(16-20 years
3-5 years
21-25 years
6-10 years
26-30 years
11-15 years
More than 30 years

* 3. Which of the following subjects or courses have you taught (please check all that apply)?
$\square$ Math
$\square$ Reading
English
$\square$ Social Studies
Science
Art

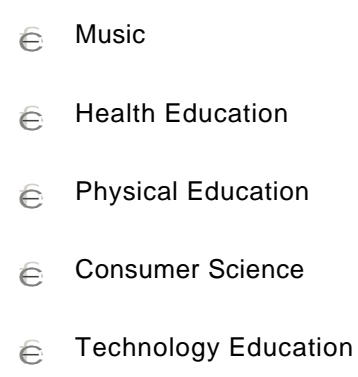

* 4. Which of the following statements BEST reflects the way health education is implemented at your school?

Taught by a certified health education teacher or a health education specialist

Taught by a physical education teacher

Taught by the classroom teacher

$\bigcirc$ Health education is not taught

Other (please specify below)

Other (please specify) 


\section{Dispositions in Teacher Education}

* 5. Which of the following BEST describes how physical education is implemented at your school

Taught by a certified physical educator

Taught by a teacher certified in a field other than physical education

Taught by the classroom teacher

Is not taught

$\bigcirc$ Other (please specify below)

Other (please specify) 


\section{Dispositions in Teacher Education}

\section{Dispositions in Teacher Education}

* 1. Do you currently or have you ever taught at Frostburg State University?

Yes

No 


\section{Dispositions in Teacher Education}

\section{Dispositions in Teacher Education}

* 1. Please select those items that describe either programs in which your FSU students are enrolled or areas in which they have taught? (Check all that apply)

Early Childhood/Elementary Education (undergraduate)

$\square$ Administration and Supervision

Elementary Education (undergraduate)

Curriculum and Instruction-Elementary

Elementary (MAT)

Curriculum and Instruction-Secondary

Secondary Education (undergraduate)

Educational Technology

Secondary Education (MAT)

Interdisciplinary

Art Education (undergraduate)

$\square$ Reading

Art Education (MAT)

School Counseling

Music Education (undergraduate)

Special Education

Health and Physical Education

Other (please specify below)

Other (please specify)

* 2. How would you describe the extent to which you observe or interact with PK-12 school age children in a school or school-like setting?

Daily

Several times per week

Once per week

One or two times per month

Parely

$\bigcirc$ Never

\section{* 3. Do you work full-time or part-time/adjunct at FSU?}

Full time (tenured, tenure-track, or full-time contractual)

Part time or adjunct 


\section{Dispositions in Teacher Education}

* 4. Please give examples of how you address dispositions in (some or all of) your courses. If you do not address dispositions in any way, put "N/A".

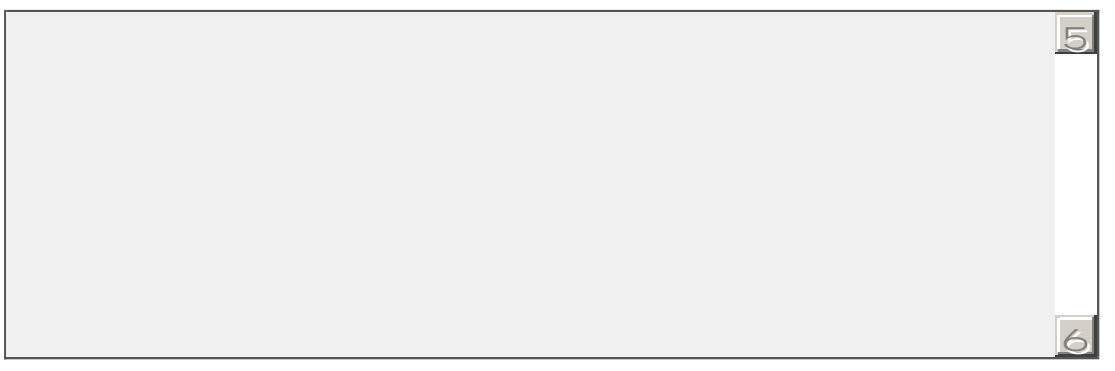




\section{Dispositions in Teacher Education}

\section{Dispositions in Teacher Education}

* 1. Have you completed/are you enrolled in an UNDERGRADUATE program at FSU?

Yes (Please indicate major and graduation date/anticipated graduation date below)

No

If yes, please indicate your major and graduation date/anticipated graduation date (Ex. Elementary, Spring 2010)

* 2. Have you completed/are you enrolled in a GRADUATE program at FSU?

Yes (please indicate major and graduation date/anticipated graduation date below)

$\bigcirc$ No

If yes, please list major and graduation date/anticipated graduation date (ex. A \& S, Spring 2010) 


\section{Dispositions in Teacher Education}

\section{Dispositions in Teacher Education}

1. For each of the following questions, select the response that best describes your perception of importance.

How important do you feel Health Education is to a PK-
12 student's overall education?
How important do you feel Physical Education is to a
PK-12 student's overall education?

Please comment on either of your responses (optional) 


\section{Dispositions in Teacher Education}

\section{Dispositions in Teacher Education}

* 1. The items below reflect general types of dispositions that PK-12 educators may possess. Please rate the relative importance of each of these items as they relate to teachers and other education professionals.

Educator responds to students' social and educational needs

Educator builds rapport with entire educational community (including students, parents, etc.)

Educator exhibits personable qualities that make her/him approachable to students

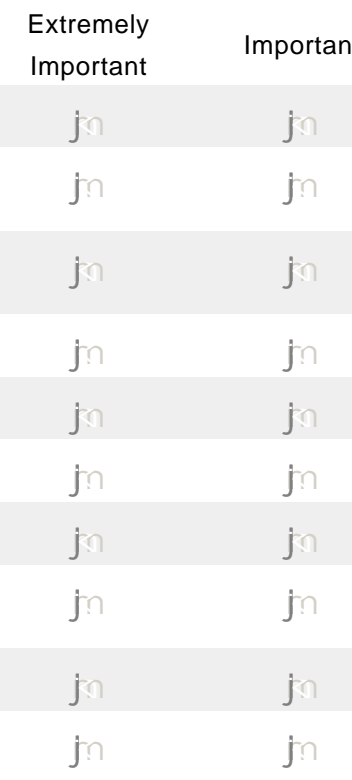

Educator communicates enthusiasm to students

Educator exhibits psychosocial maturity

Educator exhibits appropriate appearance and personal hygiene

Educator demonstrates awareness of one's own strengths and limitations

Educator is capable of responding appropriately to challenging

situations

Educator effectively manages resources

Educator exhibits professionalism

A Little Important

Not at All

Important
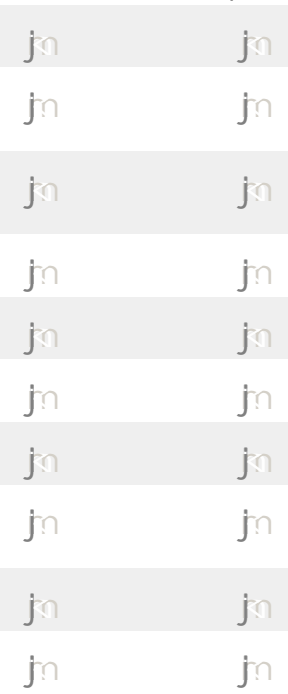

2. The prior question asked you to consider general categories of dispositions in relation to all areas of $\mathrm{K} 12$ Education. For this question below, consider more specifically the area of Health and Physical Education. List below (up to 15) specific dispositions that you believe are necessary for teaching Health and Physical Education in the K12 setting. Please list very specific dispositions as opposed to general categories.

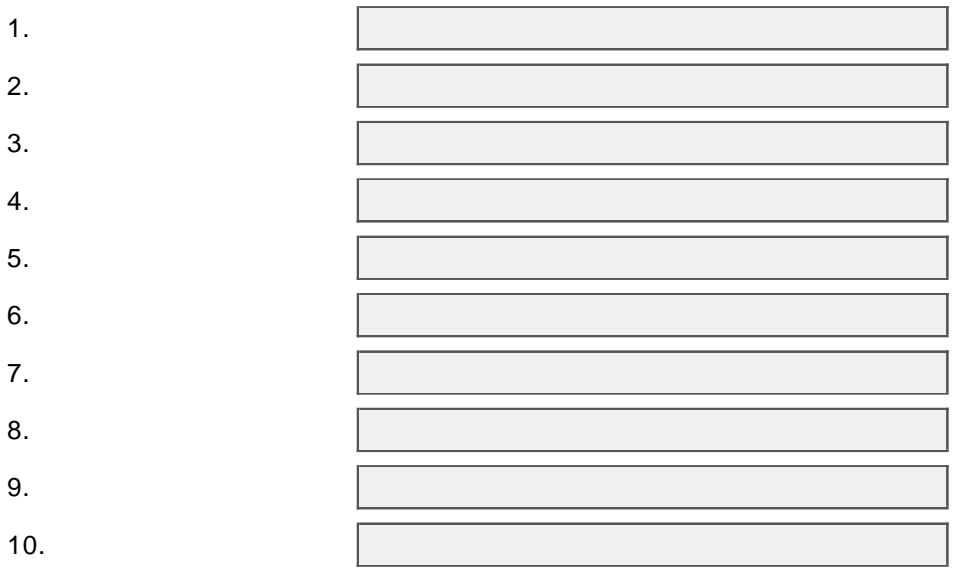




\section{Dispositions in Teacher Education}

\section{Dispositions in Teacher Education}

* 1. The items below reflect general categories of dispositions that K12 educators might possess. For each of the items, please rate how well the Frostburg State University College of Education Curriculum helps students develop these dispositions.

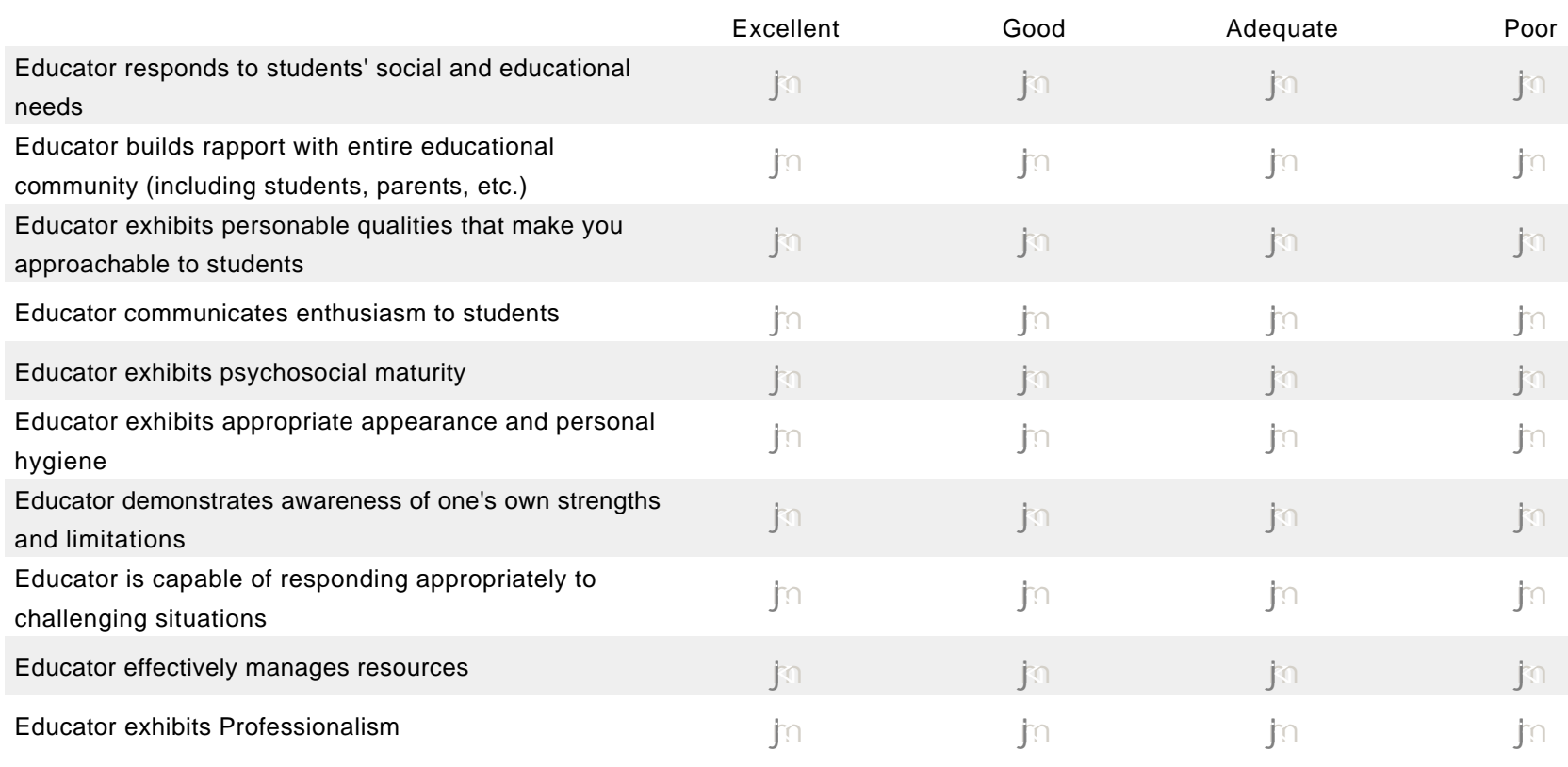

2. For this question, please consider those dispositions you believe a student should have BEFORE being admitted to any Teacher Education program. Please list up to 10 specific dispositions that are the most important for students to have before starting a Teacher Education program. (If you feel there are no dispositions that should be required for admission to a teacher education program, please respond "none" in the first space.)

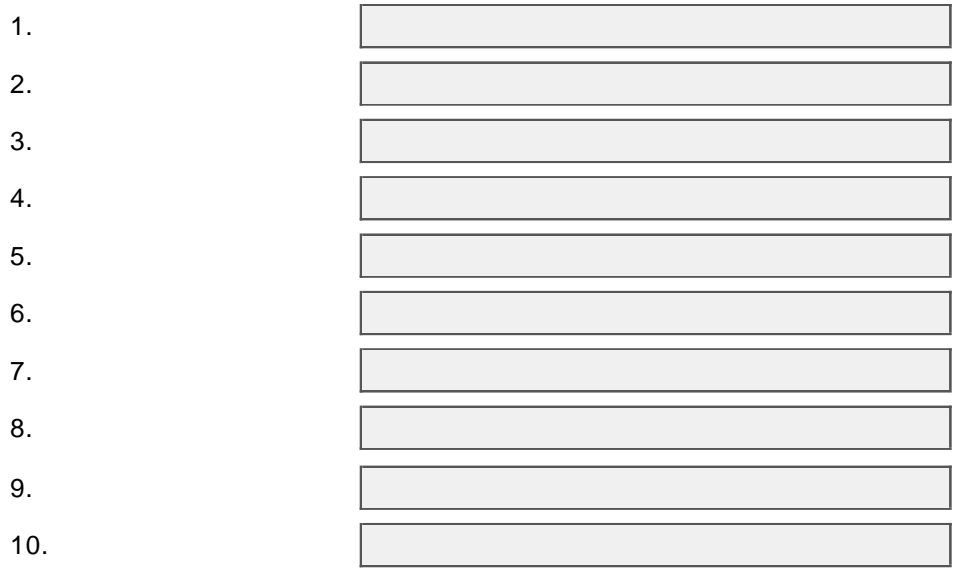




\section{Dispositions in Teacher Education}

\section{Dispositions in Teacher Education}

1. Please include in the space below any general comments you may have regarding dispositions needed for teaching in Health and/or Physical Education.

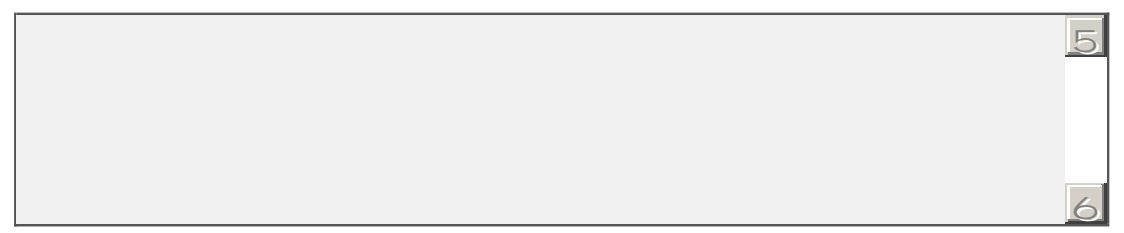

2. Thank you for your participation in this survey. If you are willing participate in a follow-up study, if needed, please provide your email address in the comment box below.

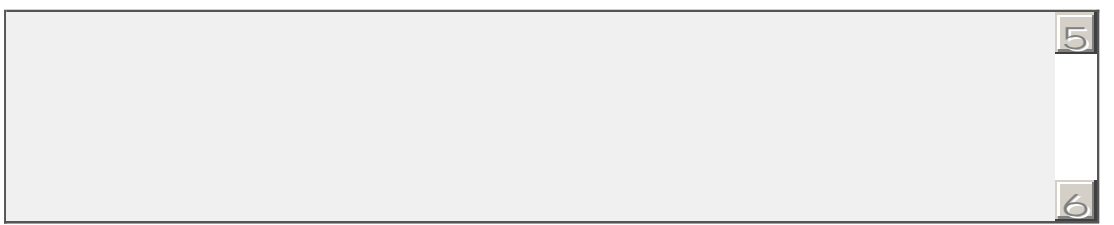


Appendix B: SPSS Data Tables 
A.1 Descriptive Statistics

Descriptive Statistics

\begin{tabular}{|c|c|c|c|c|c|}
\hline & $\mathrm{N}$ & Minimum & Maximum & Mean & Std. Deviation \\
\hline $\begin{array}{l}\text { Educator responds to students' } \\
\text { social and educational needs }\end{array}$ & 220 & 2.00 & 4.00 & 3.8273 & .39074 \\
\hline $\begin{array}{l}\text { Educator builds rapport with entire } \\
\text { educational community (including } \\
\text { students, parents, etc.) }\end{array}$ & 220 & 2.00 & 4.00 & 3.7182 & .46093 \\
\hline $\begin{array}{l}\text { Educator exhibits personable } \\
\text { qualities that make her/him } \\
\text { approachable to students }\end{array}$ & 220 & 2.00 & 4.00 & 3.8455 & .38668 \\
\hline $\begin{array}{l}\text { Educator communicates enthusiasm } \\
\text { to students }\end{array}$ & 220 & 1.00 & 4.00 & 3.8682 & .38922 \\
\hline $\begin{array}{l}\text { Educator exhibits psychosocial } \\
\text { maturity }\end{array}$ & 220 & 3.00 & 4.00 & 3.8000 & .40091 \\
\hline $\begin{array}{l}\text { Educator exhibits appropriate } \\
\text { appearance and personal hygiene }\end{array}$ & 220 & 2.00 & 4.00 & 3.8000 & .41214 \\
\hline $\begin{array}{l}\text { Educator demonstrates awareness } \\
\text { of one's own strengths and } \\
\text { limitations }\end{array}$ & 220 & 2.00 & 4.00 & 3.7591 & .44941 \\
\hline $\begin{array}{l}\text { Educator is capable of responding } \\
\text { appropriately to challenging } \\
\text { situations }\end{array}$ & 220 & 3.00 & 4.00 & 3.8409 & .36659 \\
\hline $\begin{array}{l}\text { Educator effectively manages } \\
\text { resources }\end{array}$ & 220 & 2.00 & 4.00 & 3.6273 & .49397 \\
\hline Educator exhibits professionalism & 220 & 2.00 & 4.00 & 3.8773 & .34248 \\
\hline $\begin{array}{l}\text { Educator responds to students' } \\
\text { social and educational needs }\end{array}$ & 191 & 1.00 & 4.00 & 3.3037 & .72688 \\
\hline $\begin{array}{l}\text { Educator builds rapport with entire } \\
\text { educational community (including } \\
\text { students, parents, etc.) }\end{array}$ & 191 & 1.00 & 4.00 & 3.1466 & .78101 \\
\hline $\begin{array}{l}\text { Educator exhibits personable } \\
\text { qualities that make you } \\
\text { approachable to students }\end{array}$ & 191 & 1.00 & 4.00 & 3.2356 & .79604 \\
\hline $\begin{array}{l}\text { Educator communicates enthusiasm } \\
\text { to students }\end{array}$ & 191 & 1.00 & 4.00 & 3.4398 & .67690 \\
\hline
\end{tabular}




\begin{tabular}{|c|c|c|c|c|c|}
\hline $\begin{array}{l}\text { Educator exhibits psychosocial } \\
\text { maturity }\end{array}$ & 191 & 1.00 & 4.00 & 3.2304 & 82035 \\
\hline $\begin{array}{l}\text { Educator exhibits appropriate } \\
\text { appearance and personal hygiene }\end{array}$ & 191 & 1.00 & 4.00 & 3.3822 & .79173 \\
\hline $\begin{array}{l}\text { Educator demonstrates awareness } \\
\text { of one's own strengths and } \\
\text { limitations }\end{array}$ & 191 & 1.00 & 4.00 & 3.3089 & .72828 \\
\hline $\begin{array}{l}\text { Educator is capable of responding } \\
\text { appropriately to challenging } \\
\text { situations }\end{array}$ & 191 & 1.00 & 4.00 & 3.0942 & 87751 \\
\hline $\begin{array}{l}\text { Educator effectively manages } \\
\text { resources }\end{array}$ & 191 & 1.00 & 4.00 & 3.1571 & .77896 \\
\hline $\begin{array}{l}\text { Educator exhibits Professionalism } \\
\text { Valid N (listwise) }\end{array}$ & $\begin{array}{l}191 \\
191\end{array}$ & 1.00 & 4.00 & 3.4555 & .75174 \\
\hline
\end{tabular}


Table A.2 Means by Role for Importance

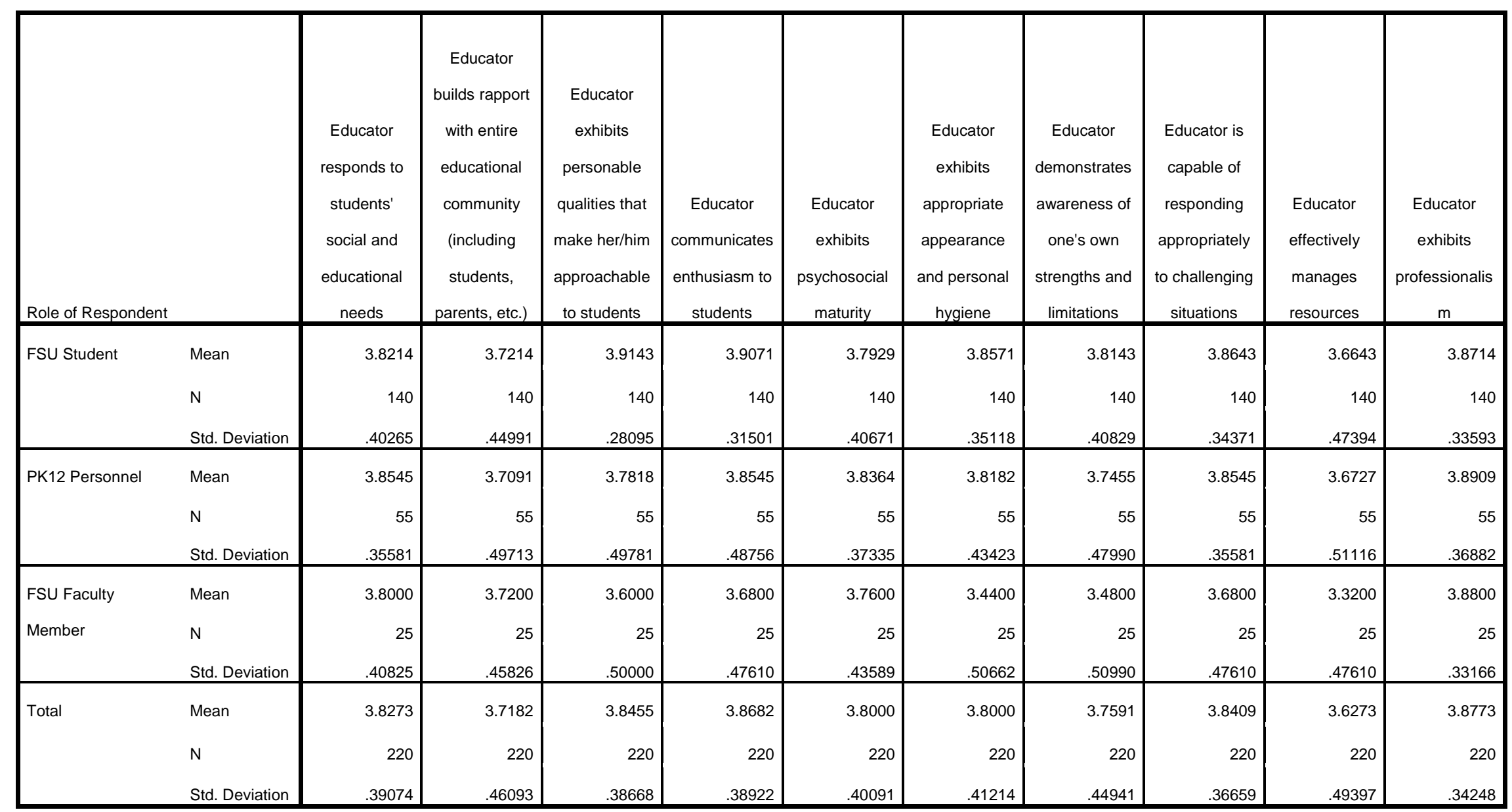


Table A.3 Means by Role for Efficacy

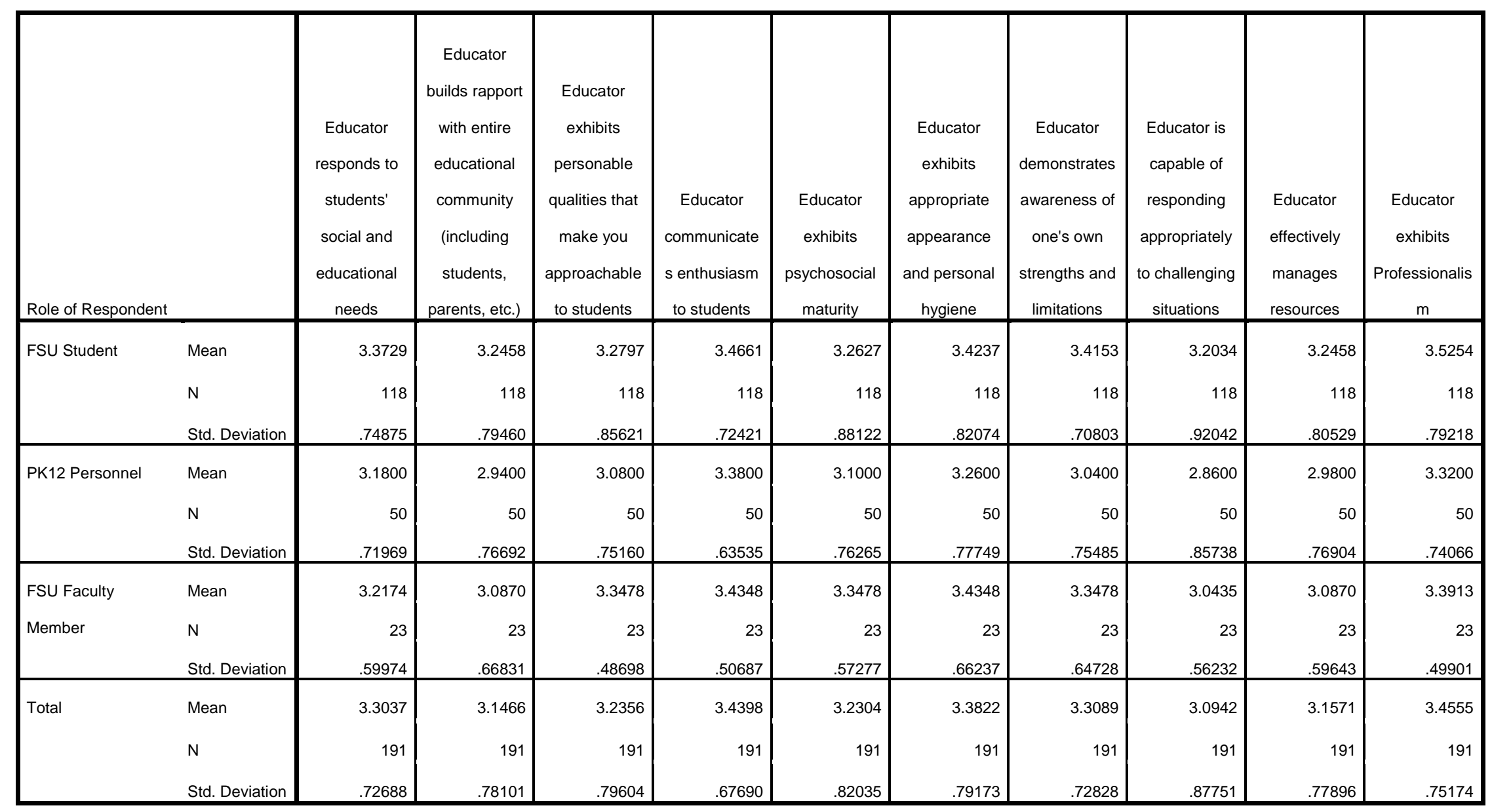


Table A.4 One-Way ANOVA

\begin{tabular}{|c|c|c|c|c|c|c|}
\hline \multicolumn{7}{|c|}{ ANOVA } \\
\hline & & Sum of Squares & $\mathrm{df}$ & Mean Square & $\mathrm{F}$ & Sig. \\
\hline $\begin{array}{l}\text { Educator responds to students' } \\
\text { social and educational needs }\end{array}$ & $\begin{array}{l}\text { Between Groups } \\
\text { Within Groups } \\
\text { Total }\end{array}$ & $\begin{array}{r}.064 \\
33.372 \\
33.436 \\
\end{array}$ & $\begin{array}{r}2 \\
217 \\
219 \\
\end{array}$ & $\begin{array}{l}.032 \\
.154\end{array}$ & .209 & .812 \\
\hline $\begin{array}{l}\text { Educator builds rapport with entire } \\
\text { educational community (including } \\
\text { students, parents, etc.) }\end{array}$ & $\begin{array}{l}\text { Between Groups } \\
\text { Within Groups } \\
\text { Total }\end{array}$ & $\begin{array}{r}.006 \\
46.521 \\
46.527 \\
\end{array}$ & $\begin{array}{r}2 \\
217 \\
219 \\
\end{array}$ & $\begin{array}{l}.003 \\
.214\end{array}$ & .014 & .986 \\
\hline $\begin{array}{l}\text { Educator exhibits personable } \\
\text { qualities that make her/him } \\
\text { approachable to students }\end{array}$ & $\begin{array}{l}\text { Between Groups } \\
\text { Within Groups } \\
\text { Total }\end{array}$ & $\begin{array}{r}2.392 \\
30.353 \\
32.745 \\
\end{array}$ & $\begin{array}{r}2 \\
217 \\
219 \\
\end{array}$ & $\begin{array}{r}1.196 \\
.140\end{array}$ & 8.551 & .000 \\
\hline $\begin{array}{l}\text { Educator communicates } \\
\text { enthusiasm to students }\end{array}$ & $\begin{array}{l}\text { Between Groups } \\
\text { Within Groups } \\
\text { Total }\end{array}$ & $\begin{array}{r}1.108 \\
32.069 \\
33.177 \\
\end{array}$ & $\begin{array}{r}2 \\
217 \\
219 \\
\end{array}$ & $\begin{array}{l}.554 \\
.148\end{array}$ & 3.749 & .025 \\
\hline $\begin{array}{l}\text { Educator exhibits psychosocial } \\
\text { maturity }\end{array}$ & $\begin{array}{l}\text { Between Groups } \\
\text { Within Groups } \\
\text { Total }\end{array}$ & $\begin{array}{r}.120 \\
35.080 \\
35.200 \\
\end{array}$ & $\begin{array}{r}2 \\
217 \\
219 \\
\end{array}$ & $\begin{array}{l}.060 \\
.162\end{array}$ & .371 & .691 \\
\hline $\begin{array}{l}\text { Educator exhibits appropriate } \\
\text { appearance and personal hygiene }\end{array}$ & $\begin{array}{l}\text { Between Groups } \\
\text { Within Groups } \\
\text { Total }\end{array}$ & $\begin{array}{r}3.715 \\
33.485 \\
37.200 \\
\end{array}$ & $\begin{array}{r}2 \\
217 \\
219 \\
\end{array}$ & $\begin{array}{r}1.858 \\
.154\end{array}$ & 12.039 & .000 \\
\hline $\begin{array}{l}\text { Educator demonstrates } \\
\text { awareness of one's own strengths } \\
\text { and limitations }\end{array}$ & $\begin{array}{l}\text { Between Groups } \\
\text { Within Groups } \\
\text { Total }\end{array}$ & $\begin{array}{r}2.384 \\
41.848 \\
44.232 \\
\end{array}$ & $\begin{array}{r}2 \\
217 \\
219 \\
\end{array}$ & $\begin{array}{r}1.192 \\
.193\end{array}$ & 6.181 & .002 \\
\hline $\begin{array}{l}\text { Educator is capable of responding } \\
\text { appropriately to challenging } \\
\text { situations }\end{array}$ & $\begin{array}{l}\text { Between Groups } \\
\text { Within Groups } \\
\text { Total }\end{array}$ & $\begin{array}{r}.734 \\
28.698 \\
29.432 \\
\end{array}$ & $\begin{array}{r}2 \\
217 \\
219 \\
\end{array}$ & $\begin{array}{l}.367 \\
.132\end{array}$ & 2.775 & .065 \\
\hline $\begin{array}{l}\text { Educator effectively manages } \\
\text { resources }\end{array}$ & $\begin{array}{l}\text { Between Groups } \\
\text { Within Groups } \\
\text { Total }\end{array}$ & $\begin{array}{r}2.666 \\
50.771 \\
53.436 \\
\end{array}$ & $\begin{array}{r}2 \\
217 \\
219 \\
\end{array}$ & $\begin{array}{r}1.333 \\
.234\end{array}$ & 5.697 & .004 \\
\hline Educator exhibits professionalism & $\begin{array}{l}\text { Between Groups } \\
\text { Within Groups } \\
\text { Total }\end{array}$ & $\begin{array}{r}.015 \\
25.671 \\
25.686 \\
\end{array}$ & $\begin{array}{r}2 \\
217 \\
219 \\
\end{array}$ & $\begin{array}{l}.008 \\
.118\end{array}$ & .064 & .938 \\
\hline $\begin{array}{l}\text { Educator responds to students' } \\
\text { social and educational needs }\end{array}$ & $\begin{array}{l}\text { Between Groups } \\
\text { Within Groups } \\
\text { Total }\end{array}$ & $\begin{array}{r}1.501 \\
98.886 \\
100.387 \\
\end{array}$ & $\begin{array}{r}2 \\
188 \\
190\end{array}$ & $\begin{array}{l}.751 \\
.526\end{array}$ & 1.427 & .243 \\
\hline
\end{tabular}




\begin{tabular}{|c|c|c|c|c|c|c|}
\hline $\begin{array}{l}\text { Educator builds rapport with entire } \\
\text { educational community (including } \\
\text { students, parents, etc.) }\end{array}$ & $\begin{array}{l}\text { Between Groups } \\
\text { Within Groups } \\
\text { Total }\end{array}$ & $\begin{array}{r}3.376 \\
112.519 \\
115.895\end{array}$ & $\begin{array}{r}2 \\
188 \\
190\end{array}$ & $\begin{array}{r}1.688 \\
.599\end{array}$ & 2.821 & .062 \\
\hline $\begin{array}{l}\text { Educator exhibits personable } \\
\text { qualities that make you } \\
\text { approachable to students }\end{array}$ & $\begin{array}{l}\text { Between Groups } \\
\text { Within Groups } \\
\text { Total }\end{array}$ & $\begin{array}{r}1.729 \\
118.669 \\
120.398\end{array}$ & $\begin{array}{r}2 \\
188 \\
190\end{array}$ & $\begin{array}{l}.865 \\
.631\end{array}$ & 1.370 & .257 \\
\hline $\begin{array}{l}\text { Educator communicates } \\
\text { enthusiasm to students }\end{array}$ & $\begin{array}{l}\text { Between Groups } \\
\text { Within Groups } \\
\text { Total }\end{array}$ & $\begin{array}{r}.261 \\
86.797 \\
87.058 \\
\end{array}$ & $\begin{array}{r}2 \\
188 \\
190 \\
\end{array}$ & $\begin{array}{l}.131 \\
.462\end{array}$ & .283 & .754 \\
\hline $\begin{array}{l}\text { Educator exhibits psychosocial } \\
\text { maturity }\end{array}$ & $\begin{array}{l}\text { Between Groups } \\
\text { Within Groups } \\
\text { Total }\end{array}$ & $\begin{array}{r}1.291 \\
126.573 \\
127.864 \\
\end{array}$ & $\begin{array}{r}2 \\
188 \\
190\end{array}$ & $\begin{array}{l}.645 \\
.673\end{array}$ & .958 & .385 \\
\hline $\begin{array}{l}\text { Educator exhibits appropriate } \\
\text { appearance and personal hygiene }\end{array}$ & $\begin{array}{l}\text { Between Groups } \\
\text { Within Groups } \\
\text { Total }\end{array}$ & $\begin{array}{r}1.014 \\
118.086 \\
119.099 \\
\end{array}$ & $\begin{array}{r}2 \\
188 \\
190 \\
\end{array}$ & $\begin{array}{l}.507 \\
.628\end{array}$ & .807 & .448 \\
\hline $\begin{array}{l}\text { Educator demonstrates } \\
\text { awareness of one's own strengths } \\
\text { and limitations }\end{array}$ & $\begin{array}{l}\text { Between Groups } \\
\text { Within Groups } \\
\text { Total }\end{array}$ & $\begin{array}{r}4.985 \\
95.790 \\
100.775 \\
\end{array}$ & $\begin{array}{r}2 \\
188 \\
190 \\
\end{array}$ & $\begin{array}{r}2.492 \\
.510\end{array}$ & 4.892 & .008 \\
\hline $\begin{array}{l}\text { Educator is capable of responding } \\
\text { appropriately to challenging } \\
\text { situations }\end{array}$ & $\begin{array}{l}\text { Between Groups } \\
\text { Within Groups } \\
\text { Total }\end{array}$ & $\begin{array}{r}4.208 \\
142.095 \\
146.304\end{array}$ & $\begin{array}{r}2 \\
188 \\
190\end{array}$ & $\begin{array}{r}2.104 \\
.756\end{array}$ & 2.784 & .064 \\
\hline $\begin{array}{l}\text { Educator effectively manages } \\
\text { resources }\end{array}$ & $\begin{array}{l}\text { Between Groups } \\
\text { Within Groups } \\
\text { Total }\end{array}$ & $\begin{array}{r}2.609 \\
112.679 \\
115.288 \\
\end{array}$ & $\begin{array}{r}2 \\
188 \\
190 \\
\end{array}$ & $\begin{array}{r}1.304 \\
.599\end{array}$ & 2.176 & .116 \\
\hline Educator exhibits Professionalism & $\begin{array}{l}\text { Between Groups } \\
\text { Within Groups } \\
\text { Total }\end{array}$ & $\begin{array}{r}1.590 \\
105.782 \\
107.372\end{array}$ & $\begin{array}{r}2 \\
188 \\
190\end{array}$ & $\begin{array}{l}.795 \\
.563\end{array}$ & 1.413 & .246 \\
\hline
\end{tabular}


Table A.5 Post-Hoc Comparisons

Multiple Comparisons

\begin{tabular}{|c|c|c|c|c|c|c|c|c|}
\hline \multicolumn{9}{|c|}{ Multiple Comparisons } \\
\hline \multirow[t]{2}{*}{ Dependent Variable } & & \multirow[t]{2}{*}{ (I) Role of Respondent } & \multirow[t]{2}{*}{ (J) Role of Respondent } & \multirow{2}{*}{$\begin{array}{c}\text { Mean } \\
\text { Difference (I-J) }\end{array}$} & \multirow[b]{2}{*}{ Std. Error } & \multirow[b]{2}{*}{ Sig. } & \multicolumn{2}{|c|}{ 95\% Confidence Interval } \\
\hline & & & & & & & Lower Bound & Upper Bound \\
\hline \multirow{18}{*}{$\begin{array}{l}\text { Educator responds to } \\
\text { students' social and } \\
\text { educational needs }\end{array}$} & Scheffe & FSU Student & PK12 Personnel & .03312 & .06241 & .869 & -.1207 & 1869 \\
\hline & & & FSU Faculty Member & -.02143 & .08515 & .969 & -.2313 & 1884 \\
\hline & & PK12 Personnel & FSU Student & -.03312 & .06241 & .869 & -.1869 & .1207 \\
\hline & & & FSU Faculty Member & -.05455 & .09459 & .847 & -.2877 & 1786 \\
\hline & & FSU Faculty Member & FSU Student & .02143 & .08515 & .969 & -.1884 & .2313 \\
\hline & & & PK12 Personnel & .05455 & .09459 & .847 & -.1786 & 2877 \\
\hline & Bonferroni & FSU Student & PK12 Personnel & .03312 & .06241 & 1.000 & -.1175 & 1837 \\
\hline & & & FSU Faculty Member & -.02143 & .08515 & 1.000 & -.2269 & .1840 \\
\hline & & PK12 Personnel & FSU Student & -.03312 & .06241 & 1.000 & -.1837 & 1175 \\
\hline & & & FSU Faculty Member & -.05455 & .09459 & 1.000 & -.2828 & .1737 \\
\hline & & FSU Faculty Member & FSU Student & .02143 & .08515 & 1.000 & -.1840 & .2269 \\
\hline & & & PK12 Personnel & .05455 & .09459 & 1.000 & -.1737 & 2828 \\
\hline & Games-Howell & FSU Student & PK12 Personnel & .03312 & .05882 & .840 & -.1066 & .1728 \\
\hline & & & FSU Faculty Member & -.02143 & .08846 & .968 & -.2385 & 1957 \\
\hline & & PK12 Personnel & FSU Student & -.03312 & .05882 & .840 & -.1728 & 1066 \\
\hline & & & FSU Faculty Member & -.05455 & .09470 & .834 & -.2848 & 1757 \\
\hline & & FSU Faculty Member & FSU Student & .02143 & .08846 & .968 & -.1957 & 2385 \\
\hline & & & PK12 Personnel & .05455 & .09470 & 834 & -.1757 & 2848 \\
\hline \multirow{3}{*}{$\begin{array}{l}\text { Educator builds rapport with } \\
\text { entire educational } \\
\text { community (including }\end{array}$} & Scheffe & FSU Student & PK12 Personnel & -.01234 & .07368 & .986 & -.1939 & .1693 \\
\hline & & & FSU Faculty Member & -.00143 & .10053 & 1.000 & -.2492 & 2464 \\
\hline & & PK12 Personnel & FSU Student & .01234 & .07368 & .986 & -.1693 & 1939 \\
\hline
\end{tabular}




\begin{tabular}{|c|c|c|c|c|c|c|c|c|}
\hline \multirow[t]{15}{*}{ students, parents, etc.) } & & \multicolumn{2}{|r|}{ FSU Faculty Member } & .01091 & .11168 & .995 & -.2644 & .2862 \\
\hline & & \multirow[t]{2}{*}{ FSU Faculty Member } & FSU Student & .00143 & .10053 & 1.000 & -.2464 & .2492 \\
\hline & & & PK12 Personnel & -.01091 & .11168 & .995 & -.2862 & .2644 \\
\hline & \multirow[t]{6}{*}{ Bonferroni } & \multirow[t]{2}{*}{ FSU Student } & PK12 Personnel & -.01234 & .07368 & 1.000 & -.1901 & .1654 \\
\hline & & & FSU Faculty Member & -.00143 & .10053 & 1.000 & -.2440 & .2411 \\
\hline & & \multirow[t]{2}{*}{ PK12 Personnel } & FSU Student & .01234 & .07368 & 1.000 & -.1654 & .1901 \\
\hline & & & FSU Faculty Member & .01091 & .11168 & 1.000 & -.2585 & .2804 \\
\hline & & \multirow[t]{2}{*}{ FSU Faculty Member } & FSU Student & .00143 & .10053 & 1.000 & -.2411 & .2440 \\
\hline & & & PK12 Personnel & -.01091 & .11168 & 1.000 & -.2804 & .2585 \\
\hline & \multirow[t]{6}{*}{ Games-Howell } & \multirow[t]{2}{*}{ FSU Student } & PK12 Personnel & -.01234 & .07707 & .986 & -.1960 & .1713 \\
\hline & & & FSU Faculty Member & -.00143 & .09923 & 1.000 & -.2450 & .2421 \\
\hline & & \multirow[t]{2}{*}{ PK12 Personnel } & FSU Student & .01234 & .07707 & .986 & -.1713 & .1960 \\
\hline & & & FSU Faculty Member & 01091 & .11355 & .995 & -.2633 & .2852 \\
\hline & & \multirow[t]{2}{*}{ FSU Faculty Member } & FSU Student & .00143 & .09923 & 1.000 & -.2421 & .2450 \\
\hline & & & PK12 Personnel & -.01091 & .11355 & .995 & -.2852 & .2633 \\
\hline \multirow{12}{*}{$\begin{array}{l}\text { Educator exhibits } \\
\text { personable qualities that } \\
\text { make her/him approachable } \\
\text { to students }\end{array}$} & \multirow[t]{6}{*}{ Scheffe } & \multirow[t]{2}{*}{ FSU Student } & PK12 Personnel & -.13247 & .05952 & .086 & -.2792 & .0142 \\
\hline & & & FSU Faculty Member & $-.31429^{*}$ & .08120 & .001 & -.5144 & -.1141 \\
\hline & & \multirow[t]{2}{*}{ PK12 Personnel } & FSU Student & .13247 & .05952 & .086 & -.0142 & .2792 \\
\hline & & & FSU Faculty Member & -.18182 & .09021 & .134 & -.4042 & .0405 \\
\hline & & \multirow[t]{2}{*}{ FSU Faculty Member } & FSU Student & $.31429^{*}$ & .08120 & .001 & .1141 & .5144 \\
\hline & & & PK12 Personnel & .18182 & .09021 & .134 & -.0405 & .4042 \\
\hline & \multirow[t]{6}{*}{ Bonferroni } & \multirow[t]{2}{*}{ FSU Student } & PK12 Personnel & -.13247 & .05952 & .081 & -.2761 & .0111 \\
\hline & & & FSU Faculty Member & $-.31429^{*}$ & .08120 & .000 & -.5102 & -.1184 \\
\hline & & \multirow[t]{2}{*}{ PK12 Personnel } & FSU Student & .13247 & .05952 & .081 & -.0111 & .2761 \\
\hline & & & FSU Faculty Member & -.18182 & .09021 & .135 & -.3995 & .0358 \\
\hline & & \multirow[t]{2}{*}{ FSU Faculty Member } & FSU Student & $.31429^{*}$ & .08120 & .000 & .1184 & .5102 \\
\hline & & & PK12 Personnel & .18182 & .09021 & .135 & -.0358 & .3995 \\
\hline
\end{tabular}




\begin{tabular}{|c|c|c|c|c|c|c|c|c|}
\hline & Games-Howell & FSU Student & $\begin{array}{l}\text { PK12 Personnel } \\
\text { FSU Faculty Member }\end{array}$ & \begin{tabular}{r|}
-.13247 \\
$-.31429^{*}$ \\
\end{tabular} & $\begin{array}{l}.07120 \\
.10278 \\
\end{array}$ & $\begin{array}{l}.158 \\
.013 \\
\end{array}$ & $\begin{array}{r}-.3031 \\
-.5692 \\
\end{array}$ & $\begin{array}{r}.0381 \\
-.0593 \\
\end{array}$ \\
\hline & & PK12 Personnel & $\begin{array}{l}\text { FSU Student } \\
\text { FSU Faculty Member }\end{array}$ & $\begin{array}{r}.13247 \\
-.18182\end{array}$ & $\begin{array}{l}.07120 \\
.12044\end{array}$ & $\begin{array}{l}.158 \\
.296\end{array}$ & $\begin{array}{l}-.0381 \\
-.4734\end{array}$ & $\begin{array}{l}.3031 \\
.1098\end{array}$ \\
\hline & & FSU Faculty Member & $\begin{array}{l}\text { FSU Student } \\
\text { PK12 Personnel }\end{array}$ & $\begin{array}{l}.31429^{*} \\
.18182 \\
\end{array}$ & $\begin{array}{l}.10278 \\
.12044 \\
\end{array}$ & $\begin{array}{l}.013 \\
.296 \\
\end{array}$ & $\begin{array}{r}.0593 \\
-.1098 \\
\end{array}$ & $\begin{array}{l}.5692 \\
.4734 \\
\end{array}$ \\
\hline \multirow[t]{9}{*}{$\begin{array}{l}\text { Educator communicates } \\
\text { enthusiasm to students }\end{array}$} & Scheffe & FSU Student & $\begin{array}{l}\text { PK12 Personnel } \\
\text { FSU Faculty Member }\end{array}$ & $\begin{array}{r}-.05260 \\
-.22714^{*} \\
\end{array}$ & $\begin{array}{l}.06118 \\
.08347 \\
\end{array}$ & $\begin{array}{l}.691 \\
.026 \\
\end{array}$ & $\begin{array}{l}-.2034 \\
-.4329 \\
\end{array}$ & $\begin{array}{r}.0982 \\
-.0214 \\
\end{array}$ \\
\hline & & PK12 Personnel & $\begin{array}{l}\text { FSU Student } \\
\text { FSU Faculty Member }\end{array}$ & $\begin{array}{r}.05260 \\
-.17455 \\
\end{array}$ & $\begin{array}{l}.06118 \\
.09273 \\
\end{array}$ & $\begin{array}{l}.691 \\
.173 \\
\end{array}$ & $\begin{array}{r}-.0982 \\
-.4031 \\
\end{array}$ & $\begin{array}{l}.2034 \\
.0540 \\
\end{array}$ \\
\hline & & FSU Faculty Member & $\begin{array}{l}\text { FSU Student } \\
\text { PK12 Personnel } \\
\end{array}$ & $\begin{array}{r}.22714^{\star} \\
.17455 \\
\end{array}$ & $\begin{array}{l}.08347 \\
.09273 \\
\end{array}$ & $\begin{array}{l}.026 \\
.173 \\
\end{array}$ & $\begin{array}{r}.0214 \\
-.0540 \\
\end{array}$ & $\begin{array}{l}.4329 \\
.4031 \\
\end{array}$ \\
\hline & Bonferroni & FSU Student & $\begin{array}{l}\text { PK12 Personnel } \\
\text { FSU Faculty Member }\end{array}$ & $\begin{array}{r}-.05260 \\
-.22714^{*} \\
\end{array}$ & $\begin{array}{l}.06118 \\
.08347 \\
\end{array}$ & $\begin{array}{r}1.000 \\
.021 \\
\end{array}$ & $\begin{array}{l}-.2002 \\
-.4285 \\
\end{array}$ & $\begin{array}{r}.0950 \\
-.0258 \\
\end{array}$ \\
\hline & & PK12 Personnel & $\begin{array}{l}\text { FSU Student } \\
\text { FSU Faculty Member }\end{array}$ & $\begin{array}{r}.05260 \\
-.17455 \\
\end{array}$ & $\begin{array}{l}.06118 \\
.09273 \\
\end{array}$ & $\begin{array}{r}1.000 \\
.183 \\
\end{array}$ & $\begin{array}{r}-.0950 \\
-.3983 \\
\end{array}$ & $\begin{array}{l}.2002 \\
.0492 \\
\end{array}$ \\
\hline & & FSU Faculty Member & $\begin{array}{l}\text { FSU Student } \\
\text { PK12 Personnel } \\
\end{array}$ & $\begin{array}{r}.22714^{*} \\
.17455 \\
\end{array}$ & $\begin{array}{l}.08347 \\
.09273 \\
\end{array}$ & $\begin{array}{r}.021 \\
.183 \\
\end{array}$ & $\begin{array}{r}.0258 \\
-.0492 \\
\end{array}$ & $\begin{array}{r}.4285 \\
.3983 \\
\end{array}$ \\
\hline & Games-Howell & FSU Student & $\begin{array}{l}\text { PK12 Personnel } \\
\text { FSU Faculty Member }\end{array}$ & $\begin{array}{l}-.05260 \\
-.22714 \\
\end{array}$ & $\begin{array}{l}.07093 \\
.09887 \\
\end{array}$ & $\begin{array}{l}.740 \\
.073 \\
\end{array}$ & $\begin{array}{l}-.2223 \\
-.4718 \\
\end{array}$ & $\begin{array}{l}.1171 \\
.0176 \\
\end{array}$ \\
\hline & & PK12 Personnel & $\begin{array}{l}\text { FSU Student } \\
\text { FSU Faculty Member }\end{array}$ & $\begin{array}{r}.05260 \\
-.17455 \\
\end{array}$ & $\begin{array}{l}.07093 \\
.11571 \\
\end{array}$ & $\begin{array}{r}.740 \\
.296 \\
\end{array}$ & $\begin{array}{l}-.1171 \\
-.4545 \\
\end{array}$ & $\begin{array}{l}.2223 \\
.1054 \\
\end{array}$ \\
\hline & & FSU Faculty Member & $\begin{array}{l}\text { FSU Student } \\
\text { PK12 Personnel } \\
\end{array}$ & $\begin{array}{l}.22714 \\
.17455 \\
\end{array}$ & $\begin{array}{l}.09887 \\
.11571 \\
\end{array}$ & $\begin{array}{l}.073 \\
.296 \\
\end{array}$ & $\begin{array}{l}-.0176 \\
-.1054 \\
\end{array}$ & $\begin{array}{l}.4718 \\
.4545 \\
\end{array}$ \\
\hline \multirow[t]{2}{*}{$\begin{array}{l}\text { Educator exhibits } \\
\text { psychosocial maturity }\end{array}$} & Scheffe & FSU Student & $\begin{array}{l}\text { PK12 Personnel } \\
\text { FSU Faculty Member }\end{array}$ & $\begin{array}{r}.04351 \\
-.03286 \\
\end{array}$ & $\begin{array}{l}.06398 \\
.08730 \\
\end{array}$ & $\begin{array}{l}.794 \\
.932 \\
\end{array}$ & $\begin{array}{l}-.1142 \\
-.2480 \\
\end{array}$ & $\begin{array}{l}.2012 \\
.1823 \\
\end{array}$ \\
\hline & & PK12 Personnel & FSU Student & $-04351 \mid$ & .06398 & .794 & -2012 & . 1142 \\
\hline
\end{tabular}




\begin{tabular}{|c|c|c|c|c|c|c|c|c|}
\hline & & & FSU Faculty Member & -.07636 & .09698 & .734 & -.3154 & 1627 \\
\hline & & FSU Faculty Member & FSU Student & .03286 & .08730 & .932 & -.1823 & .2480 \\
\hline & & & PK12 Personnel & .07636 & .09698 & .734 & -.1627 & 3154 \\
\hline & Bonferroni & FSU Student & PK12 Personnel & .04351 & .06398 & 1.000 & -.1109 & 1979 \\
\hline & & & FSU Faculty Member & -.03286 & .08730 & 1.000 & -.2435 & 1778 \\
\hline & & PK12 Personnel & FSU Student & -.04351 & .06398 & 1.000 & -.1979 & 1109 \\
\hline & & & FSU Faculty Member & -.07636 & .09698 & 1.000 & -.3104 & 1576 \\
\hline & & FSU Faculty Member & FSU Student & .03286 & .08730 & 1.000 & -.1778 & .2435 \\
\hline & & & PK12 Personnel & .07636 & .09698 & 1.000 & -.1576 & .3104 \\
\hline & Games-Howell & FSU Student & PK12 Personnel & .04351 & .06096 & .756 & -.1014 & 1884 \\
\hline & & & FSU Faculty Member & -.03286 & .09371 & .935 & -.2632 & 1975 \\
\hline & & PK12 Personnel & FSU Student & -.04351 & .06096 & .756 & -.1884 & 1014 \\
\hline & & & FSU Faculty Member & -.07636 & .10067 & .730 & -.3212 & 1685 \\
\hline & & FSU Faculty Member & FSU Student & .03286 & .09371 & .935 & -.1975 & .2632 \\
\hline & & & PK12 Personnel & .07636 & .10067 & .730 & -.1685 & .3212 \\
\hline Educator exhibits & Scheffe & FSU Student & PK12 Personnel & -.03896 & .06251 & .824 & -.1930 & .1151 \\
\hline appropriate appearance and & & & FSU Faculty Member & $-.41714^{\star}$ & .08529 & .000 & -.6274 & -.2069 \\
\hline personal hygiene & & PK12 Personnel & FSU Student & .03896 & .06251 & 824 & -.1151 & 1930 \\
\hline & & & FSU Faculty Member & $-.37818^{*}$ & .09475 & .000 & -.6117 & -.1446 \\
\hline & & FSU Faculty Member & FSU Student & $.41714^{\star}$ & .08529 & .000 & .2069 & .6274 \\
\hline & & & PK12 Personnel & $.37818^{*}$ & .09475 & .000 & .1446 & 6117 \\
\hline & Bonferroni & FSU Student & PK12 Personnel & -.03896 & .06251 & 1.000 & -.1898 & .1119 \\
\hline & & & FSU Faculty Member & $-.41714^{*}$ & .08529 & .000 & -.6229 & -.2114 \\
\hline & & PK12 Personnel & FSU Student & .03896 & .06251 & 1.000 & -.1119 & .1898 \\
\hline & & & FSU Faculty Member & $-.37818^{*}$ & .09475 & .000 & -.6068 & -.1496 \\
\hline & & FSU Faculty Member & FSU Student & $.41714^{*}$ & .08529 & .000 & .2114 & .6229 \\
\hline & & & PK12 Personnel & $.37818^{*}$ & .09475 & .000 & .1496 & .6068 \\
\hline
\end{tabular}




\begin{tabular}{|c|c|c|c|c|c|c|c|c|}
\hline & Games-Howell & FSU Student & $\begin{array}{l}\text { PK12 Personnel } \\
\text { FSU Faculty Member }\end{array}$ & $\begin{array}{r}-.03896 \\
-.41714^{\star} \\
\end{array}$ & $\begin{array}{r}.06564 \\
.10558 \\
\end{array}$ & $\begin{array}{l}.824 \\
.001 \\
\end{array}$ & $\begin{array}{l}-.1956 \\
-.6783 \\
\end{array}$ & $\begin{array}{r}.1177 \\
-.1560 \\
\end{array}$ \\
\hline & & PK12 Personnel & $\begin{array}{l}\text { FSU Student } \\
\text { FSU Faculty Member }\end{array}$ & $\begin{array}{r}.03896 \\
-.37818^{*} \\
\end{array}$ & $\begin{array}{l}.06564 \\
.11703 \\
\end{array}$ & $\begin{array}{l}.824 \\
.007 \\
\end{array}$ & $\begin{array}{l}-.1177 \\
-.6628 \\
\end{array}$ & $\begin{array}{r}.1956 \\
-.0935 \\
\end{array}$ \\
\hline & & FSU Faculty Member & $\begin{array}{l}\text { FSU Student } \\
\text { PK12 Personnel }\end{array}$ & $\begin{array}{l}.41714^{*} \\
.37818^{*} \\
\end{array}$ & $\begin{array}{l}.10558 \\
.11703 \\
\end{array}$ & $\begin{array}{l}.001 \\
.007 \\
\end{array}$ & $\begin{array}{l}.1560 \\
.0935 \\
\end{array}$ & $\begin{array}{l}.6783 \\
.6628 \\
\end{array}$ \\
\hline \multirow{9}{*}{$\begin{array}{l}\text { Educator demonstrates } \\
\text { awareness of one's own } \\
\text { strengths and limitations }\end{array}$} & Scheffe & FSU Student & $\begin{array}{l}\text { PK12 Personnel } \\
\text { FSU Faculty Member }\end{array}$ & $\begin{array}{r}-.06883 \\
-.33429^{*} \\
\end{array}$ & $\begin{array}{l}.06988 \\
.09535 \\
\end{array}$ & $\begin{array}{l}.616 \\
.003 \\
\end{array}$ & $\begin{array}{l}-.2411 \\
-.5693 \\
\end{array}$ & $\begin{array}{r}.1034 \\
-.0993 \\
\end{array}$ \\
\hline & & PK12 Personnel & $\begin{array}{l}\text { FSU Student } \\
\text { FSU Faculty Member }\end{array}$ & $\begin{array}{r}.06883 \\
-.26545^{*} \\
\end{array}$ & $\begin{array}{l}.06988 \\
.10593 \\
\end{array}$ & $\begin{array}{l}.616 \\
.045 \\
\end{array}$ & $\begin{array}{l}-.1034 \\
-.5265 \\
\end{array}$ & $\begin{array}{r}.2411 \\
-.0044 \\
\end{array}$ \\
\hline & & FSU Faculty Member & $\begin{array}{l}\text { FSU Student } \\
\text { PK12 Personnel }\end{array}$ & $\begin{array}{l}.33429^{*} \\
.26545^{*} \\
\end{array}$ & $\begin{array}{l}.09535 \\
.10593 \\
\end{array}$ & $\begin{array}{r}.003 \\
.045 \\
\end{array}$ & $\begin{array}{l}.0993 \\
.0044 \\
\end{array}$ & $\begin{array}{l}.5693 \\
.5265 \\
\end{array}$ \\
\hline & Bonferroni & FSU Student & $\begin{array}{l}\text { PK12 Personnel } \\
\text { FSU Faculty Member }\end{array}$ & $\begin{array}{r}-.06883 \\
-.33429^{*} \\
\end{array}$ & $\begin{array}{l}.06988 \\
.09535 \\
\end{array}$ & $\begin{array}{l}.977 \\
.002 \\
\end{array}$ & $\begin{array}{l}-.2374 \\
-.5643 \\
\end{array}$ & $\begin{array}{r}.0998 \\
-.1042 \\
\end{array}$ \\
\hline & & PK12 Personnel & $\begin{array}{l}\text { FSU Student } \\
\text { FSU Faculty Member }\end{array}$ & $\begin{array}{r}.06883 \\
-.26545^{*} \\
\end{array}$ & $\begin{array}{l}.06988 \\
.10593 \\
\end{array}$ & $\begin{array}{l}.977 \\
.039 \\
\end{array}$ & $\begin{array}{l}-.0998 \\
-.5210 \\
\end{array}$ & $\begin{array}{r}.2374 \\
-.0099 \\
\end{array}$ \\
\hline & & FSU Faculty Member & $\begin{array}{l}\text { FSU Student } \\
\text { PK12 Personnel }\end{array}$ & $\begin{array}{l}.33429^{*} \\
.26545^{*} \\
\end{array}$ & $\begin{array}{l}.09535 \\
.10593 \\
\end{array}$ & $\begin{array}{l}.002 \\
.039 \\
\end{array}$ & $\begin{array}{l}.1042 \\
.0099 \\
\end{array}$ & $\begin{array}{l}.5643 \\
.5210 \\
\end{array}$ \\
\hline & Games-Howell & FSU Student & $\begin{array}{l}\text { PK12 Personnel } \\
\text { FSU Faculty Member }\end{array}$ & $\begin{array}{r}-.06883 \\
-.33429^{*} \\
\end{array}$ & $\begin{array}{l}.07334 \\
.10766 \\
\end{array}$ & $\begin{array}{l}.617 \\
.011 \\
\end{array}$ & $\begin{array}{l}-.2437 \\
-.5998 \\
\end{array}$ & $\begin{array}{r}.1061 \\
-.0688 \\
\end{array}$ \\
\hline & & PK12 Personnel & $\begin{array}{l}\text { FSU Student } \\
\text { FSU Faculty Member }\end{array}$ & $\begin{array}{r}.06883 \\
-.26545 \\
\end{array}$ & $\begin{array}{r}.07334 \\
.12078 \\
\end{array}$ & $\begin{array}{l}.617 \\
.083 \\
\end{array}$ & $\begin{array}{l}-.1061 \\
-.5584 \\
\end{array}$ & $\begin{array}{l}.2437 \\
.0275 \\
\end{array}$ \\
\hline & & FSU Faculty Member & $\begin{array}{l}\text { FSU Student } \\
\text { PK12 Personnel }\end{array}$ & $\begin{array}{l}.33429^{*} \\
.26545 \\
\end{array}$ & $\begin{array}{l}.10766 \\
.12078 \\
\end{array}$ & $\begin{array}{l}.011 \\
.083 \\
\end{array}$ & $\begin{array}{r}.0688 \\
-.0275 \\
\end{array}$ & $\begin{array}{l}.5998 \\
.5584 \\
\end{array}$ \\
\hline $\begin{array}{l}\text { Educator is capable of } \\
\text { responding appropriately to }\end{array}$ & Scheffe & FSU Student & $\begin{array}{l}\text { PK12 Personnel } \\
\text { FSU Faculty Member }\end{array}$ & $\begin{array}{l}-.00974 \\
-.18429 \\
\end{array}$ & $\begin{array}{l}.05787 \\
.07896 \\
\end{array}$ & $\begin{array}{l}.986 \\
.068 \\
\end{array}$ & $\begin{array}{l}-.1524 \\
-.3789 \\
\end{array}$ & $\begin{array}{l}.1329 \\
.0103 \\
\end{array}$ \\
\hline challenging situations & & PK12 Personnel & FSU Student & .00974 & .05787 & .986 & -.1329 & .1524 \\
\hline
\end{tabular}




\begin{tabular}{|c|c|c|c|c|c|c|c|c|}
\hline & & & FSU Faculty Member & -.17455 & .08772 & 141 & -.3907 & .0417 \\
\hline & & FSU Faculty Member & FSU Student & .18429 & .07896 & .068 & -.0103 & .3789 \\
\hline & & & PK12 Personnel & .17455 & .08772 & 141 & -.0417 & .3907 \\
\hline & Bonferroni & FSU Student & PK12 Personnel & -.00974 & .05787 & 1.000 & -.1494 & .1299 \\
\hline & & & FSU Faculty Member & -.18429 & .07896 & .062 & -.3748 & .0062 \\
\hline & & PK12 Personnel & FSU Student & .00974 & .05787 & 1.000 & -.1299 & 1494 \\
\hline & & & FSU Faculty Member & -.17455 & .08772 & 144 & -.3862 & 0371 \\
\hline & & FSU Faculty Member & FSU Student & .18429 & .07896 & .062 & -.0062 & .3748 \\
\hline & & & PK12 Personnel & .17455 & .08772 & 144 & -.0371 & .3862 \\
\hline & Games-Howell & FSU Student & PK12 Personnel & -.00974 & .05609 & .984 & -.1433 & 1238 \\
\hline & & & FSU Faculty Member & -.18429 & .09955 & .171 & -.4303 & .0617 \\
\hline & & PK12 Personnel & FSU Student & .00974 & .05609 & .984 & -.1238 & .1433 \\
\hline & & & FSU Faculty Member & -.17455 & .10662 & 243 & -.4350 & .0859 \\
\hline & & FSU Faculty Member & FSU Student & .18429 & .09955 & .171 & -.0617 & .4303 \\
\hline & & & PK12 Personnel & .17455 & .10662 & .243 & -.0859 & .4350 \\
\hline Educator effectively & Scheffe & FSU Student & PK12 Personnel & .00844 & .07697 & .994 & -.1813 & .1982 \\
\hline manages resources & & & FSU Faculty Member & $-.34429^{*}$ & .10502 & .005 & -.6031 & -.0854 \\
\hline & & PK12 Personnel & FSU Student & -.00844 & .07697 & .994 & -.1982 & .1813 \\
\hline & & & FSU Faculty Member & $-.35273^{*}$ & .11667 & .011 & -.6403 & -.0652 \\
\hline & & FSU Faculty Member & FSU Student & $.34429^{*}$ & .10502 & .005 & .0854 & .6031 \\
\hline & & & PK12 Personnel & $.35273^{*}$ & .11667 & 011 & .0652 & .6403 \\
\hline & Bonferroni & FSU Student & PK12 Personnel & .00844 & .07697 & 1.000 & -.1773 & .1942 \\
\hline & & & FSU Faculty Member & $-.34429^{*}$ & .10502 & .004 & -.5977 & -.0909 \\
\hline & & PK12 Personnel & FSU Student & -.00844 & .07697 & 1.000 & -.1942 & .1773 \\
\hline & & & FSU Faculty Member & $-.35273^{*}$ & .11667 & .008 & -.6342 & -.0712 \\
\hline & & FSU Faculty Member & FSU Student & $.34429^{*}$ & .10502 & .004 & .0909 & .5977 \\
\hline & & & PK12 Personnel & $.35273^{*}$ & .11667 & .008 & .0712 & .6342 \\
\hline
\end{tabular}




\begin{tabular}{|c|c|c|c|c|c|c|c|c|}
\hline & Games-Howell & FSU Student & $\begin{array}{l}\text { PK12 Personnel } \\
\text { FSU Faculty Member }\end{array}$ & $\begin{array}{r}.00844 \\
-.34429^{*} \\
\end{array}$ & $\begin{array}{l}.07972 \\
.10330 \\
\end{array}$ & $\begin{array}{l}.994 \\
.006 \\
\end{array}$ & $\begin{array}{l}-.1814 \\
-.5977 \\
\end{array}$ & $\begin{array}{r}.1983 \\
-.0908 \\
\end{array}$ \\
\hline & & PK12 Personnel & $\begin{array}{l}\text { FSU Student } \\
\text { FSU Faculty Member }\end{array}$ & $\begin{array}{r}-.00844 \\
-.35273^{*} \\
\end{array}$ & $\begin{array}{l}.07972 \\
.11755 \\
\end{array}$ & $\begin{array}{l}.994 \\
.012 \\
\end{array}$ & $\begin{array}{l}-.1983 \\
-.6367 \\
\end{array}$ & $\begin{array}{r}.1814 \\
-.0687 \\
\end{array}$ \\
\hline & & FSU Faculty Member & $\begin{array}{l}\text { FSU Student } \\
\text { PK12 Personnel }\end{array}$ & $\begin{array}{l}.34429^{*} \\
.35273^{*} \\
\end{array}$ & $\begin{array}{l}.10330 \\
.11755 \\
\end{array}$ & $\begin{array}{l}.006 \\
.012 \\
\end{array}$ & $\begin{array}{l}.0908 \\
.0687 \\
\end{array}$ & $\begin{array}{l}.5977 \\
.6367 \\
\end{array}$ \\
\hline \multirow[t]{9}{*}{$\begin{array}{l}\text { Educator exhibits } \\
\text { professionalism }\end{array}$} & Scheffe & FSU Student & $\begin{array}{l}\text { PK12 Personnel } \\
\text { FSU Faculty Member }\end{array}$ & $\begin{array}{l}.01948 \\
.00857 \\
\end{array}$ & $\begin{array}{l}.05473 \\
.07468 \\
\end{array}$ & $\begin{array}{l}.939 \\
.993 \\
\end{array}$ & $\begin{array}{l}-.1154 \\
-.1755 \\
\end{array}$ & $\begin{array}{l}.1544 \\
.1926 \\
\end{array}$ \\
\hline & & PK12 Personnel & $\begin{array}{l}\text { FSU Student } \\
\text { FSU Faculty Member }\end{array}$ & $\begin{array}{l}-.01948 \\
-.01091 \\
\end{array}$ & $\begin{array}{l}.05473 \\
.08296 \\
\end{array}$ & $\begin{array}{l}.939 \\
.991 \\
\end{array}$ & $\begin{array}{l}-.1544 \\
-.2154 \\
\end{array}$ & $\begin{array}{r}.1154 \\
.1936 \\
\end{array}$ \\
\hline & & FSU Faculty Member & $\begin{array}{l}\text { FSU Student } \\
\text { PK12 Personnel }\end{array}$ & $\begin{array}{r}.00857 \\
.01091 \\
\end{array}$ & $\begin{array}{l}.07468 \\
.08296 \\
\end{array}$ & $\begin{array}{l}.993 \\
.991 \\
\end{array}$ & $\begin{array}{l}-.1926 \\
-.1936 \\
\end{array}$ & $\begin{array}{l}.1755 \\
.2154 \\
\end{array}$ \\
\hline & Bonferroni & FSU Student & $\begin{array}{l}\text { PK12 Personnel } \\
\text { FSU Faculty Member }\end{array}$ & $\begin{array}{l}.01948 \\
.00857 \\
\end{array}$ & $\begin{array}{l}.05473 \\
.07468 \\
\end{array}$ & $\begin{array}{l}1.000 \\
1.000 \\
\end{array}$ & $\begin{array}{l}-.1126 \\
-.1716 \\
\end{array}$ & $\begin{array}{l}.1515 \\
.1887 \\
\end{array}$ \\
\hline & & PK12 Personnel & $\begin{array}{l}\text { FSU Student } \\
\text { FSU Faculty Member }\end{array}$ & $\begin{array}{r}-.01948 \\
-.01091 \\
\end{array}$ & $\begin{array}{l}.05473 \\
.08296 \\
\end{array}$ & $\begin{array}{l}1.000 \\
1.000 \\
\end{array}$ & $\begin{array}{l}-.1515 \\
-.2111 \\
\end{array}$ & $\begin{array}{l}.1126 \\
.1893 \\
\end{array}$ \\
\hline & & FSU Faculty Member & $\begin{array}{l}\text { FSU Student } \\
\text { PK12 Personnel }\end{array}$ & $\begin{array}{r}.00857 \\
.01091 \\
\end{array}$ & $\begin{array}{l}.07468 \\
.08296 \\
\end{array}$ & $\begin{array}{l}1.000 \\
1.000 \\
\end{array}$ & $\begin{array}{l}-.1887 \\
-.1893 \\
\end{array}$ & $\begin{array}{l}.1716 \\
.2111 \\
\end{array}$ \\
\hline & Games-Howell & FSU Student & $\begin{array}{l}\text { PK12 Personnel } \\
\text { FSU Faculty Member }\end{array}$ & $\begin{array}{l}.01948 \\
.00857 \\
\end{array}$ & $\begin{array}{l}.05726 \\
.07215 \\
\end{array}$ & $\begin{array}{l}.938 \\
.992 \\
\end{array}$ & $\begin{array}{l}-.1170 \\
-.1684 \\
\end{array}$ & $\begin{array}{l}.1559 \\
.1855 \\
\end{array}$ \\
\hline & & PK12 Personnel & $\begin{array}{l}\text { FSU Student } \\
\text { FSU Faculty Member }\end{array}$ & $\begin{array}{l}-.01948 \\
-.01091 \\
\end{array}$ & $\begin{array}{l}.05726 \\
.08290 \\
\end{array}$ & $\begin{array}{l}.938 \\
.991 \\
\end{array}$ & $\begin{array}{l}-.1559 \\
-.2110 \\
\end{array}$ & $\begin{array}{l}.1170 \\
.1892 \\
\end{array}$ \\
\hline & & FSU Faculty Member & $\begin{array}{l}\text { FSU Student } \\
\text { PK12 Personnel }\end{array}$ & $\begin{array}{r}.00857 \\
.01091 \\
\end{array}$ & $\begin{array}{l}.07215 \\
.08290 \\
\end{array}$ & $\begin{array}{l}.992 \\
.991 \\
\end{array}$ & $\begin{array}{l}-.1855 \\
-.1892 \\
\end{array}$ & $\begin{array}{l}.1684 \\
.2110 \\
\end{array}$ \\
\hline $\begin{array}{l}\text { Educator responds to } \\
\text { students' social and }\end{array}$ & Scheffe & FSU Student & $\begin{array}{l}\text { PK12 Personnel } \\
\text { FSU Faculty Member }\end{array}$ & $\begin{array}{r}-.19288 \\
-.15549 \\
\end{array}$ & $\begin{array}{l}.12238 \\
.16531 \\
\end{array}$ & $\begin{array}{l}.291 \\
.643 \\
\end{array}$ & $\begin{array}{l}-.4948 \\
-.5634 \\
\end{array}$ & $\begin{array}{l}.1091 \\
.2524 \\
\end{array}$ \\
\hline educational needs & & PK12 Personnel & FSU Student & .19288 & .12238 & .291 & -.1091 & .4948 \\
\hline
\end{tabular}




\begin{tabular}{|c|c|c|c|c|c|c|c|c|}
\hline & & & FSU Faculty Member & .03739 & .18273 & .979 & -.4135 & .4882 \\
\hline & & FSU Faculty Member & FSU Student & .15549 & .16531 & .643 & -.2524 & .5634 \\
\hline & & & PK12 Personnel & -.03739 & .18273 & .979 & -.4882 & .4135 \\
\hline & Bonferroni & FSU Student & PK12 Personnel & -.19288 & .12238 & .350 & -.4885 & 1027 \\
\hline & & & FSU Faculty Member & -.15549 & .16531 & 1.000 & -.5548 & 2438 \\
\hline & & PK12 Personnel & FSU Student & .19288 & .12238 & .350 & -.1027 & .4885 \\
\hline & & & FSU Faculty Member & .03739 & .18273 & 1.000 & -.4040 & .4788 \\
\hline & & FSU Faculty Member & FSU Student & .15549 & .16531 & 1.000 & -.2438 & .5548 \\
\hline & & & PK12 Personnel & -.03739 & .18273 & 1.000 & -.4788 & .4040 \\
\hline & Games-Howell & FSU Student & PK12 Personnel & -.19288 & .12292 & .264 & -.4855 & .0998 \\
\hline & & & FSU Faculty Member & -.15549 & .14279 & .527 & -.5042 & 1932 \\
\hline & & PK12 Personnel & FSU Student & .19288 & .12292 & .264 & -.0998 & .4855 \\
\hline & & & FSU Faculty Member & .03739 & .16124 & .971 & -.3519 & .4267 \\
\hline & & FSU Faculty Member & FSU Student & .15549 & .14279 & .527 & -.1932 & .5042 \\
\hline & & & PK12 Personnel & -.03739 & .16124 & .971 & -.4267 & .3519 \\
\hline Educator builds rapport with & Scheffe & FSU Student & PK12 Personnel & -.30576 & .13055 & .067 & -.6279 & .0163 \\
\hline entire educational & & & FSU Faculty Member & -.15881 & .17634 & 667 & -.5939 & .2763 \\
\hline community (including & & PK12 Personnel & FSU Student & .30576 & .13055 & .067 & -.0163 & 6279 \\
\hline students, parents, etc.) & & & FSU Faculty Member & .14696 & .19492 & .753 & -.3340 & .6279 \\
\hline & & FSU Faculty Member & FSU Student & .15881 & .17634 & 667 & -.2763 & .5939 \\
\hline & & & PK12 Personnel & -.14696 & .19492 & .753 & -.6279 & .3340 \\
\hline & Bonferroni & FSU Student & PK12 Personnel & -.30576 & .13055 & .061 & -.6211 & .0096 \\
\hline & & & FSU Faculty Member & -.15881 & .17634 & 1.000 & -.5848 & 2671 \\
\hline & & PK12 Personnel & FSU Student & .30576 & .13055 & .061 & -.0096 & .6211 \\
\hline & & & FSU Faculty Member & .14696 & .19492 & 1.000 & -.3239 & .6178 \\
\hline & & FSU Faculty Member & FSU Student & .15881 & .17634 & 1.000 & -.2671 & .5848 \\
\hline & & & PK12 Personnel & -.14696 & .19492 & 1.000 & -.6178 & .3239 \\
\hline
\end{tabular}




\begin{tabular}{|c|c|c|c|c|c|c|c|c|}
\hline & Games-Howell & FSU Student & $\begin{array}{l}\text { PK12 Personnel } \\
\text { FSU Faculty Member }\end{array}$ & $\begin{array}{l}-.30576 \\
-.15881 \\
\end{array}$ & $\begin{array}{l}.13082 \\
.15738 \\
\end{array}$ & $\begin{array}{l}.056 \\
.576 \\
\end{array}$ & $\begin{array}{l}-.6172 \\
-.5438 \\
\end{array}$ & $\begin{array}{l}.0057 \\
.2262 \\
\end{array}$ \\
\hline & & PK12 Personnel & $\begin{array}{l}\text { FSU Student } \\
\text { FSU Faculty Member }\end{array}$ & $\begin{array}{l}.30576 \\
.14696 \\
\end{array}$ & $\begin{array}{l}.13082 \\
.17659 \\
\end{array}$ & $\begin{array}{l}.056 \\
.685 \\
\end{array}$ & $\begin{array}{l}-.0057 \\
-.2799 \\
\end{array}$ & $\begin{array}{l}.6172 \\
.5738 \\
\end{array}$ \\
\hline & & FSU Faculty Member & $\begin{array}{l}\text { FSU Student } \\
\text { PK12 Personnel }\end{array}$ & $\begin{array}{r}.15881 \\
-.14696 \\
\end{array}$ & $\begin{array}{l}.15738 \\
.17659 \\
\end{array}$ & $\begin{array}{l}.576 \\
.685 \\
\end{array}$ & $\begin{array}{l}-.2262 \\
-.5738 \\
\end{array}$ & $\begin{array}{l}.5438 \\
.2799 \\
\end{array}$ \\
\hline \multirow{9}{*}{$\begin{array}{l}\text { Educator exhibits } \\
\text { personable qualities that } \\
\text { make you approachable to } \\
\text { students }\end{array}$} & Scheffe & FSU Student & $\begin{array}{l}\text { PK12 Personnel } \\
\text { FSU Faculty Member }\end{array}$ & $\begin{array}{r}-.19966 \\
.06817 \\
\end{array}$ & $\begin{array}{l}.13407 \\
.18109 \\
\end{array}$ & $\begin{array}{l}.332 \\
.932 \\
\end{array}$ & $\begin{array}{l}-.5305 \\
-.3787 \\
\end{array}$ & $\begin{array}{r}.1311 \\
.5150 \\
\end{array}$ \\
\hline & & PK12 Personnel & $\begin{array}{l}\text { FSU Student } \\
\text { FSU Faculty Member }\end{array}$ & $\begin{array}{l}.19966 \\
.26783 \\
\end{array}$ & $\begin{array}{l}.13407 \\
.20017 \\
\end{array}$ & $\begin{array}{l}.332 \\
.410 \\
\end{array}$ & $\begin{array}{l}-.1311 \\
-.2261 \\
\end{array}$ & $\begin{array}{l}.5305 \\
.7617 \\
\end{array}$ \\
\hline & & FSU Faculty Member & $\begin{array}{l}\text { FSU Student } \\
\text { PK12 Personnel }\end{array}$ & $\begin{array}{l}-.06817 \\
-.26783 \\
\end{array}$ & $\begin{array}{l}.18109 \\
.20017 \\
\end{array}$ & $\begin{array}{l}.932 \\
.410 \\
\end{array}$ & $\begin{array}{l}-.5150 \\
-.7617 \\
\end{array}$ & $\begin{array}{l}.3787 \\
.2261 \\
\end{array}$ \\
\hline & Bonferroni & FSU Student & $\begin{array}{l}\text { PK12 Personnel } \\
\text { FSU Faculty Member }\end{array}$ & $\begin{array}{r}-.19966 \\
.06817 \\
\end{array}$ & $\begin{array}{l}.13407 \\
.18109 \\
\end{array}$ & $\begin{array}{r}.414 \\
1.000 \\
\end{array}$ & $\begin{array}{r}-.5235 \\
-.3693 \\
\end{array}$ & $\begin{array}{l}.1242 \\
.5056 \\
\end{array}$ \\
\hline & & PK12 Personnel & $\begin{array}{l}\text { FSU Student } \\
\text { FSU Faculty Member }\end{array}$ & $\begin{array}{l}.19966 \\
.26783 \\
\end{array}$ & $\begin{array}{l}.13407 \\
.20017 \\
\end{array}$ & $\begin{array}{l}.414 \\
.548 \\
\end{array}$ & $\begin{array}{l}-.1242 \\
-.2157 \\
\end{array}$ & $\begin{array}{l}.5235 \\
.7514 \\
\end{array}$ \\
\hline & & FSU Faculty Member & $\begin{array}{l}\text { FSU Student } \\
\text { PK12 Personnel }\end{array}$ & $\begin{array}{l}-.06817 \\
-.26783 \\
\end{array}$ & $\begin{array}{l}.18109 \\
.20017 \\
\end{array}$ & $\begin{array}{r}1.000 \\
.548 \\
\end{array}$ & $\begin{array}{l}-.5056 \\
-.7514 \\
\end{array}$ & $\begin{array}{l}.3693 \\
.2157 \\
\end{array}$ \\
\hline & Games-Howell & FSU Student & $\begin{array}{l}\text { PK12 Personnel } \\
\text { FSU Faculty Member }\end{array}$ & $\begin{array}{r}-.19966 \\
.06817 \\
\end{array}$ & $\begin{array}{l}.13233 \\
.12854 \\
\end{array}$ & $\begin{array}{l}.291 \\
.857 \\
\end{array}$ & $\begin{array}{r}-.5143 \\
-.2418 \\
\end{array}$ & $\begin{array}{l}.1150 \\
.3781 \\
\end{array}$ \\
\hline & & PK12 Personnel & $\begin{array}{l}\text { FSU Student } \\
\text { FSU Faculty Member }\end{array}$ & $\begin{array}{l}.19966 \\
.26783 \\
\end{array}$ & $\begin{array}{l}.13233 \\
.14700 \\
\end{array}$ & $\begin{array}{l}.291 \\
.171 \\
\end{array}$ & $\begin{array}{l}-.1150 \\
-.0851 \\
\end{array}$ & $\begin{array}{l}.5143 \\
.6207 \\
\end{array}$ \\
\hline & & FSU Faculty Member & $\begin{array}{l}\text { FSU Student } \\
\text { PK12 Personnel }\end{array}$ & $\begin{array}{l}-.06817 \\
-.26783 \\
\end{array}$ & $\begin{array}{l}.12854 \\
.14700 \\
\end{array}$ & $\begin{array}{l}.857 \\
.171 \\
\end{array}$ & $\begin{array}{l}-.3781 \\
-.6207 \\
\end{array}$ & $\begin{array}{l}.2418 \\
.0851 \\
\end{array}$ \\
\hline \multirow[t]{2}{*}{$\begin{array}{l}\text { Educator communicates } \\
\text { enthusiasm to students }\end{array}$} & Scheffe & FSU Student & $\begin{array}{l}\text { PK12 Personnel } \\
\text { FSU Faculty Member }\end{array}$ & $\begin{array}{l}-.08610 \\
-.03132 \\
\end{array}$ & $\begin{array}{l}.11466 \\
.15487 \\
\end{array}$ & $\begin{array}{l}.755 \\
.980 \\
\end{array}$ & $\begin{array}{l}-.3690 \\
-.4135 \\
\end{array}$ & $\begin{array}{l}.1968 \\
.3508 \\
\end{array}$ \\
\hline & & PK12 Personnel & FSU Student & .08610 & .11466 & .755 & -.1968 & .3690 \\
\hline
\end{tabular}




\begin{tabular}{|c|c|c|c|c|c|c|c|c|}
\hline & & & FSU Faculty Member & .05478 & .17119 & .950 & -.3676 & .4772 \\
\hline & & FSU Faculty Member & FSU Student & .03132 & .15487 & .980 & -.3508 & .4135 \\
\hline & & & PK12 Personnel & -.05478 & .17119 & .950 & -.4772 & .3676 \\
\hline & Bonferroni & FSU Student & PK12 Personnel & -.08610 & .11466 & 1.000 & -.3631 & 1909 \\
\hline & & & FSU Faculty Member & -.03132 & .15487 & 1.000 & -.4054 & .3428 \\
\hline & & PK12 Personnel & FSU Student & .08610 & .11466 & 1.000 & -1909 & .3631 \\
\hline & & & FSU Faculty Member & .05478 & .17119 & 1.000 & -.3587 & 4683 \\
\hline & & FSU Faculty Member & FSU Student & .03132 & 15487 & 1.000 & -.3428 & .4054 \\
\hline & & & PK12 Personnel & -.05478 & .17119 & 1.000 & -.4683 & .3587 \\
\hline & Games-Howell & FSU Student & PK12 Personnel & -.08610 & .11188 & .722 & -.3521 & .1799 \\
\hline & & & FSU Faculty Member & -.03132 & .12496 & .966 & -.3350 & .2723 \\
\hline & & PK12 Personnel & FSU Student & .08610 & .11188 & .722 & -.1799 & .3521 \\
\hline & & & FSU Faculty Member & .05478 & .13872 & .918 & -.2797 & .3893 \\
\hline & & FSU Faculty Member & FSU Student & .03132 & .12496 & .966 & -.2723 & .3350 \\
\hline & & & PK12 Personnel & -.05478 & .13872 & .918 & -.3893 & .2797 \\
\hline Educator exhibits & Scheffe & FSU Student & PK12 Personnel & -.16271 & .13846 & .503 & -.5043 & 1789 \\
\hline psychosocial maturity & & & FSU Faculty Member & .08511 & .18702 & .902 & -.3763 & .5466 \\
\hline & & PK12 Personnel & FSU Student & .16271 & .13846 & .503 & -.1789 & .5043 \\
\hline & & & FSU Faculty Member & .24783 & .20673 & .489 & -.2623 & .7579 \\
\hline & & FSU Faculty Member & FSU Student & -.08511 & .18702 & .902 & -.5466 & .3763 \\
\hline & & & PK12 Personnel & -.24783 & .20673 & .489 & -.7579 & .2623 \\
\hline & Bonferroni & FSU Student & PK12 Personnel & -.16271 & .13846 & .724 & -.4972 & 1717 \\
\hline & & & FSU Faculty Member & .08511 & .18702 & 1.000 & -.3667 & .5369 \\
\hline & & PK12 Personnel & FSU Student & .16271 & .13846 & .724 & -.1717 & .4972 \\
\hline & & & FSU Faculty Member & .24783 & .20673 & .696 & -.2516 & .7472 \\
\hline & & FSU Faculty Member & FSU Student & -.08511 & .18702 & 1.000 & -.5369 & .3667 \\
\hline & & & PK12 Personnel & -.24783 & .20673 & .696 & -.7472 & .2516 \\
\hline
\end{tabular}




\begin{tabular}{|c|c|c|c|c|c|c|c|c|}
\hline & Games-Howell & FSU Student & $\begin{array}{l}\text { PK12 Personnel } \\
\text { FSU Faculty Member }\end{array}$ & $\begin{array}{r}. .16271 \\
.08511 \\
\end{array}$ & $\begin{array}{r}.13496 \\
.14438 \\
\end{array}$ & $\begin{array}{l}.452 \\
.826 \\
\end{array}$ & $\begin{array}{r}-.4835 \\
-.2648 \\
\end{array}$ & $\begin{array}{l}.1581 \\
.4350 \\
\end{array}$ \\
\hline & & PK12 Personnel & $\begin{array}{l}\text { FSU Student } \\
\text { FSU Faculty Member }\end{array}$ & $\begin{array}{l}.16271 \\
.24783 \\
\end{array}$ & $\begin{array}{l}.13496 \\
.16092 \\
\end{array}$ & $\begin{array}{l}.452 \\
.280 \\
\end{array}$ & $\begin{array}{l}-.1581 \\
-.1396 \\
\end{array}$ & $\begin{array}{l}.4835 \\
.6353 \\
\end{array}$ \\
\hline & & FSU Faculty Member & $\begin{array}{l}\text { FSU Student } \\
\text { PK12 Personnel }\end{array}$ & $\begin{array}{l}-.08511 \\
-.24783 \\
\end{array}$ & $\begin{array}{l}.14438 \\
.16092 \\
\end{array}$ & $\begin{array}{l}.826 \\
.280 \\
\end{array}$ & $\begin{array}{l}-.4350 \\
-.6353 \\
\end{array}$ & $\begin{array}{l}.2648 \\
.1396 \\
\end{array}$ \\
\hline \multirow{9}{*}{$\begin{array}{l}\text { Educator exhibits } \\
\text { appropriate appearance and } \\
\text { personal hygiene }\end{array}$} & Scheffe & FSU Student & $\begin{array}{l}\text { PK12 Personnel } \\
\text { FSU Faculty Member }\end{array}$ & $\begin{array}{r}. .16373 \\
.01105 \\
\end{array}$ & $\begin{array}{l}.13374 \\
.18064 \\
\end{array}$ & $\begin{array}{l}.474 \\
.998 \\
\end{array}$ & $\begin{array}{l}-.4937 \\
-.4347 \\
\end{array}$ & $\begin{array}{l}.1662 \\
.4568 \\
\end{array}$ \\
\hline & & PK12 Personnel & $\begin{array}{l}\text { FSU Student } \\
\text { FSU Faculty Member }\end{array}$ & $\begin{array}{l}.16373 \\
.17478 \\
\end{array}$ & $\begin{array}{l}.13374 \\
.19968 \\
\end{array}$ & $\begin{array}{l}.474 \\
.682 \\
\end{array}$ & $\begin{array}{l}-.1662 \\
-.3179 \\
\end{array}$ & $\begin{array}{l}.4937 \\
.6675 \\
\end{array}$ \\
\hline & & FSU Faculty Member & $\begin{array}{l}\text { FSU Student } \\
\text { PK12 Personnel }\end{array}$ & $\begin{array}{l}-.01105 \\
-.17478 \\
\end{array}$ & $\begin{array}{l}.18064 \\
.19968 \\
\end{array}$ & $\begin{array}{l}.998 \\
.682 \\
\end{array}$ & $\begin{array}{l}-.4568 \\
-.6675 \\
\end{array}$ & $\begin{array}{l}.4347 \\
.3179 \\
\end{array}$ \\
\hline & Bonferroni & FSU Student & $\begin{array}{l}\text { PK12 Personnel } \\
\text { FSU Faculty Member }\end{array}$ & $\begin{array}{r}-.16373 \\
.01105 \\
\end{array}$ & $\begin{array}{l}.13374 \\
.18064 \\
\end{array}$ & $\begin{array}{r}.667 \\
1.000 \\
\end{array}$ & $\begin{array}{l}-.4868 \\
-.4253 \\
\end{array}$ & $\begin{array}{r}.1593 \\
.4474 \\
\end{array}$ \\
\hline & & PK12 Personnel & $\begin{array}{l}\text { FSU Student } \\
\text { FSU Faculty Member }\end{array}$ & $\begin{array}{l}.16373 \\
.17478 \\
\end{array}$ & $\begin{array}{l}.13374 \\
.19968 \\
\end{array}$ & $\begin{array}{r}.667 \\
1.000 \\
\end{array}$ & $\begin{array}{l}-.1593 \\
-.3076 \\
\end{array}$ & $\begin{array}{r}.4868 \\
.6571 \\
\end{array}$ \\
\hline & & FSU Faculty Member & $\begin{array}{l}\text { FSU Student } \\
\text { PK12 Personnel }\end{array}$ & $\begin{array}{l}-.01105 \\
-.17478 \\
\end{array}$ & $\begin{array}{l}.18064 \\
.19968 \\
\end{array}$ & $\begin{array}{l}1.000 \\
1.000 \\
\end{array}$ & $\begin{array}{l}-.4474 \\
-.6571 \\
\end{array}$ & $\begin{array}{l}.4253 \\
.3076 \\
\end{array}$ \\
\hline & Games-Howell & FSU Student & $\begin{array}{l}\text { PK12 Personnel } \\
\text { FSU Faculty Member }\end{array}$ & $\begin{array}{r}-.16373 \\
.01105 \\
\end{array}$ & $\begin{array}{l}.13341 \\
.15743 \\
\end{array}$ & $\begin{array}{l}.440 \\
.997 \\
\end{array}$ & $\begin{array}{l}-.4813 \\
-.3735 \\
\end{array}$ & $\begin{array}{l}.1538 \\
.3956 \\
\end{array}$ \\
\hline & & PK12 Personnel & $\begin{array}{l}\text { FSU Student } \\
\text { FSU Faculty Member }\end{array}$ & $\begin{array}{l}.16373 \\
.17478 \\
\end{array}$ & $\begin{array}{l}.13341 \\
.17654 \\
\end{array}$ & $\begin{array}{l}.440 \\
.587 \\
\end{array}$ & $\begin{array}{l}-.1538 \\
-.2517 \\
\end{array}$ & $\begin{array}{r}.4813 \\
.6013 \\
\end{array}$ \\
\hline & & FSU Faculty Member & $\begin{array}{l}\text { FSU Student } \\
\text { PK12 Personnel }\end{array}$ & $\begin{array}{l}-.01105 \\
-.17478 \\
\end{array}$ & $\begin{array}{l}.15743 \\
.17654 \\
\end{array}$ & $\begin{array}{l}.997 \\
.587 \\
\end{array}$ & $\begin{array}{l}-.3956 \\
-.6013 \\
\end{array}$ & $\begin{array}{l}.3735 \\
.2517 \\
\end{array}$ \\
\hline \multirow{2}{*}{$\begin{array}{l}\text { Educator demonstrates } \\
\text { awareness of one's own } \\
\text { strengths and limitations }\end{array}$} & Scheffe & FSU Student & $\begin{array}{l}\text { PK12 Personnel } \\
\text { FSU Faculty Member }\end{array}$ & $\begin{array}{r}-.37525^{*} \\
-.06743 \\
\end{array}$ & $\begin{array}{l}.12045 \\
.16270 \\
\end{array}$ & $\begin{array}{l}.009 \\
.918 \\
\end{array}$ & $\begin{array}{r}-.6725 \\
-.4689 \\
\end{array}$ & $\begin{array}{r}. .0781 \\
.3340 \\
\end{array}$ \\
\hline & & PK12 Personnel & FSU Student & $.37525^{*}$ & .12045 & .009 & .0781 & .6725 \\
\hline
\end{tabular}




\begin{tabular}{|c|c|c|c|c|c|c|c|c|}
\hline & & & FSU Faculty Member & .30783 & .17984 & .234 & -.1359 & .7516 \\
\hline & & FSU Faculty Member & FSU Student & .06743 & .16270 & .918 & -.3340 & .4689 \\
\hline & & & PK12 Personnel & -.30783 & .17984 & .234 & -.7516 & .1359 \\
\hline & Bonferroni & FSU Student & PK12 Personnel & $-.37525^{*}$ & .12045 & .006 & -.6662 & -.0843 \\
\hline & & & FSU Faculty Member & -.06743 & .16270 & 1.000 & -.4604 & .3256 \\
\hline & & PK12 Personnel & FSU Student & $.37525^{*}$ & .12045 & .006 & .0843 & .6662 \\
\hline & & & FSU Faculty Member & .30783 & .17984 & .266 & -.1266 & .7423 \\
\hline & & FSU Faculty Member & FSU Student & .06743 & .16270 & 1.000 & -.3256 & .4604 \\
\hline & & & PK12 Personnel & -.30783 & .17984 & .266 & -.7423 & 1266 \\
\hline & Games-Howell & FSU Student & PK12 Personnel & $-.37525^{*}$ & .12508 & .010 & -.6735 & -.0770 \\
\hline & & & FSU Faculty Member & -.06743 & .14988 & .895 & -.4351 & .3003 \\
\hline & & PK12 Personnel & FSU Student & $.37525^{*}$ & .12508 & .010 & .0770 & .6735 \\
\hline & & & FSU Faculty Member & .30783 & .17208 & .184 & -.1080 & .7236 \\
\hline & & FSU Faculty Member & FSU Student & .06743 & .14988 & .895 & -.3003 & .4351 \\
\hline & & & PK12 Personnel & -.30783 & .17208 & .184 & -.7236 & .1080 \\
\hline Educator is capable of & Scheffe & FSU Student & PK12 Personnel & -.34339 & .14670 & .067 & -.7054 & .0186 \\
\hline responding appropriately to & & & FSU Faculty Member & -.15991 & .19816 & .722 & -.6488 & .3290 \\
\hline challenging situations & & PK12 Personnel & FSU Student & .34339 & 14670 & .067 & -.0186 & .7054 \\
\hline & & & FSU Faculty Member & .18348 & .21904 & .705 & -.3570 & .7239 \\
\hline & & FSU Faculty Member & FSU Student & .15991 & .19816 & .722 & -.3290 & .6488 \\
\hline & & & PK12 Personnel & -.18348 & .21904 & .705 & -.7239 & .3570 \\
\hline & Bonferroni & FSU Student & PK12 Personnel & -.34339 & 14670 & .061 & -.6978 & .0110 \\
\hline & & & FSU Faculty Member & -.15991 & .19816 & 1.000 & -.6386 & .3188 \\
\hline & & PK12 Personnel & FSU Student & .34339 & 14670 & .061 & -.0110 & .6978 \\
\hline & & & FSU Faculty Member & .18348 & .21904 & 1.000 & -.3456 & .7126 \\
\hline & & FSU Faculty Member & FSU Student & 15991 & .19816 & 1.000 & -.3188 & .6386 \\
\hline & & & PK12 Personnel & -.18348 & .21904 & 1.000 & -.7126 & .3456 \\
\hline
\end{tabular}




\begin{tabular}{|c|c|c|c|c|c|c|c|c|}
\hline & Games-Howell & FSU Student & $\begin{array}{l}\text { PK12 Personnel } \\
\text { FSU Faculty Member }\end{array}$ & $\begin{array}{l}-.34339 \\
-.15991 \\
\end{array}$ & $\begin{array}{l}.14792 \\
.14466 \\
\end{array}$ & $\begin{array}{l}.057 \\
.515 \\
\end{array}$ & $\begin{array}{l}-.6954 \\
-.5097 \\
\end{array}$ & $\begin{array}{r}.0086 \\
.1898 \\
\end{array}$ \\
\hline & & PK12 Personnel & $\begin{array}{l}\text { FSU Student } \\
\text { FSU Faculty Member }\end{array}$ & $\begin{array}{l}.34339 \\
.18348 \\
\end{array}$ & $\begin{array}{l}.14792 \\
.16867 \\
\end{array}$ & $\begin{array}{l}.057 \\
.525 \\
\end{array}$ & $\begin{array}{l}-.0086 \\
-.2215 \\
\end{array}$ & $\begin{array}{l}.6954 \\
.5885 \\
\end{array}$ \\
\hline & & FSU Faculty Member & $\begin{array}{l}\text { FSU Student } \\
\text { PK12 Personnel }\end{array}$ & $\begin{array}{r}.15991 \\
-.18348 \\
\end{array}$ & $\begin{array}{l}.14466 \\
.16867 \\
\end{array}$ & $\begin{array}{l}.515 \\
.525 \\
\end{array}$ & $\begin{array}{l}-.1898 \\
-.5885 \\
\end{array}$ & $\begin{array}{r}.5097 \\
.2215 \\
\end{array}$ \\
\hline \multirow[t]{9}{*}{$\begin{array}{l}\text { Educator effectively } \\
\text { manages resources }\end{array}$} & Scheffe & FSU Student & $\begin{array}{l}\text { PK12 Personnel } \\
\text { FSU Faculty Member }\end{array}$ & $\begin{array}{l}-.26576 \\
-.15881 \\
\end{array}$ & $\begin{array}{l}.13064 \\
.17646 \\
\end{array}$ & $\begin{array}{l}.129 \\
.668 \\
\end{array}$ & $\begin{array}{l}-.5881 \\
-.5942 \\
\end{array}$ & $\begin{array}{r}.0566 \\
.2766 \\
\end{array}$ \\
\hline & & PK12 Personnel & $\begin{array}{l}\text { FSU Student } \\
\text { FSU Faculty Member }\end{array}$ & $\begin{array}{l}.26576 \\
.10696 \\
\end{array}$ & $\begin{array}{l}.13064 \\
.19505 \\
\end{array}$ & $\begin{array}{l}.129 \\
.861 \\
\end{array}$ & $\begin{array}{l}-.0566 \\
-.3743 \\
\end{array}$ & $\begin{array}{r}.5881 \\
.5882 \\
\end{array}$ \\
\hline & & FSU Faculty Member & $\begin{array}{l}\text { FSU Student } \\
\text { PK12 Personnel }\end{array}$ & $\begin{array}{r}.15881 \\
-.10696 \\
\end{array}$ & $\begin{array}{l}.17646 \\
.19505 \\
\end{array}$ & $\begin{array}{l}.668 \\
.861 \\
\end{array}$ & $\begin{array}{l}-.2766 \\
-.5882 \\
\end{array}$ & $\begin{array}{r}.5942 \\
.3743 \\
\end{array}$ \\
\hline & Bonferroni & FSU Student & $\begin{array}{l}\text { PK12 Personnel } \\
\text { FSU Faculty Member }\end{array}$ & $\begin{array}{l}-.26576 \\
-.15881 \\
\end{array}$ & $\begin{array}{l}.13064 \\
.17646 \\
\end{array}$ & $\begin{array}{r}.130 \\
1.000 \\
\end{array}$ & $\begin{array}{l}-.5813 \\
-.5851 \\
\end{array}$ & $\begin{array}{l}.0498 \\
.2675 \\
\end{array}$ \\
\hline & & PK12 Personnel & $\begin{array}{l}\text { FSU Student } \\
\text { FSU Faculty Member }\end{array}$ & $\begin{array}{l}.26576 \\
.10696 \\
\end{array}$ & $\begin{array}{l}.13064 \\
.19505 \\
\end{array}$ & $\begin{array}{r}.130 \\
1.000 \\
\end{array}$ & $\begin{array}{l}-.0498 \\
-.3642 \\
\end{array}$ & $\begin{array}{r}.5813 \\
.5781 \\
\end{array}$ \\
\hline & & FSU Faculty Member & $\begin{array}{l}\text { FSU Student } \\
\text { PK12 Personnel }\end{array}$ & $\begin{array}{r}.15881 \\
-.10696 \\
\end{array}$ & $\begin{array}{l}.17646 \\
.19505 \\
\end{array}$ & $\begin{array}{l}1.000 \\
1.000 \\
\end{array}$ & $\begin{array}{l}-.2675 \\
-.5781 \\
\end{array}$ & $\begin{array}{l}.5851 \\
.3642 \\
\end{array}$ \\
\hline & Games-Howell & FSU Student & $\begin{array}{l}\text { PK12 Personnel } \\
\text { FSU Faculty Member }\end{array}$ & $\begin{array}{l}-.26576 \\
-.15881 \\
\end{array}$ & $\begin{array}{l}.13162 \\
.14478 \\
\end{array}$ & $\begin{array}{l}.113 \\
.522 \\
\end{array}$ & $\begin{array}{l}-.5791 \\
-.5114 \\
\end{array}$ & $\begin{array}{r}.0476 \\
.1938 \\
\end{array}$ \\
\hline & & PK12 Personnel & $\begin{array}{l}\text { FSU Student } \\
\text { FSU Faculty Member }\end{array}$ & $\begin{array}{l}.26576 \\
.10696 \\
\end{array}$ & $\begin{array}{l}.13162 \\
.16521 \\
\end{array}$ & $\begin{array}{l}.113 \\
.795 \\
\end{array}$ & $\begin{array}{l}-.0476 \\
-.2911 \\
\end{array}$ & $\begin{array}{l}.5791 \\
.5051 \\
\end{array}$ \\
\hline & & FSU Faculty Member & $\begin{array}{l}\text { FSU Student } \\
\text { PK12 Personnel }\end{array}$ & $\begin{array}{r}.15881 \\
-.10696 \\
\end{array}$ & $\begin{array}{l}.14478 \\
.16521 \\
\end{array}$ & $\begin{array}{r}.522 \\
.795 \\
\end{array}$ & $\begin{array}{l}-.1938 \\
-.5051 \\
\end{array}$ & $\begin{array}{r}.5114 \\
.2911 \\
\end{array}$ \\
\hline \multirow[t]{2}{*}{$\begin{array}{l}\text { Educator exhibits } \\
\text { Professionalism }\end{array}$} & Scheffe & FSU Student & $\begin{array}{l}\text { PK12 Personnel } \\
\text { FSU Faculty Member }\end{array}$ & $\begin{array}{l}-.20542 \\
-.13412 \\
\end{array}$ & $\begin{array}{l}.12658 \\
.17097 \\
\end{array}$ & $\begin{array}{l}.270 \\
.736 \\
\end{array}$ & $\begin{array}{l}-.5177 \\
-.5560 \\
\end{array}$ & $\begin{array}{l}.1069 \\
.2877 \\
\end{array}$ \\
\hline & & PK12 Personnel & FSU Student & .20542 & .12658 & .270 & -.1069 & .5177 \\
\hline
\end{tabular}




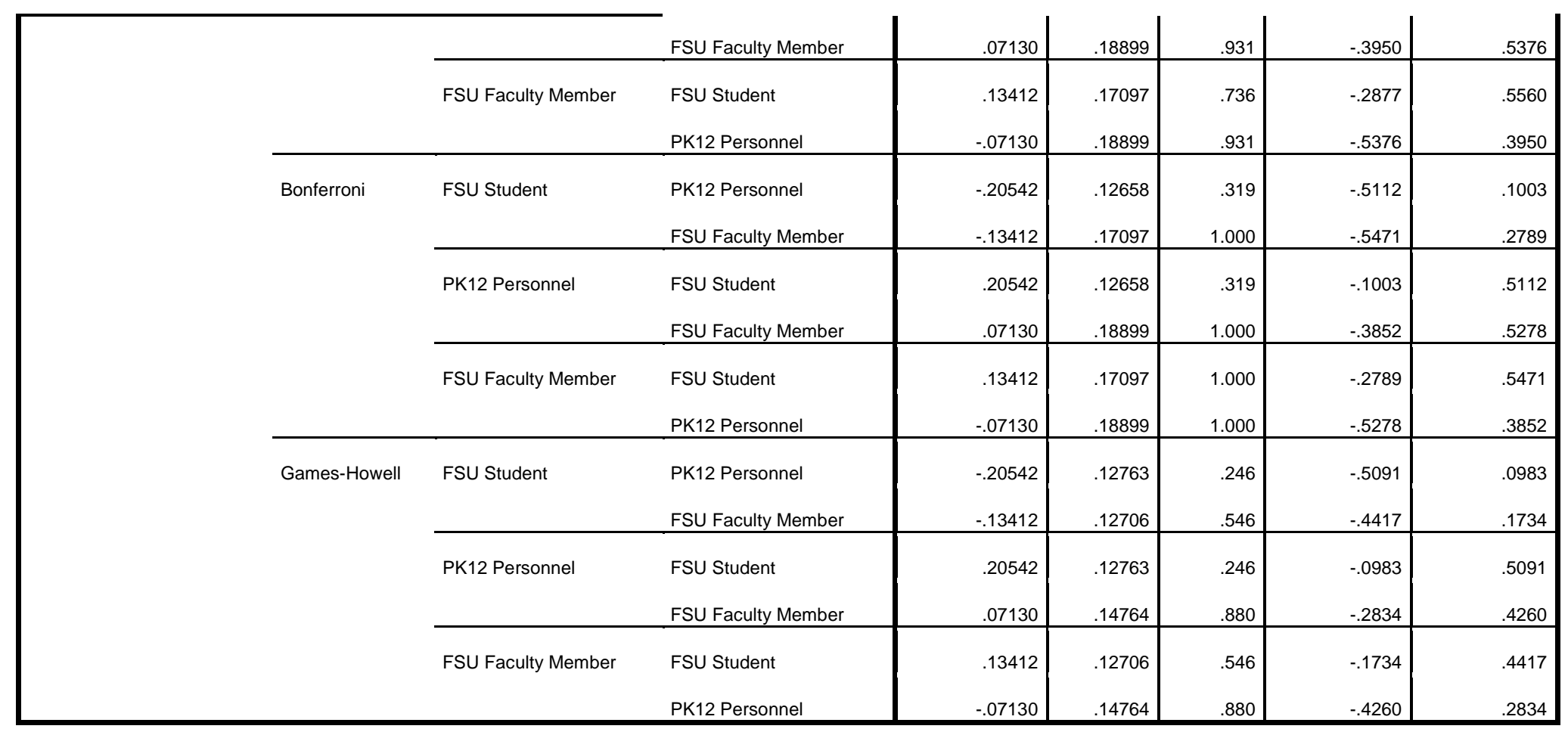

*. The mean difference is significant at the 0.05 level.

John $\mathrm{H}$

Hagen 